\title{
Nickel-Catalyzed Suzuki Polycondensation for Controlled Synthesis of Ester- Functionalized Conjugated Polymers
}

Yunyan Qiu, Joshua C. Worch, Andria Fortney, Chakicherla Gayathri, Roberto R. Gil, Kevin J. T. Noonan

Department of Chemistry, Carnegie Mellon University, 4400 Fifth Avenue, Pittsburgh, Pennsylvania 15213, United States

Corresponding Author: noonan@andrew.cmu.edu

\section{Table of Contents}

Materials and Methods S4-S6

Experimental Procedures S7-S13

Methyl-2,5-dibromothiophene-3-carboxylate. S7

$\mathrm{Ni}(1-\mathrm{Naph})\left(\mathrm{PCy}_{3}\right)_{2} \mathrm{Br}$ $. S 7-S 8$

Scheme S1. Synthesis of Monomer 1 S8

Compound A $. \mathrm{S} 8-\mathrm{S} 9$

Compound $\mathbf{B}$ S9-S10

Compound 1 $\mathrm{S} 10$

Scheme S2. Synthesis of Monomer 3 S 11

Compound $\mathbf{C}$ S11

Compound D $\mathrm{S} 12$

Compound 3 S12-S13

Model Compound Studies $\mathrm{S} 14-\mathrm{S} 21$

Representative procedure. S14

Table S1. Catalyst screening using Suzuki-Miyaura coupling. $\mathrm{S} 15$

Figure S1. Representative crude ${ }^{1} \mathrm{H}$ NMR Spectrum using $\mathrm{Ni}\left(\mathrm{PPh}_{3}\right) \mathrm{IPrCl}_{2} \ldots \ldots \ldots \ldots \ldots . . . . . . .616$

Figure S2. Representative GC-MS chromatogram using $\mathrm{Ni}\left(\mathrm{PPh}_{3}\right) \mathrm{IPrCl}_{2} \ldots \ldots \ldots \ldots \ldots \ldots . . . . . . . .17$

Figure S3. Representative crude ${ }^{1} \mathrm{H}$ NMR Spectrum using PEPPSI-IPr.................... S18

Figure S4. Representative GC-MS chromatogram using PEPPSI-IPr...................... S19

Figure S5. GC-MS chromatogram using 5:1 ratio (dibromo:ThBpin)................. S20 
Figure S6. GC-MS chromatogram using $\mathrm{Ni}\left(\mathrm{PPh}_{3}\right) \mathrm{IPrCl}_{2}$ at $65^{\circ} \mathrm{C}$ S21

Polymerization Studies.

S22-S25

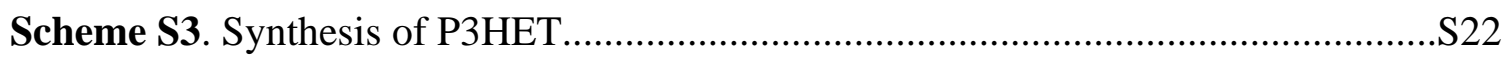

Representative Procedure for P3HET Synthesis.....................................................S22

Table S2. Optimization of P3HET synthesis from monomer 1 ................................S23

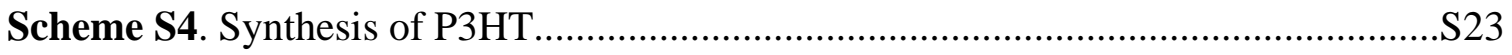

Representative Procedure for P3HT Synthesis.....................................................S23

Table S3. Optimization of water content in P3HT synthesis from monomer 2.............S24

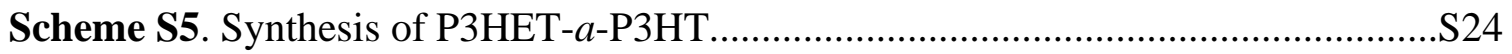

Representative Procedure for P3HET- $a$-P3HT Synthesis...................................S24-S25

Table S4. Synthesis of P3HET- $a$-P3HT from monomer 3 .......................................S25

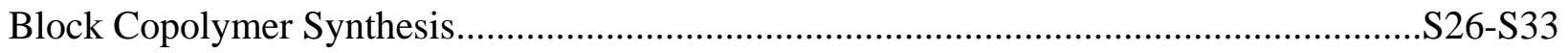

Using $\mathrm{Ni}\left(\mathrm{PPh}_{3}\right) \mathrm{IPrCl}_{2}$ as the catalyst and synthesizing P3HT first..........................S26

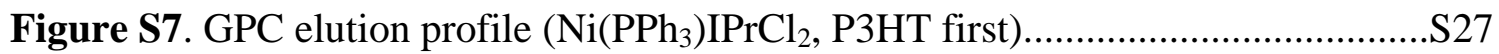

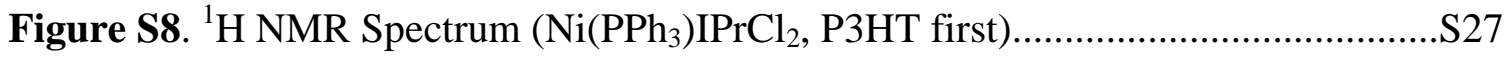

Using $\mathrm{Ni}\left(\mathrm{PPh}_{3}\right) \mathrm{IPrCl}_{2}$ as the catalyst and synthesizing P3HET first...........................S28

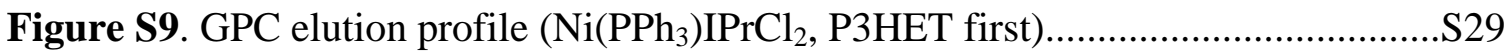

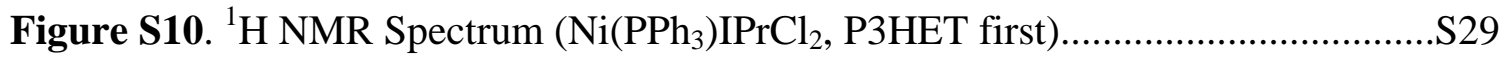

Using $\mathrm{Ni}(\mathrm{dppp}) \mathrm{Cl}_{2}$ as the catalyst and synthesizing P3HT first.................................S30

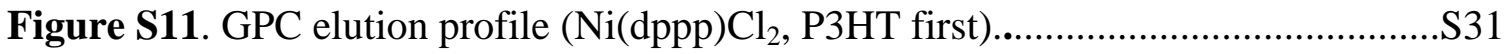

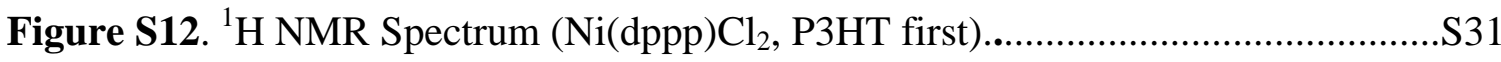

Using $\mathrm{Ni}(\mathrm{dppp}) \mathrm{Cl}_{2}$ as the catalyst and synthesizing P3HET first...............................S32

Figure S13. GPC elution profile (Ni(dppp)Cl $\mathrm{Cl}_{2}$, P3HET first)...................................S33

Figure S14. ${ }^{1} \mathrm{H}$ NMR Spectrum (Ni(dppp)Cl 2 , P3HET first)..................................S33

Figures S15-S29 NMR Spectra Collected for Small Molecules....................................S34-S41

Figure S30-S39 NMR Spectra Collected for All Polymers..........................................S42-S49

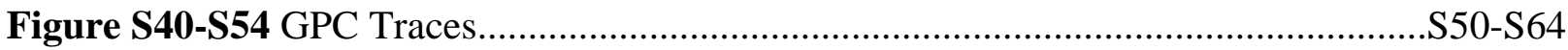




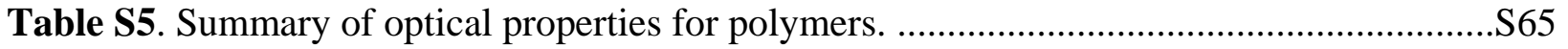

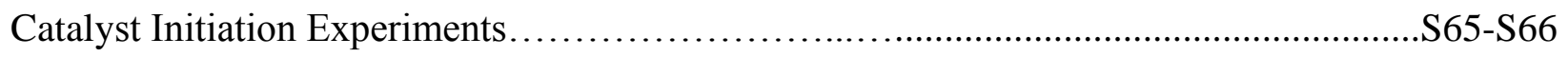

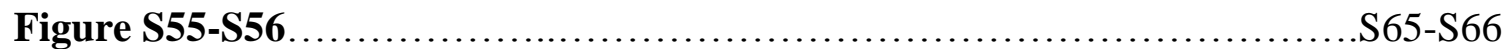

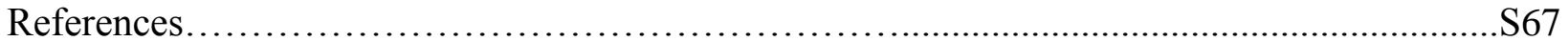


Materials and Methods. All reactions and manipulations of air and water sensitive compounds were carried out under a dry nitrogen atmosphere using an mBraun glovebox or standard Schlenk techniques. All compounds were purchased from commercial sources and used as received. 2,5Dibromothiophene-3-carboxylic $\quad$ acid $^{1}, \quad$ 2-(4-hexylthiophen-2-yl)-4,4,5,5-tetramethyl-1,3,2dioxaborolane ${ }^{2}$ and monomer $\mathbf{2}^{3}$ were synthesized according to literature procedures. All reaction solvents (tetrahydrofuran, dichloromethane, hexanes) were degassed with argon and dried prior to use. All solvents and chemicals used for extraction and column chromatography were used as received. Polymer samples were precipitated with $6 \mathrm{M}$ methanolic $\mathrm{HCl}$ and washed with both methanol and acetone for GPC, NMR, and UV-vis analysis. Monomer conversion in polymerization experiments was typically monitored by GC-MS comparing the protodeborylated monomer to an internal standard. Since deborylation was not always quantitative (mixtures of monomer and protodeborylated monomer) and since it can occur either as a side reaction or also during GC analysis, it was simply used as a rough estimate for monomer conversion.

NMR analysis. All NMR experiments were collected at $300 \mathrm{~K}$ on a two-channel Bruker Avance III NMR instrument equipped with a Broad Band Inverse (BBI) probe, operating at $500 \mathrm{MHz}$ for ${ }^{1} \mathrm{H}\left(126 \mathrm{MHz}\right.$ for $\left.{ }^{13} \mathrm{C}\right) .{ }^{1} \mathrm{H}$ NMR spectra are referenced to residual protio solvent (7.26 for $\mathrm{CHCl}_{3}$, 5.32 for $\mathrm{CHDCl}_{2}$, and 7.16 for $\left.\mathrm{C}_{6} \mathrm{D}_{5} \mathrm{H}\right)$ and ${ }^{13} \mathrm{C}$ NMR spectra are referenced to the solvent signal ( $\delta 77.23$ for $\mathrm{CDCl}_{3}, 54.00$ for $\mathrm{CD}_{2} \mathrm{Cl}_{2}$ and 128.39 for $\mathrm{C}_{6} \mathrm{D}_{6}$ ). The F2 proton-coupled HSQC was performed using the recently published Perfect-HSQC pulse program. ${ }^{4}$ The HMBC experiments were optimized for 4 and $8 \mathrm{~Hz}$ long-range proton-coupling $\left({ }^{\mathrm{n}} J_{\mathrm{CH}}\right)$.

Mass Spectrometry. High Resolution Electron Impact Mass Spectrometry (HRMS), Electrospray Mass Spectrometry (ESI-MS) and MALDI-TOF Mass Spectrometry were 
performed in the School of Chemical Sciences Mass Spectrometry Laboratory at the University of Illinois, Urbana-Champaign.

GC-MS Analysis. GC-MS analysis was performed on a Hewlett-Packard Agilent 6890-5973 GC-MS workstation. The GC column was a Hewlett-Packard fused silica capillary column crosslinked with $5 \%$ phenylmethylsiloxane. Helium was used as the carrier gas. The following conditions were used for all GC-MS analyses: injector temperature, $250{ }^{\circ} \mathrm{C}$; initial temperature, $70{ }^{\circ} \mathrm{C}$; temperature ramp, $10{ }^{\circ} \mathrm{C} / \mathrm{min}$; final temperature, $280{ }^{\circ} \mathrm{C}$. Polymer aliquots were typically subjected to GC-MS analysis to provide rough estimates of monomer conversion by comparing the protodeborylated monomer to an internal standard. Since deborylation was not always quantitative and since it can occur either as a side reaction or also during GC analysis, conversion values were not reported in the main article or in the supporting information. Polymer aliquots were prepared by quenching $\sim 0.2 \mathrm{~mL}$ of the polymer solution with $\sim 1.0 \mathrm{~mL}$ of methanol in a $20 \mathrm{~mL}$ scintillation vial. This was diluted with $\sim 1.0 \mathrm{~mL}$ of diethyl ether and $\sim 0.1 \mathrm{~mL}$ of this resultant solution was filtered through a $0.22 \mu \mathrm{m}$ PTFE syringe filter into a $2 \mathrm{~mL}$ vial and diethyl ether was added to fill the vial.

UV-vis Spectroscopy. UV-vis spectra of polymers were recorded on a Varian Cary 5000 spectrophotometer. Solution measurements were conducted in $\mathrm{CHCl}_{3}$ at $0.01 \mathrm{mg} / \mathrm{mL}$ concentration. Thin film samples were prepared from a spin-coating process. $22 \times 22 \mathrm{~mm}$ glass cover slips were cleaned by spraying with fresh acetone, isopropanol and dried under a jet of filtered, dry nitrogen. Polymer solutions $(5 \mathrm{mg} / \mathrm{mL})$ in dry toluene were heated to $80{ }^{\circ} \mathrm{C}$ in amber glass vials for $10 \mathrm{~min}$, filtered through a $0.22 \mu \mathrm{m}$ PTFE syringe filter using a glass syringe, and re-heated for $5 \mathrm{~min}$ prior to spin-casting from hot solutions. The spin-coating conditions 
consisted of three cycles, a 400 RPM spreading cycle for $5 \mathrm{~s}$, a 1000 RPM main cycle for $30 \mathrm{~s}$ and a 2000 RPM wicking cycle for $15 \mathrm{~s}$. The films were annealed at $150{ }^{\circ} \mathrm{C}$ for $1 \mathrm{~h}$ under $\mathrm{N}_{2}$.

Gel-Permeation Chromatography. GPC measurements were performed on a Waters Instrument equipped with a 717 plus autosampler, a Waters 2414 refractive index (RI) detector and two SDV columns (Porosity 1000 and $100000 \AA$; Polymer Standard Services) with THF as the eluent (flow rate $1 \mathrm{~mL} / \mathrm{min}, 40^{\circ} \mathrm{C}$ ). A 10 -point calibration based on polystyrene standards (Polystyrene, ReadyCal Kit, Polymer Standard Services) was applied for determination of molecular weights. All polymer aliquots subjected to GPC analysis were prepared by quenching $\sim 0.2 \mathrm{~mL}$ of the polymer solution with $\sim 2.0 \mathrm{~mL}$ of $6 \mathrm{M}$ methanolic $\mathrm{HCl}$. The precipitate was filtered and washed with methanol and acetone to remove any monomer and low molecular weight oligomers. The resultant polymer was dissolved in $\sim 1 \mathrm{~mL}$ of THF, filtered through a $0.22 \mu \mathrm{m}$ PTFE syringe filter and analyzed. 


\section{Experimental Procedures}

methyl-2,5-dibromothiophene-3-carboxylate. An oven-dried $250 \mathrm{~mL}$ Schlenk

flask was charged with 2,5-dibromothiophene-3-carboxylic acid (4.56 g, 15.9

mmol), $15 \mathrm{~mL}$ of thionyl chloride and catalytic dimethylformamide $(\sim 0.05 \mathrm{~mL})$.

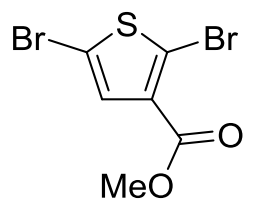

The solution was heated to $40{ }^{\circ} \mathrm{C}$ and stirred overnight. Excess thionyl chloride was removed in vacuo and the residue was triturated with diethyl ether to afford an off-white solid that was used without further purification. An oven-dried $100 \mathrm{~mL}$ Schlenk flask was charged with a portion of the crude acid chloride $(3.04 \mathrm{~g}, 10.0 \mathrm{mmol})$ and $25 \mathrm{~mL}$ of dichloromethane. The flask was cooled to $0{ }^{\circ} \mathrm{C}$ using an ice bath, then methanol $(0.8 \mathrm{~mL}, 19.8 \mathrm{mmol})$ and triethylamine $(2.78 \mathrm{~mL}, 19.9$ mmol) were added to the flask. The mixture was stirred at room temperature for $2 \mathrm{~h}$ and, an aliquot was removed and analyzed using GC-MS to confirm formation of the product. The reaction mixture was then transferred to a separatory funnel and $1 \mathrm{M} \mathrm{HCl}$ solution $(30 \mathrm{~mL})$ was added. The organic layer was separated and the aqueous layer was extracted twice more with dichloromethane $(2 \times 30 \mathrm{~mL})$. The combined organic extracts were washed with a saturated $\mathrm{NaHCO}_{3}$ solution $(10 \mathrm{~mL})$, dried over $\mathrm{MgSO}_{4}$ and concentrated to yield an off-white solid. The compound was purified on a short path of silica, eluting with hexanes:ethyl acetate (5:1), affording the title compound as a white crystalline solid $(2.72 \mathrm{~g}, 91 \%) .{ }^{1} \mathrm{H}$ NMR (500 MHz, $\left.\mathrm{CDCl}_{3}\right) \delta 7.34(\mathrm{~s}, 1 \mathrm{H}), 3.86(\mathrm{~s}, 3 \mathrm{H}) .{ }^{13} \mathrm{C} \mathrm{NMR}\left(126 \mathrm{MHz}, \mathrm{CDCl}_{3}\right) \delta 161.4,131.9,131.8,119.5$, 111.6, 52.3. HRMS (ESI-TOF) $(\mathrm{m} / \mathrm{z})$ : $[\mathrm{M}+\mathrm{H}]^{+}$calculated for $\mathrm{C}_{6} \mathrm{H}_{5} \mathrm{Br}_{2} \mathrm{O}_{2} \mathrm{~S}$, 298.8377; found, 298.8382.

$\mathrm{Ni}(1-\mathrm{Naph})\left(\mathrm{PC} \mathrm{y}_{3}\right)_{2} \mathrm{Br}$. This compound was prepared according to a modified literature procedure. ${ }^{5}$ In a $\mathrm{N}_{2}$ filled glove box, a $20 \mathrm{~mL}$ scintillation vial was

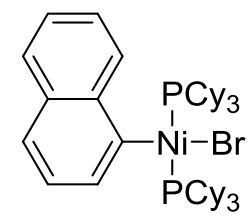


charged with $\mathrm{Ni}(\mathrm{COD})_{2}(0.10 \mathrm{~g}, 0.36 \mathrm{mmol})$, tricyclohexylphosphine $(0.30 \mathrm{~g}, 1.07 \mathrm{mmol})$, and THF (1.5 mL). The solution was stirred at room temperature for $30 \mathrm{~min}$, turning deep red, at which time, 1-bromonaphthalene $(0.075 \mathrm{~g}, 0.36 \mathrm{mmol})$ was added to the reaction mixture. The mixture was stirred overnight and a yellow precipitate formed. The precipitate was collected using vacuum filtration and washed with hexanes $(5 \times 5 \mathrm{~mL})$. The yellow solid was transferred to a scintillation vial and dried in vacuo $(0.16 \mathrm{~g}, 54 \%) .{ }^{31} \mathrm{P}\left\{{ }^{1} \mathrm{H}\right\} \mathrm{NMR}\left(202 \mathrm{MHz}, \mathrm{C}_{6} \mathrm{D}_{6}\right) \delta$ 11.6. ${ }^{1} \mathrm{H}$ NMR (500 MHz, $\left.\mathrm{C}_{6} \mathrm{D}_{6}\right) \delta 10.68(\mathrm{~d}, J=8.3 \mathrm{~Hz}, 1 \mathrm{H}), 7.71(\mathrm{~d}, J=6.7 \mathrm{~Hz}, 1 \mathrm{H}), 7.62(\mathrm{br} \mathrm{t}, J=$ $6.8 \mathrm{~Hz}, 1 \mathrm{H}), 7.53(\mathrm{~d}, J=8.2 \mathrm{~Hz}, 1 \mathrm{H}), 7.32(\mathrm{brt}, J=9.3 \mathrm{~Hz}, 2 \mathrm{H}), 7.14(\mathrm{~d}, J=7.5 \mathrm{~Hz}, 1 \mathrm{H}), 2.75-$

$0.35(\mathrm{~m}, 66 \mathrm{H})$. Note: the signal at $7.14 \mathrm{ppm}$ overlaps with the solvent signal. ${ }^{13} \mathrm{C}$ NMR (126 $\left.\mathrm{MHz}, \mathrm{C}_{6} \mathrm{D}_{6}\right) \delta 157.2\left(\mathrm{t}, J_{\mathrm{PC}}=32.7 \mathrm{~Hz}\right), 142.9,137.7\left(\mathrm{t}, J_{\mathrm{PC}}=3.7 \mathrm{~Hz}\right), 135.4,133.5\left(\mathrm{t}, J_{\mathrm{PC}}=2.6\right.$ $\mathrm{Hz}), 128.8\left(\mathrm{~d}, J_{\mathrm{PC}}=26.1 \mathrm{~Hz}\right), 125.6,125.2\left(\mathrm{t}, J_{\mathrm{PC}}=2.7 \mathrm{~Hz}\right), 123.6,122.6\left(\mathrm{t}, J_{\mathrm{PC}}=2.3 \mathrm{~Hz}\right), 34.8$ $\left(\mathrm{t}, J_{\mathrm{PC}}=8.5 \mathrm{~Hz}\right), 31.2,30.7,28.7\left(\mathrm{t}, J_{\mathrm{PC}}=5.4 \mathrm{~Hz}\right), 28.4\left(\mathrm{t}, J_{\mathrm{PC}}=4.3 \mathrm{~Hz}\right), 27.4$. HR-EIMS $(m / z)$ : $[\mathrm{M}-\mathrm{Br}]^{+}$calculated for $\mathrm{C}_{46} \mathrm{H}_{73} \mathrm{P}_{2} \mathrm{Ni}, 745.4541$; found, 745.4533 .

Scheme S1. Synthesis of Monomer 1.

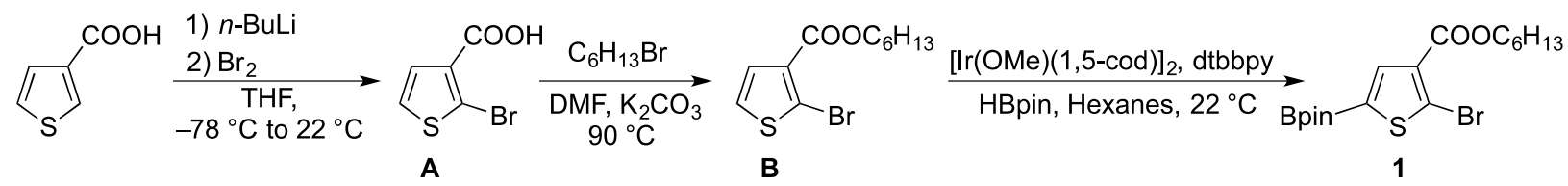

2-bromothiophene-3-carboxylic acid (A). An oven-dried $500 \mathrm{~mL}$ Schlenk flask was charged with thiophene-3-carboxylic acid (15.9 g, $124 \mathrm{mmol})$ and $300 \mathrm{~mL}$ of THF.

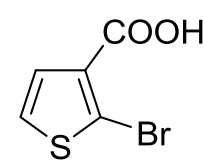
The solution was cooled to $-78{ }^{\circ} \mathrm{C}$ using a dry-ice acetone bath and $2.5 \mathrm{M} n$-butyllithium in hexanes $(100 \mathrm{~mL}, 250 \mathrm{mmol})$ was added via cannula over a $20 \mathrm{~min}$ period. During the addition, a white precipitate formed. The reaction mixture was stirred for 30 min at $-78{ }^{\circ} \mathrm{C}$ and then, bromine $(6.67 \mathrm{~mL}, 130 \mathrm{mmol})$ was added dropwise by syringe. The flask was not removed from 
the cold bath to ensure the reaction vessel returned to room temperature slowly overnight. A small amount of $1 \mathrm{M} \mathrm{HCl}$ solution $(5-10 \mathrm{~mL})$ was added to quench the reaction mixture and then, the mixture was concentrated to approximately $50 \mathrm{~mL}$. The remaining solution was transferred to a separatory funnel, diluted with $150 \mathrm{~mL}$ of $1 \mathrm{M} \mathrm{HCl}$ solution and, extracted with ethyl acetate $(3 \times 150 \mathrm{~mL})$. The combined organic extracts were washed with brine, dried over $\mathrm{MgSO}_{4}$ and concentrated to afford an off-white solid. The compound was recrystallized twice using a water:ethanol mixture (4:1) to furnish the title compound as faint yellow needles (16.53 g, 64\%). The ${ }^{1} \mathrm{H}$ and ${ }^{13} \mathrm{C}$ NMR spectra were compared to a previous report. ${ }^{6}$

hexyl 2-bromothiophene-3-carboxylate (B). An oven-dried $100 \mathrm{~mL}$ Schlenk flask was charged with 2-bromothiophene-3-carboxylic acid (A) (6.00 g, 29.0

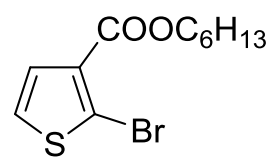
$\mathrm{mmol}), \mathrm{K}_{2} \mathrm{CO}_{3}(12.0 \mathrm{~g}, 86.8 \mathrm{mmol})$ and $40 \mathrm{~mL}$ of dimethylformamide. 1-Bromohexane $(9.60 \mathrm{~g}$, $58.2 \mathrm{mmol}$ ) was subsequently added by syringe. The flask was immersed in an oil bath at $90{ }^{\circ} \mathrm{C}$ and the solution was stirred for $12 \mathrm{~h}$ under a $\mathrm{N}_{2}$ atmosphere. The reaction mixture was cooled to room temperature, diluted with $50 \mathrm{~mL}$ of water and transferred to a $500 \mathrm{~mL}$ separatory funnel. The aqueous layer was extracted with diethyl ether $(3 \times 100 \mathrm{~mL})$ and the combined organic extracts were washed with water $(50 \mathrm{~mL})$ and brine $(50 \mathrm{~mL})$, then dried over $\mathrm{Na}_{2} \mathrm{SO}_{4}$ and concentrated using rotary evaporation. The crude product was purified using column chromatography on silica gel eluting with hexanes:ethyl acetate $(50: 1)$ to afford the final product as a clear liquid $(6.06 \mathrm{~g}, 72 \%)$. The $R_{\mathrm{f}}$ of the product is $\sim 0.7$ in hexanes:ethyl acetate $=9: 1 .{ }^{1} \mathrm{H}$ $\operatorname{NMR}\left(500 \mathrm{MHz}, \mathrm{CDCl}_{3}\right) \delta 7.37(\mathrm{~d}, J=5.8 \mathrm{~Hz}, 1 \mathrm{H}), 7.21(\mathrm{~d}, J=5.8 \mathrm{~Hz}, 1 \mathrm{H}), 4.28(\mathrm{t}, J=6.7 \mathrm{~Hz}$, 2H), $1.79-1.70(\mathrm{~m}, 2 \mathrm{H}), 1.49-1.40(\mathrm{~m}, 2 \mathrm{H}), 1.38-1.28(\mathrm{~m}, 4 \mathrm{H}), 0.94-0.85(\mathrm{~m}, 3 \mathrm{H}) .{ }^{13} \mathrm{C}$ 
NMR $\left(126 \mathrm{MHz}, \mathrm{CDCl}_{3}\right) \delta 162.3,131.6,129.7,126.0,119.8,65.4,31.6,28.8,25.9,22.8,14.2$.

HRMS (ESI-TOF) $(m / z):[\mathrm{M}+\mathrm{H}]^{+}$calculated for $\mathrm{C}_{11} \mathrm{H}_{16} \mathrm{O}_{2} \mathrm{SBr}$, 291.0054; found, 291.0062 .

hexyl 2-bromo-5-(4,4,5,5-tetramethyl-1,3,2-dioxaborolan-2-

yl)thiophene-3-carboxylate (1). In a $\mathrm{N}_{2}$ filled glovebox, a $40 \mathrm{~mL}$ scintillation vial was charged with pinacolborane (HBpin) (1.16 g, $9.06 \mathrm{mmol})$, di- $\mu-$ methoxobis(1,5-cyclooctadiene)diiridium $(0.045 \mathrm{~g}, 0.068 \mathrm{mmol})$ and $3 \mathrm{~mL}$ of dry hexanes. To this stirring mixture, 4,4'-Bis(di-t-butyl)-2,2'-bipyridine (dtbbpy) $(0.036 \mathrm{~g}, 0.13 \mathrm{mmol})$ in $3 \mathrm{~mL}$ of hexanes was added in portions and the mixture was stirred for $15 \mathrm{~min}$. The color of the reaction mixture went from yellow to dark brown during that period. Compound $\mathbf{B}(1.32 \mathrm{~g}, 4.53$ mmol) was then dissolved in $4 \mathrm{~mL}$ of hexanes and added to the mixture slowly $\left(\mathrm{H}_{2}\right.$ gas evolves in this step). The solution was kept in the glovebox and stirred overnight. The crude mixture was then removed from the glovebox, loaded directly onto silica gel, and eluted with hexanes:dichloromethane $(1: 1)$. The $R_{\mathrm{f}}$ of the product is $\sim 0.4$ in hexanes:dichloromethane $=1: 1$. The final product was collected as a clear oil and slowly solidified after drying in vacuo to afford an off-white powder $(1.40 \mathrm{~g}, 74 \%) .{ }^{1} \mathrm{H}$ NMR $\left(500 \mathrm{MHz}, \mathrm{CDCl}_{3}\right) \delta 7.85(\mathrm{~s}, 1 \mathrm{H}), 4.27(\mathrm{t}, J=6.7$ $\mathrm{Hz}, 2 \mathrm{H}), 1.77-1.70(\mathrm{~m}, 2 \mathrm{H}), 1.47-1.39(\mathrm{~m}, 2 \mathrm{H}), 1.37-1.28(\mathrm{~m}, 16 \mathrm{H}), 0.93-0.87(\mathrm{~m}, 3 \mathrm{H})$. ${ }^{13} \mathrm{C}$ NMR $\left(126 \mathrm{MHz}, \mathrm{CDCl}_{3}\right) \delta 162.2,139.2,132.7,126.3,84.9,65.4,31.7,28.8,25.9,25.0$, 22.8, 14.2. Note: one aromatic signal is missing in the ${ }^{13} \mathrm{C}$ NMR spectrum due to quadrupolar relaxation. HR-EIMS (m/z): [M] calculated for $\mathrm{C}_{17} \mathrm{H}_{26} \mathrm{O}_{4} \mathrm{BrSB}, 416.0828$; found, 416.0832 . 
Scheme S2. Synthesis of Monomer 3.

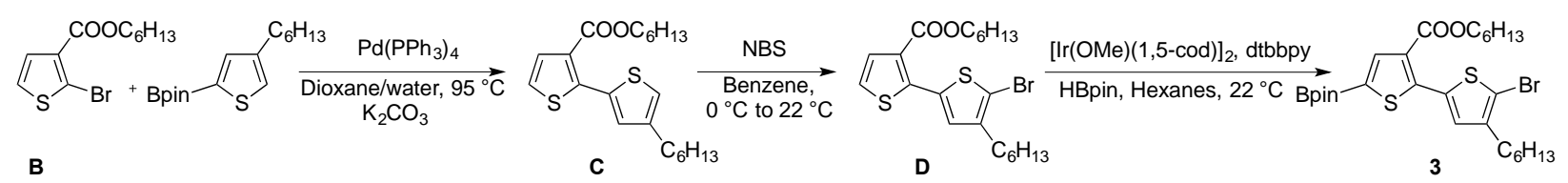

hexyl 4'-hexyl-[2,2'-bithiophene]-3-carboxylate (C). In a $\mathrm{N}_{2}$ filled glovebox, a $20 \mathrm{~mL}$ scintillation vial was charged with compound $\mathbf{B}(0.50 \mathrm{~g}, 1.72$ mmol), 2-(4-hexylthiophen-2-yl)-4,4,5,5-tetramethyl-1,3,2-dioxaborolane

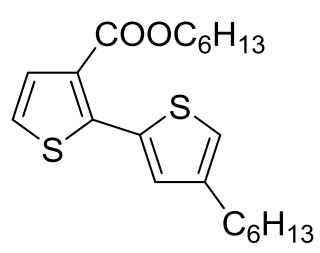
(0.51 g, $1.73 \mathrm{mmol}), \mathrm{Pd}\left(\mathrm{PPh}_{3}\right)_{4}(0.10 \mathrm{~g}, 0.087 \mathrm{mmol}), \mathrm{K}_{2} \mathrm{CO}_{3}(0.71 \mathrm{~g}, 5.14 \mathrm{mmol})$ and $10 \mathrm{~mL}$ of dioxane. The vial was removed from the glovebox and $2 \mathrm{~mL}$ of water was added into the vial by syringe. The vial was then immersed in an oil bath at $95{ }^{\circ} \mathrm{C}$ and the solution was stirred for $12 \mathrm{~h}$ before cooling to room temperature. The mixture was transferred to a separatory funnel, diluted with $100 \mathrm{~mL}$ of diethyl ether and washed with water and brine. The organic layer was dried using $\mathrm{Na}_{2} \mathrm{SO}_{4}$, and concentrated using rotary evaporation. The crude material was purified using column chromatography on silica gel, eluting with hexanes:dichloromethane (3:1) to afford the final product as a clear oil $(0.58 \mathrm{~g}, 89 \%)$. The $R_{\mathrm{f}}$ of the product is $\sim 0.6$ in hexanes:dichloromethane $=1: 1 .{ }^{1} \mathrm{H}$ NMR $\left(500 \mathrm{MHz}, \mathrm{CD}_{2} \mathrm{Cl}_{2}\right) \delta 7.45(\mathrm{~d}, J=5.5 \mathrm{~Hz}, 1 \mathrm{H}), 7.26(\mathrm{~d}$, $J=1.4 \mathrm{~Hz}, 1 \mathrm{H}), 7.20(\mathrm{~d}, J=5.4 \mathrm{~Hz}, 1 \mathrm{H}), 7.01(\mathrm{q}, J=1.1 \mathrm{~Hz}, 1 \mathrm{H}), 4.20(\mathrm{t}, J=6.7 \mathrm{~Hz}, 2 \mathrm{H}), 2.61$ $(\mathrm{t}, J=7.7 \mathrm{~Hz}, 2 \mathrm{H}), 1.70-1.59(\mathrm{~m}, 4 \mathrm{H}), 1.41-1.25(\mathrm{~m}, 12 \mathrm{H}), 0.94-0.84(\mathrm{~m}, 6 \mathrm{H}) .{ }^{13} \mathrm{C} \mathrm{NMR}$ $\left(126 \mathrm{MHz}, \mathrm{CD}_{2} \mathrm{Cl}_{2}\right) \delta 163.7,144.1,143.6,134.0,131.1,130.9,128.7,124.4,122.8,65.5,32.3$, $32.1,31.1,31.0,29.6,29.2,26.3,23.22$ and 23.15 (2 overlapping signals), 14.44 and 14.37 (2 overlapping signals). HRMS (ESI-TOF) $(\mathrm{m} / \mathrm{z})$ : $[\mathrm{M}+\mathrm{H}]^{+}$calculated for $\mathrm{C}_{21} \mathrm{H}_{31} \mathrm{O}_{2} \mathrm{~S}_{2}, 379.1765$; found, 379.1772 . 
hexyl 5'-bromo-4'-hexyl-[2,2'-bithiophene]-3-carboxylate (D). Compound $\mathbf{C}$

(0.58 g, $1.53 \mathrm{mmol})$ was dissolved in $100 \mathrm{~mL}$ of benzene and the solution was cooled to $0{ }^{\circ} \mathrm{C}$. N-Bromosuccinimide $(0.30 \mathrm{~g}, 1.69 \mathrm{mmol})$ was then

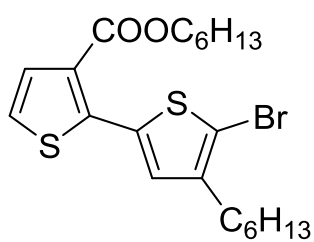
added to the reaction mixture in portions while maintaining a temperature of $0{ }^{\circ} \mathrm{C}$. The reaction mixture was slowly warmed to room temperature and stirred overnight. The mixture was quenched with $50 \mathrm{~mL}$ of a saturated $\mathrm{NaHCO}_{3}$ solution and the entire contents of the flask were transferred to a separatory funnel. The aqueous layer was extracted with diethyl ether $(3 \times 50 \mathrm{~mL})$ and the combined organic extracts were washed with a saturated $\mathrm{NaHCO}_{3}$ solution and brine. The extracts were then dried over $\mathrm{Na}_{2} \mathrm{SO}_{4}$ and concentrated using rotary evaporation. The crude product was purified using column chromatography on silica gel, eluting with hexanes:dichloromethane (15:1) to afford the final product as a clear oil $(0.45 \mathrm{~g}, 64 \%)$. The $R_{\mathrm{f}}$ of the product is $\sim 0.4$ in hexanes:dichloromethane $=7: 3 .{ }^{1} \mathrm{H} \mathrm{NMR}\left(500 \mathrm{MHz}, \mathrm{CDCl}_{3}\right) \delta 7.46(\mathrm{~d}, J=$ $5.4 \mathrm{~Hz}, 1 \mathrm{H}), 7.17(\mathrm{~d}, J=5.4 \mathrm{~Hz}, 1 \mathrm{H}), 7.11(\mathrm{~s}, 1 \mathrm{H}), 4.24(\mathrm{t}, J=6.7 \mathrm{~Hz}, 2 \mathrm{H}), 2.56(\mathrm{t}, J=7.7 \mathrm{~Hz}$, 2H), $1.73-1.64(\mathrm{~m}, 2 \mathrm{H}), 1.64-1.56(\mathrm{~m}, 2 \mathrm{H}), 1.41-1.24(\mathrm{~m}, 12 \mathrm{H}), 0.94-0.84(\mathrm{~m}, 6 \mathrm{H}) .{ }^{13} \mathrm{C}$ NMR $\left(126 \mathrm{MHz} \mathrm{CDCl}_{3}\right) \delta 163.4,142.8,142.2,133.6,130.7,130.1,128.2,124.0,112.1,65.3$, $31.8,31.7,29.9,29.8,29.2,28.8,25.9,22.82$ and 22.78 (2 overlapping signals), 14.3, 14.2. HRMS (ESI-TOF) $(\mathrm{m} / \mathrm{z})$ : $[\mathrm{M}+\mathrm{H}]^{+}$calculated for $\mathrm{C}_{21} \mathrm{H}_{30} \mathrm{O}_{2} \mathrm{~S}_{2} \mathrm{Br}, 457.0871$; found, 457.0869.

hexyl 5'-bromo-4'-hexyl-5-(4,4,5,5-tetramethyl-1,3,2-dioxaborolan-2yl)-[2,2'-bithiophene]-3-carboxylate (3). In a $\mathrm{N}_{2}$ filled glovebox, a 40 $\mathrm{mL}$ scintillation vial was charged with pinacolborane (HBPin) $(0.50$

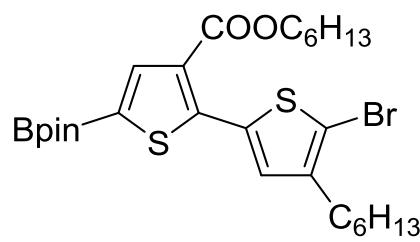
g, $3.9 \mathrm{mmol})$, Di- $\mu$-methoxobis(1,5-cyclooctadiene $)$ diiridium $(0.033 \mathrm{~g}, 0.050 \mathrm{mmol})$ and $2 \mathrm{~mL}$ of dry hexanes. To this stirring mixture, 4,4'-Bis(di-t-butyl)-2,2'-bipyridine (dtbbpy) (0.026 g, 0.097 
mmol) in $2 \mathrm{~mL}$ of hexanes was added in portions and the mixture was stirred for $15 \mathrm{~min}$. The color of the reaction mixture went from yellow to dark brown during that period. Compound $\mathbf{D}$ $(1.50 \mathrm{~g}, 3.28 \mathrm{mmol})$ was then dissolved in $4 \mathrm{~mL}$ of hexanes and added to the reaction mixture slowly ( $\mathrm{H}_{2}$ gas evolves in this step). The solution was kept in the glovebox and stirred overnight. The crude mixture was then removed from the glovebox, loaded directly onto silica gel, and eluted with gradient solvent conditions (hexanes:dichloromethane $=1: 1$, followed by dichloromethane). The $R_{\mathrm{f}}$ of the product is $\sim 0.5$ in hexanes:dichloromethane $=1: 1$. The final product was collected as a green oil and, upon drying, slowly solidified to a light-green solid (1.41 g, 74\%). ${ }^{1} \mathrm{H}$ NMR (500 MHz, $\left.\mathrm{CDCl}_{3}\right) \delta 7.95(\mathrm{~s}, 1 \mathrm{H}), 7.22(\mathrm{~s}, 1 \mathrm{H}), 4.24(\mathrm{t}, J=6.8 \mathrm{~Hz}, 2 \mathrm{H})$, $2.55(\mathrm{t}, J=7.7 \mathrm{~Hz}, 2 \mathrm{H}), 1.75-1.64(\mathrm{~m}, 2 \mathrm{H}), 1.64-1.53(\mathrm{~m}, 2 \mathrm{H}), 1.43-1.20(\mathrm{~m}, 24 \mathrm{H}), 0.95-$ $0.83(\mathrm{~m}, 6 \mathrm{H}) .{ }^{13} \mathrm{C}$ NMR $\left(126 \mathrm{MHz}, \mathrm{CDCl}_{3}\right) \delta 163.4,149.0,142.3,140.6,133.6,130.4,128.7$, $113.0,84.8,65.3,31.8,31.7,29.8,29.7,29.1,28.9,25.9,25.0,22.79$ and 22.76 (2 overlapping signals), 14.3, 14.2. Note: one aromatic signal is missing in the ${ }^{13} \mathrm{C}$ NMR spectrum due to quadrupolar relaxation. HRMS (ESI-TOF) $(m / z):[M+H]^{+}$calculated for $\mathrm{C}_{27} \mathrm{H}_{41} \mathrm{O}_{4} \mathrm{~S}_{2} \mathrm{BrB}$, 583.1723; found, 583.1719 . 


\section{Model Compound Studies}

Representative procedure. In a $\mathrm{N}_{2}$ filled glove box, a $20 \mathrm{~mL}$ scintillation vial was charged with the dihalogenated thiophene $(0.50 \mathrm{mmol}), \quad 4,4,5,5$-tetramethyl-2-(thiophen-2-yl)-1,3,2dioxaborolane (ThBPin) (0.053 g, $0.25 \mathrm{mmol}), \mathrm{K}_{3} \mathrm{PO}_{4} \cdot \mathrm{H}_{2} \mathrm{O}(0.14 \mathrm{~g}, 0.61 \mathrm{mmol})$ and either 1,3,5trimethoxybenzene $(0.042 \mathrm{~g}, 0.25 \mathrm{mmol})$ or nonadecane $(0.067 \mathrm{~g}, 0.25 \mathrm{mmol})$ as an internal standard. Finally, the catalyst (mol \% relative to ThBPin) was added along with $3 \mathrm{~mL}$ of THF. The vial was sealed, and removed from the glovebox and an aliquot was analyzed using GC-MS $(\mathrm{t}=0 \mathrm{~h})$. The vial was then placed in an oil bath at $50{ }^{\circ} \mathrm{C}$ and stirred for $24 \mathrm{~h}$. An aliquot $(0.1$ $\mathrm{mL})$ was then removed and subjected to GC-MS analysis while another aliquot $(0.3 \mathrm{~mL})$ was concentrated, dissolved in $\mathrm{CDCl}_{3}$, filtered through a $0.22 \mu \mathrm{m}$ PTFE filter, and analyzed using ${ }^{1} \mathrm{H}$ NMR spectroscopy. For the ${ }^{1} \mathrm{H}$ NMR spectra, the methyl $\left[2,2^{\prime}: 5^{\prime}, 2^{\prime \prime}\right.$-terthiophene]-3'-carboxylate

was isolated from one of the reaction mixtures for comparison. ${ }^{1} \mathrm{H} \mathrm{NMR}\left(300 \mathrm{MHz}, \mathrm{CDCl}_{3}\right) \delta$ 7.53 (s, 1H), 7.49 (dd, $J=3.7,1.2 \mathrm{~Hz}, 1 \mathrm{H}), 7.42(\mathrm{dd}, J=5.1,1.2 \mathrm{~Hz}, 1 \mathrm{H}), 7.27$ (dd, $J=5.3,1.2$ $\mathrm{Hz}, 1 \mathrm{H}), 7.20(\mathrm{dd}, J=3.6,1.2 \mathrm{~Hz}, 1 \mathrm{H}), 7.06$ (ddd, $J=11.9,5.1,3.7 \mathrm{~Hz}, 2 \mathrm{H}), 3.85$ (s, 3H). Note: the signal at $7.27 \mathrm{ppm}$ overlapped with the solvent signal. Integration of the methyl carboxylate signal was used to determine the ratio of terthiophene:bithiophene. For the monosubstituted bithiophene product, two regioisomers are possible, but we did not identify the regioisomer formed. Conversion was determined in GC-MS by integration of the ThBPin signal to the internal standard. Representative crude NMR spectra and GC-MS chromatograms are shown below in Figures S1-S4. Tabulated data for the separate catalysts are included below in Table S1. 


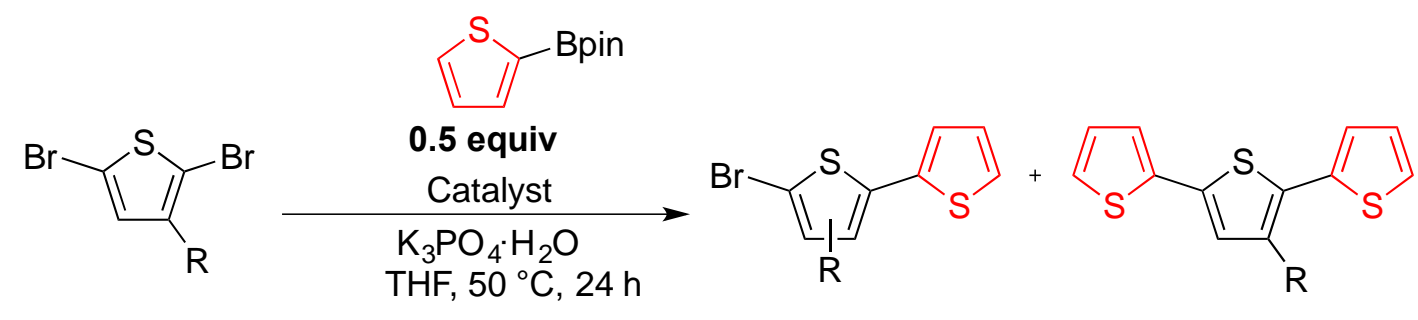

1 equiv

Table S1. Catalyst screening for dihalogenated thiophenes using Suzuki-Miyaura coupling.

\begin{tabular}{|c|c|c|c|c|c|}
\hline Dihalogen & Catalyst & $\begin{array}{l}\text { Temp. } \\
\left({ }^{\circ} \mathrm{C}\right)\end{array}$ & $\begin{array}{c}\text { mol \% } \\
\text { cat. }\end{array}$ & $\begin{array}{l}\% \text { Conv. } \\
\text { GC-MS }^{a}\end{array}$ & $\begin{array}{l}\text { \% Terthiophene } \\
\text { GC-MS (NMR) }\end{array}$ \\
\hline \multirow[b]{2}{*}{$\mathrm{MeO}^{\prime}$} & \multirow{2}{*}{$\mathrm{Ni}\left(\mathrm{PPh}_{3}\right) \mathrm{IPrCl}_{2}$} & 50 & 5 & 99 & 99 (99) \\
\hline & & 50 & 1 & 99 & 99 (99) \\
\hline & \multirow{2}{*}{$\mathrm{Ni}(1-\mathrm{Naph})\left(\mathrm{PCy}_{3}\right)_{2} \mathrm{Br}$} & 50 & 5 & 99 & $94(97)$ \\
\hline & & 50 & 1 & 72 & $44(72)$ \\
\hline \multirow[b]{2}{*}{$\mathrm{MeO}^{\prime}$} & \multirow{2}{*}{$\mathrm{Ni}(\mathrm{dppp}) \mathrm{Cl}_{2}$} & 50 & 5 & 99 & $95(96)$ \\
\hline & & 50 & 1 & 82 & $97(95)$ \\
\hline & \multirow{2}{*}{ PEPPSI-IPr } & 50 & 5 & 99 & $52(72)$ \\
\hline & & 50 & 1 & 99 & $64(78)$ \\
\hline \multirow[b]{2}{*}{$\mathrm{MeO}^{\prime}$} & \multirow{2}{*}{$\mathrm{Ni}\left(\mathrm{PPh}_{3}\right) \mathrm{IPrCl}_{2}$} & 65 & 5 & 99 & 95 \\
\hline & & $50^{b}$ & 5 & 99 & 94 \\
\hline & \multirow{2}{*}{$\mathrm{Ni}\left(\mathrm{PPh}_{3}\right) \mathrm{IPrCl}_{2}$} & 50 & 5 & 99 & 87 \\
\hline $\mathrm{C}_{6} \mathrm{H}_{13}$ & & $50^{c}$ & 5 & 79 & 94 \\
\hline
\end{tabular}

${ }^{a}$ Conversion is calculated based on the consumption of ThBpin. ${ }^{b}$ Relative molar ratio of methyl2,5-dibromothiophene-3-carboxylate:ThBpin was $5: 1{ }^{c} 0.2 \mathrm{~mL}$ of water was added to the reaction mixture at $\mathrm{t}=0 \mathrm{~h}$. 


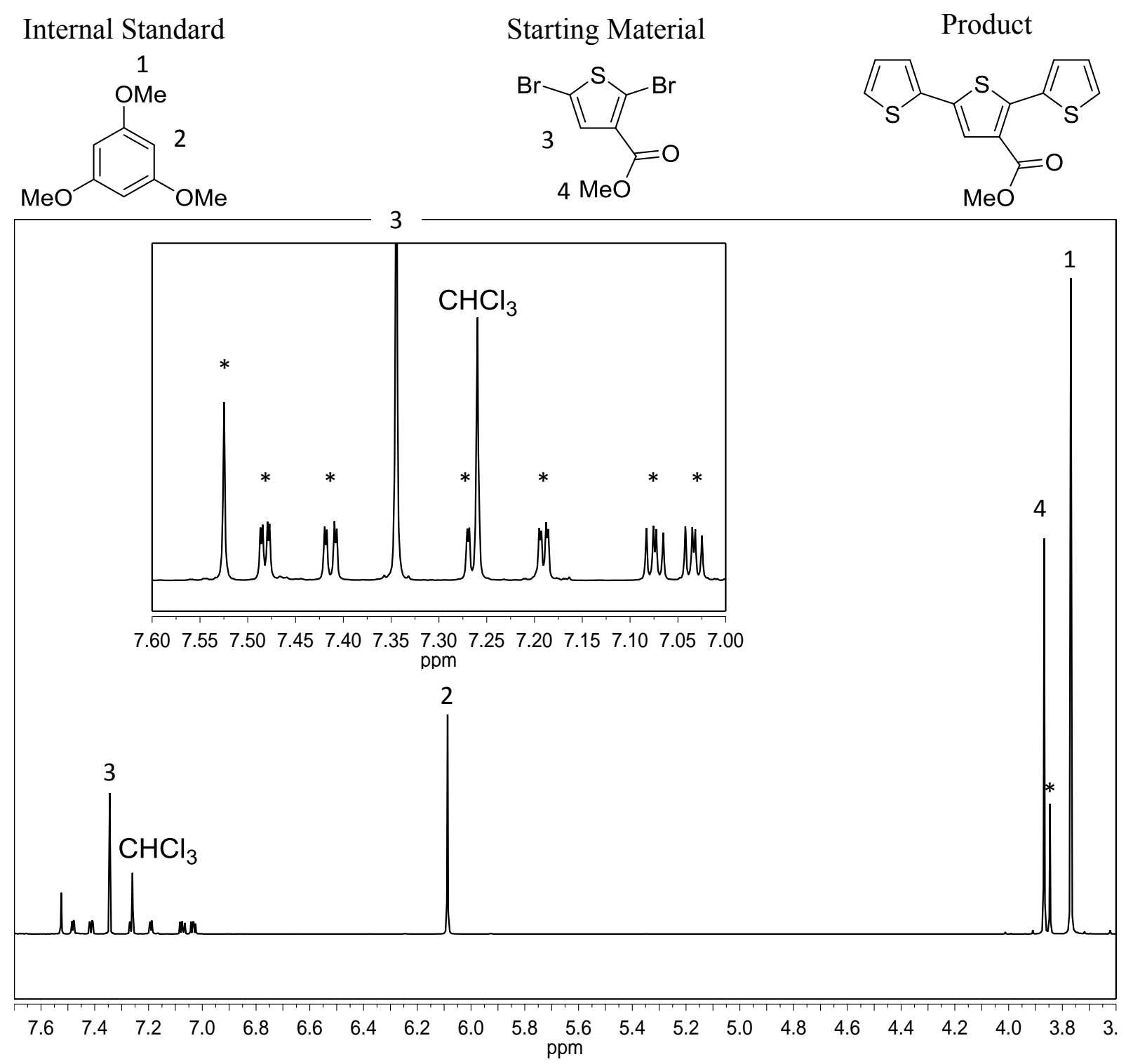

Figure S1. Representative crude ${ }^{1} \mathrm{H}$ NMR Spectrum $\left(500 \mathrm{MHz}, \mathrm{CDCl}_{3}\right)$ for model compound Suzuki-Miyaura coupling at $50{ }^{\circ} \mathrm{C}$ using methyl-2,5-dibromothiophene-3-carboxylate and $\mathrm{Ni}\left(\mathrm{PPh}_{3}\right) \mathrm{IPrCl}_{2}(1 \mathrm{~mol} \%)$. The star symbols correspond to the terthiophene product. 

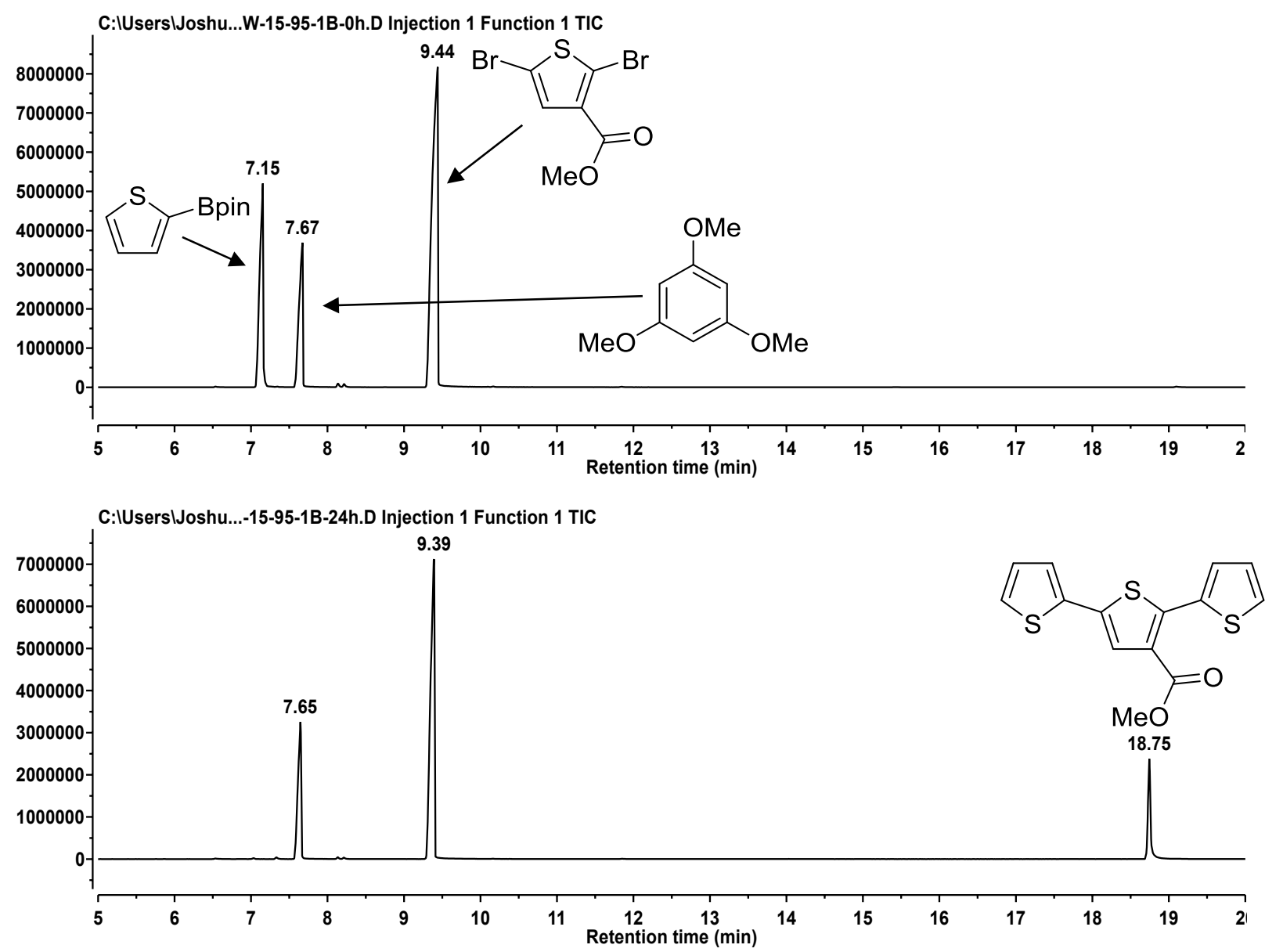

Figure S2. Representative GC-MS chromatograms for model compound Suzuki-Miyaura coupling at $50{ }^{\circ} \mathrm{C}$ using methyl-2,5-dibromothiophene-3-carboxylate and $\mathrm{Ni}\left(\mathrm{PPh}_{3}\right) \mathrm{IPrCl}_{2}(1$ mol \%). Top - reaction mixture at time $=0 \mathrm{~h}$. Bottom - reaction mixture after $24 \mathrm{~h}$. 
Internal Standard Starting Material

Product
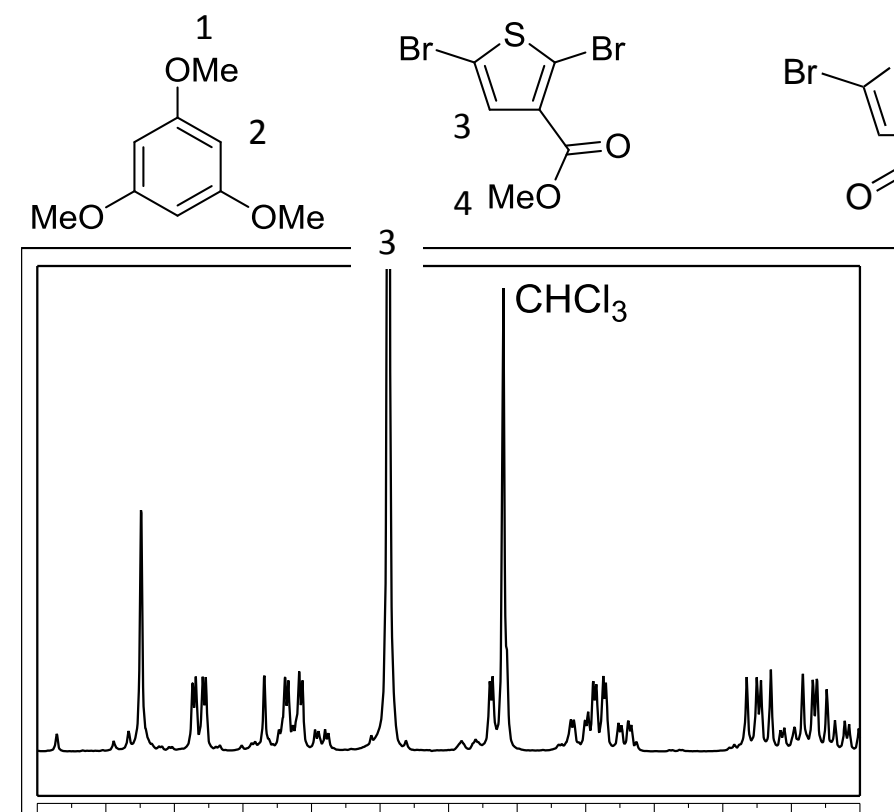

1.60 $7.55 \quad 7.507 .45 \quad 7.40 \quad 7.35 \quad 7.30 \quad 7.25 \quad 7.20 \quad 7.15 \quad 7.107 .05 \quad 7.004 .00$ ppm
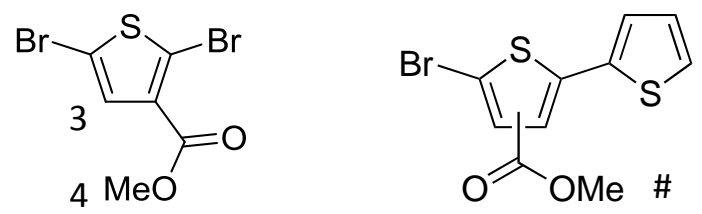

Product

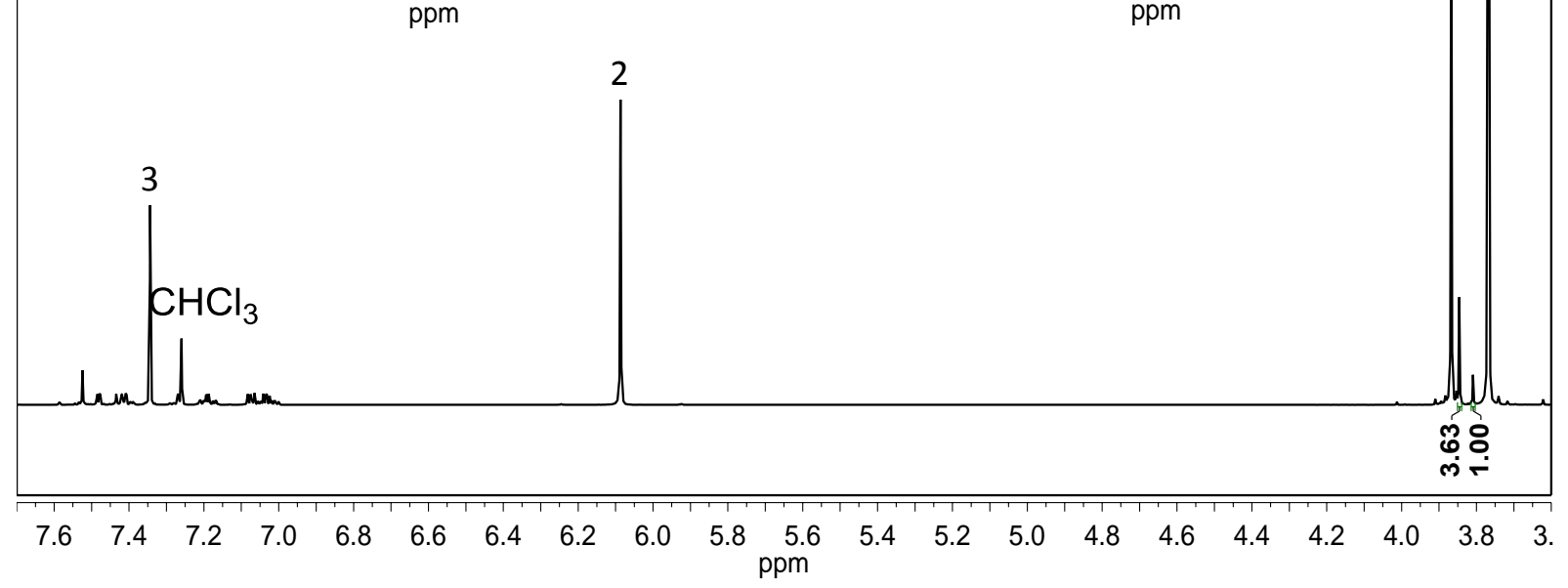

Figure S3. Crude ${ }^{1} \mathrm{H}$ NMR Spectrum $\left(500 \mathrm{MHz}, \mathrm{CDCl}_{3}\right)$ for model compound Suzuki-Miyaura coupling at $50{ }^{\circ} \mathrm{C}$ using methyl-2,5-dibromothiophene-3-carboxylate and PEPPSI-IPr (1 mol \%). Ratio of products was determined from integration of the carboxylate signal. 


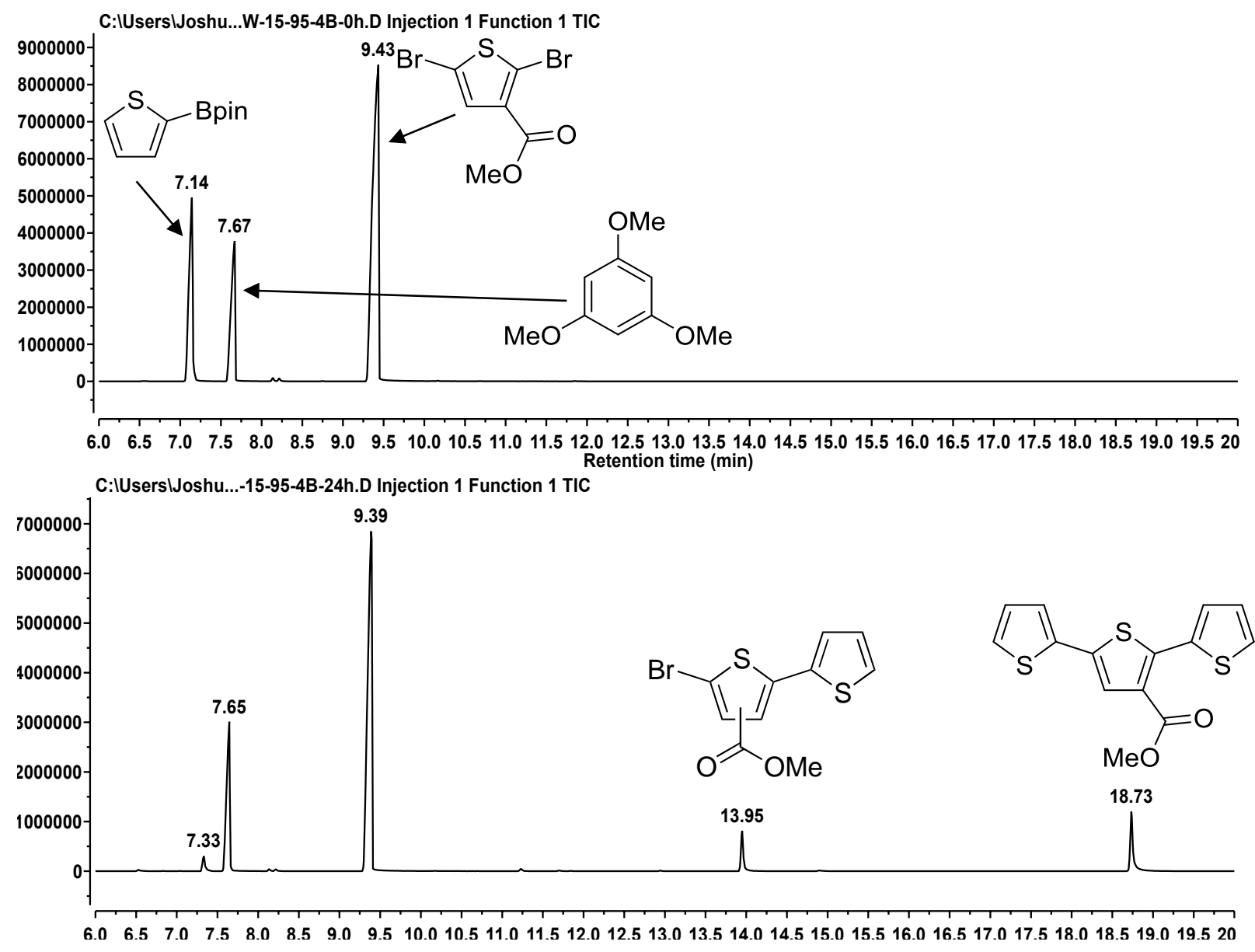

Figure S4. GC-MS chromatograms for model compound Suzuki-Miyaura coupling at $50{ }^{\circ} \mathrm{C}$ using methyl-2,5-dibromothiophene-3-carboxylate and PEPPSI-IPr (1 mol \%). Top - reaction mixture at time $=0 \mathrm{~h}$. Bottom - reaction mixture after $24 \mathrm{~h}$. Signal at $7.33 \mathrm{~min}$ is bithiophene formed from precatalyst initiation. 


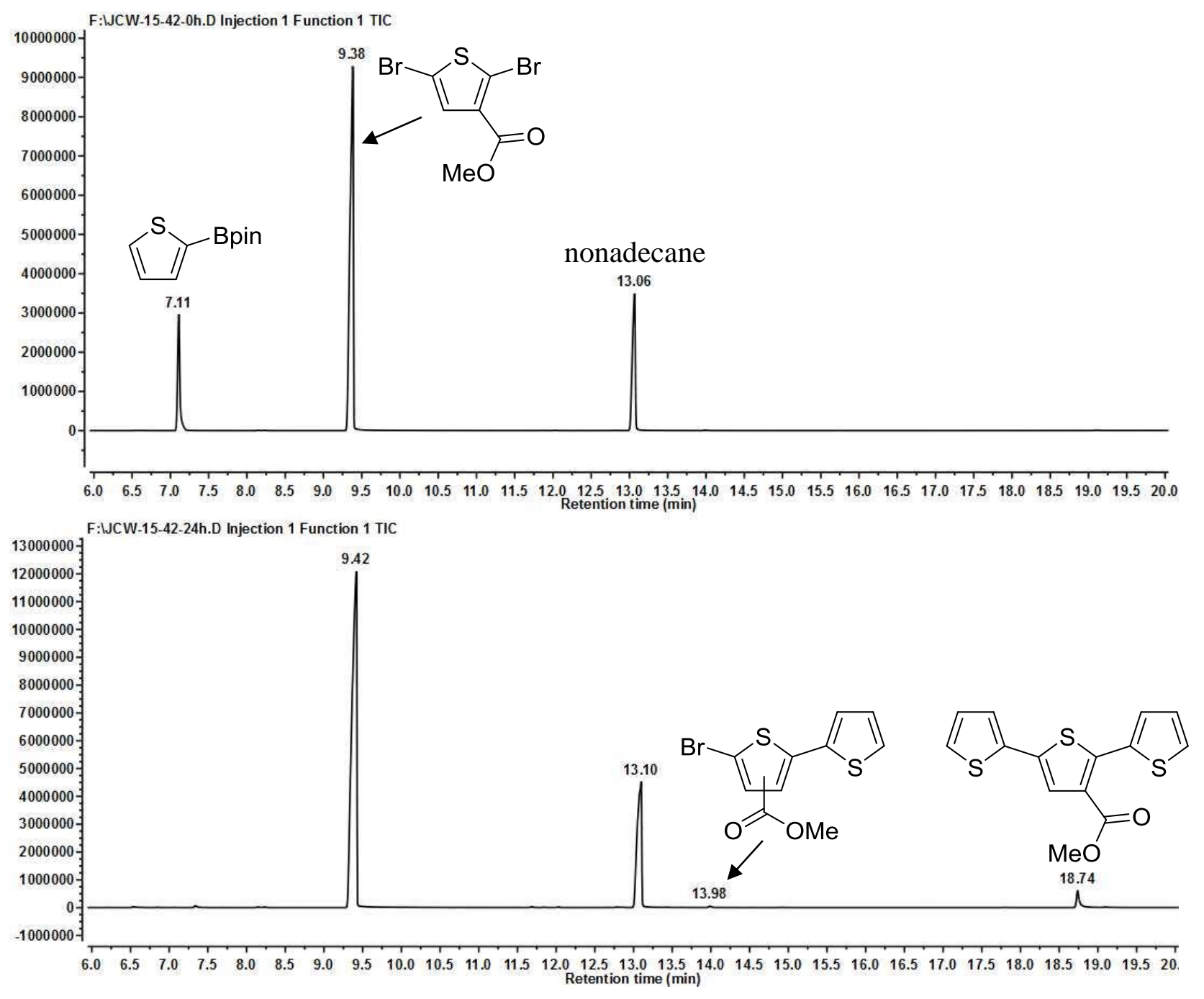

Figure S5. GC-MS chromatograms for model compound Suzuki-Miyaura coupling at $50{ }^{\circ} \mathrm{C}$ using methyl-2,5-dibromothiophene-3-carboxylate:ThBpin (5:1 ratio) and $\mathrm{Ni}\left(\mathrm{PPh}_{3}\right) \mathrm{IPrCl}_{2}(5$ mol \%). Top - reaction mixture at time $=0 \mathrm{~h}$. Bottom - reaction mixture after $24 \mathrm{~h}$. 


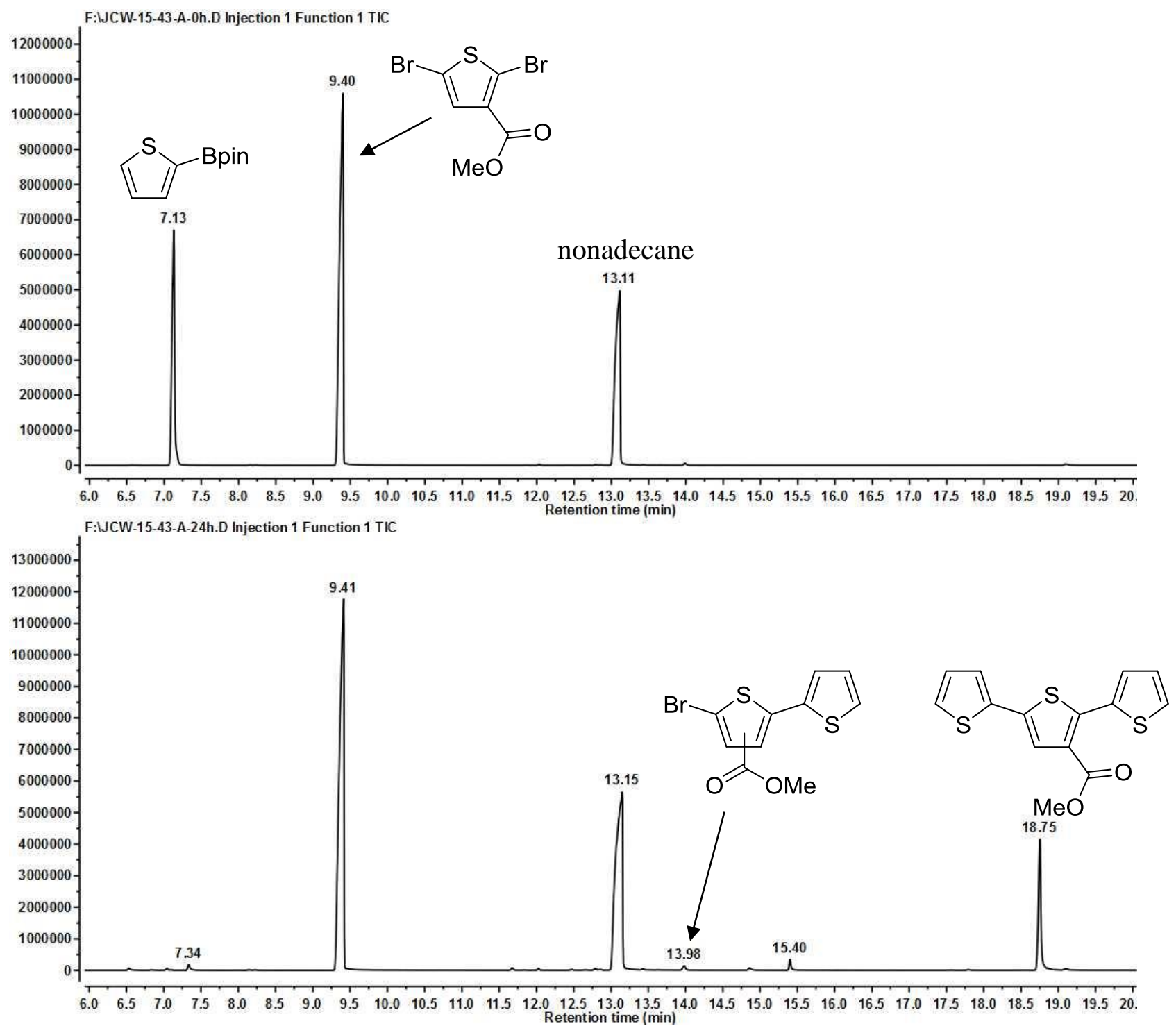

Figure S6. GC-MS chromatograms for model compound Suzuki-Miyaura coupling at $65{ }^{\circ} \mathrm{C}$ using methyl-2,5-dibromothiophene-3-carboxylate and $\mathrm{Ni}\left(\mathrm{PPh}_{3}\right) \mathrm{IPrCl}_{2}(5 \mathrm{~mol} \%)$. Top - reaction mixture at time $=0 \mathrm{~h}$. Bottom - reaction mixture after $24 \mathrm{~h}$. Signal at $7.34 \mathrm{~min}$ is bithiophene formed from precatalyst initiation and signal at 15.40 is $\mathrm{PPh}_{3}$ from catalyst. 


\section{Polymerization Studies}

Scheme S3. Synthesis of P3HET.

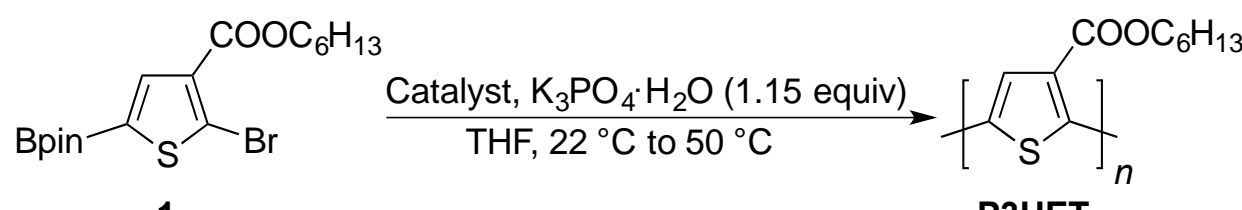

1

P3HET

Representative procedure for P3HET synthesis. In a $\mathrm{N}_{2}$ filled glovebox, a $20 \mathrm{~mL}$ scintillation vial equipped with a Teflon screw cap was charged with a calculated amount of catalyst (mol \% listed in Table S2), $\mathrm{K}_{3} \mathrm{PO}_{4} \cdot \mathrm{H}_{2} \mathrm{O}(0.080 \mathrm{~g}, 0.35 \mathrm{mmol})$, nonadecane $(0.080 \mathrm{~g}, 0.30 \mathrm{mmol})$ as the internal standard, and $5 \mathrm{~mL}$ of THF. The vial was capped, removed from the glovebox and the reaction mixture was stirred at room temperature under $\mathrm{N}_{2}$. Monomer $1(0.13 \mathrm{~g}, 0.31 \mathrm{mmol})$ in $2 \mathrm{~mL}$ of THF was injected into the solution to initiate the polymerization. After $30 \mathrm{~s}$ of stirring, an aliquot $(0.2 \mathrm{~mL})$ was withdrawn from the solution, quenched with methanol $(1 \mathrm{~mL})$, diluted with diethyl ether $(1 \mathrm{~mL})$ and subjected to GC-MS analysis. The reaction mixture was stirred at room temperature for $30 \mathrm{~min}$ before being placed in an oil bath at $50^{\circ} \mathrm{C}$. A final aliquot $(0.2 \mathrm{~mL})$ was withdrawn to determine the monomer conversion and the polymerization was quenched using 6 $\mathrm{M}$ methanolic $\mathrm{HCl}$ solution. The precipitate was collected using vacuum filtration, then washed with methanol and acetone to remove any unreacted monomer and oligomers. The final polymer was collected as a red solid and dried in vacuo. ${ }^{1} \mathrm{H}$ NMR $\left(500 \mathrm{MHz}, \mathrm{CDCl}_{3}\right) \delta 7.86$ (br s, $\left.1 \mathrm{H}\right)$, $4.30(\mathrm{t}, J=6.8 \mathrm{~Hz}, 2 \mathrm{H}), 1.81-1.67(\mathrm{~m}, 2 \mathrm{H}), 1.44-1.22(\mathrm{~m}, 6 \mathrm{H}), 0.96-0.81(\mathrm{~m}, 3 \mathrm{H}) .{ }^{13} \mathrm{C}$ NMR $\left(126 \mathrm{MHz} \mathrm{CDCl}_{3}\right) \delta 162.9,143.1,132.6,132.4,128.4,65.6,31.7,28.9,25.9,22.8,14.3$. 
Table S2. Optimization of P3HET synthesis from monomer 1.

\begin{tabular}{cccccc}
\hline Catalyst & $\begin{array}{c}\text { \% Cat. } \\
(\mathrm{mol})\end{array}$ & Time $(\mathrm{min})^{a}$ & $M_{\mathrm{n}}(\mathrm{GPC})$ & $Ð$ & $\begin{array}{c}\text { Yield } \\
(\%)\end{array}$ \\
\hline $\mathrm{Ni}\left(\mathrm{PPh}_{3}\right) \mathrm{IPrCl}_{2}$ & 5 & 630 & 7600 & 1.19 & 53 \\
$\mathrm{Ni}\left(\mathrm{PPh}_{3}\right) \mathrm{IPrCl}_{2}$ & 2 & 80 & 16400 & 1.25 & 75 \\
$\mathrm{Ni}\left(\mathrm{PPh}_{3}\right) \mathrm{IPrCl}_{2}$ & 1 & 140 & 30600 & 1.30 & 79 \\
$\mathrm{Ni}(1-\mathrm{Naph})\left(\mathrm{PCy}_{3}\right)_{2} \mathrm{Br}$ & 5 & 90 & 4500 & 1.14 & 58 \\
$\mathrm{Ni}(1-\mathrm{Naph})(\mathrm{PCy})_{2} \mathrm{Br}$ & 2 & 300 & 10500 & 1.60 & 69 \\
$\mathrm{PEPPSI}-\mathrm{IPr}_{\mathrm{Ni}}$ & 2 & 780 & 5500 & 1.28 & 20 \\
$\mathrm{~N}$ & 2 & 720 & 13600 & 1.55 & 69 \\
\hline
\end{tabular}

${ }^{a}$ All times listed were started when the vial was placed in the $50{ }^{\circ} \mathrm{C}$ oil bath.

Scheme S4. Synthesis of P3HT.

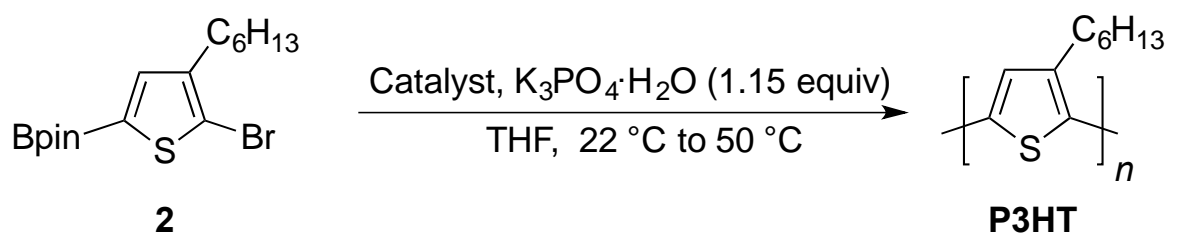

Representative procedure for P3HT synthesis. In a $\mathrm{N}_{2}$ filled glove box, a $20 \mathrm{~mL}$ scintillation vial equipped with a Teflon screw cap was charged with a calculated amount of catalyst (mol \% listed in Table S3), $\mathrm{K}_{3} \mathrm{PO}_{4} \cdot \mathrm{H}_{2} \mathrm{O}(0.080 \mathrm{~g}, 0.35 \mathrm{mmol})$, nonadecane $(0.080 \mathrm{~g}, 0.30 \mathrm{mmol})$ as the internal standard, and $5 \mathrm{~mL}$ of THF. The vial was sealed, removed from the glovebox and the reaction mixture was stirred at room temperature under $\mathrm{N}_{2}$. Monomer $2(0.114 \mathrm{~g}, 0.31 \mathrm{mmol})$ in $2 \mathrm{~mL}$ of THF was injected into the reaction mixture followed by degassed $\mathrm{H}_{2} \mathrm{O}$ then, the vial was immersed in an oil bath at $50{ }^{\circ} \mathrm{C}$. The reaction mixture was sampled periodically and polymer aliquots were prepared by quenching $\sim 0.2 \mathrm{~mL}$ of the polymer solution with $\sim 2.0 \mathrm{~mL}$ of $6 \mathrm{M}$ methanolic $\mathrm{HCl}$. The precipitate was filtered and washed with methanol and acetone to remove any monomer and low molecular weight oligomers. The resultant polymer was dissolved in $\sim 1$ $\mathrm{mL}$ of THF with gentle heating, filtered through a $0.22 \mu \mathrm{m}$ PTFE syringe filter, and analyzed using GPC (relative to polystyrene) with THF as the eluent. 
Table S3. Optimization of water content in P3HT synthesis from monomer 2.

\begin{tabular}{|c|c|c|c|c|c|}
\hline Catalyst & $\begin{array}{c}\% \text { Cat. } \\
\text { (mol) }\end{array}$ & $\mathrm{H}_{2} \mathrm{O}(\mathrm{mL})$ & Time (min) & $M_{\mathrm{n}}(\mathrm{GPC})$ & $D$ \\
\hline $\mathrm{Ni}\left(\mathrm{PPh}_{3}\right) \mathrm{IPrCl}_{2}$ & 2 & 0 & 1200 & 6200 & 1.65 \\
\hline $\mathrm{Ni}\left(\mathrm{PPh}_{3}\right) \mathrm{IPrCl}_{2}$ & 2 & 0.02 & 35 & 8100 & 1.54 \\
\hline $\mathrm{Ni}\left(\mathrm{PPh}_{3}\right) \mathrm{IPrCl}_{2}$ & 2 & 0.05 & 35 & 8700 & 1.50 \\
\hline $\mathrm{Ni}\left(\mathrm{PPh}_{3}\right) \mathrm{IPrCl}_{2}$ & 2 & 0.08 & 35 & 42100 & 1.37 \\
\hline $\mathrm{Ni}\left(\mathrm{PPh}_{3}\right) \mathrm{IPrCl}_{2}$ & 2 & 0.10 & 15 & 61300 & 1.13 \\
\hline $\mathrm{Ni}\left(\mathrm{PPh}_{3}\right) \mathrm{IPrCl}_{2}{ }^{a}$ & 2 & 0.10 & 45 & 74400 & 1.30 \\
\hline $\mathrm{Ni}(\mathrm{dppp}) \mathrm{Cl}_{2}$ & 2 & 0 & 1110 & 8200 & 1.54 \\
\hline $\mathrm{Ni}(\mathrm{dppp}) \mathrm{Cl}_{2}$ & 2 & 0.05 & 140 & 16000 & 1.15 \\
\hline $\mathrm{Ni}(\mathrm{dppp}) \mathrm{Cl}_{2}$ & 2 & 0.10 & 30 & 17100 & 1.09 \\
\hline $\mathrm{Ni}(\mathrm{dppp}) \mathrm{Cl}_{2}^{b}$ & 2 & 0.10 & 60 & 18600 & 1.08 \\
\hline
\end{tabular}

${ }^{a}$ Isolated yield $=71 \% .{ }^{b}$ Isolated yield $=59 \%$.

Scheme S5. Synthesis of P3HET- $a$-P3HT.

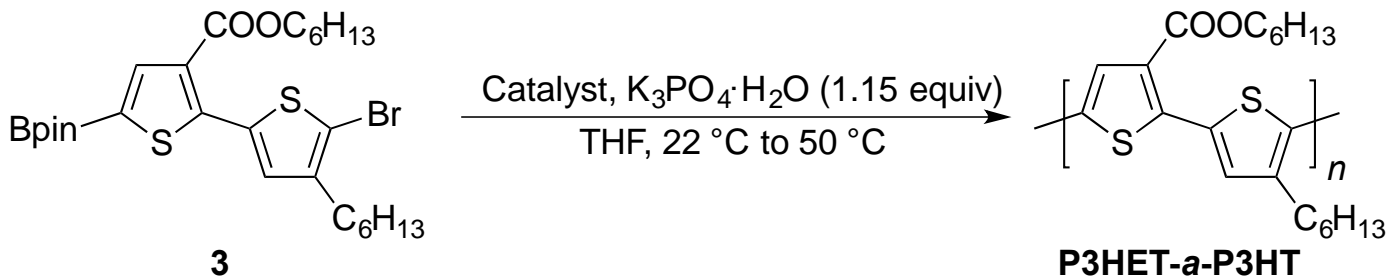

Representative procedure for P3HET-a-P3HT synthesis. In a $\mathrm{N}_{2}$ filled glovebox, a $20 \mathrm{~mL}$ scintillation vial equipped with a Teflon screw cap was charged with a calculated amount of catalyst (listed in Table S5 below), $\mathrm{K}_{3} \mathrm{PO}_{4} \cdot \mathrm{H}_{2} \mathrm{O}(0.080 \mathrm{~g}, 0.35 \mathrm{mmol})$ and $5 \mathrm{~mL}$ of THF. The vial was capped, removed from the glovebox and the reaction mixture was stirred at room temperature under $\mathrm{N}_{2}$. Monomer $3(0.18 \mathrm{~g}, 0.31 \mathrm{mmol})$ in $2 \mathrm{~mL}$ of THF was injected into the reaction mixture followed by degassed $\mathrm{H}_{2} \mathrm{O}$ then, the vial was immersed in an oil bath at $50{ }^{\circ} \mathrm{C}$. The reaction mixture was stirred for period of time and then, the polymerization was quenched using $6 \mathrm{M}$ methanolic $\mathrm{HCl}$ solution. The precipitate was collected using vacuum filtration, then washed with methanol and acetone to remove any unreacted monomer and oligomers. The final polymer was collected as a purple solid and dried in vacuo. ${ }^{1} \mathrm{H}$ NMR $\left(500 \mathrm{MHz}, \mathrm{CDCl}_{3}\right) \delta 7.54$ 
(s, 1H), $7.38(\mathrm{~s}, 1 \mathrm{H}), 4.30$ (t, $J=6.7 \mathrm{~Hz}, 2 \mathrm{H}), 2.80$ (t, $J=7.9 \mathrm{~Hz}, 2 \mathrm{H}), 1.81-1.57$ (m, 4H), 1.49

$-1.27(\mathrm{~m}, 12 \mathrm{H}), 0.97-0.83(\mathrm{~m}, 6 \mathrm{H}) .{ }^{13} \mathrm{C} \mathrm{NMR}\left(126 \mathrm{MHz}, \mathrm{CDCl}_{3}\right) \delta 163.3,142.3,140.9,133.9$, $132.5,132.0,129.1,128.1,65.5,31.9,31.7,30.8,29.6,29.5,28.9,26.0,22.9,22.8,14.34$ and 14.26 ( 2 overlapping signals). Note: only 7 of the 8 possible signals from the thiophene rings are visible due to similarities between chemical environments.

Table S4. Synthesis of P3HET- $a$-P3HT from monomer 3.

\begin{tabular}{ccccccc}
\hline Catalyst & $\begin{array}{c}\text { \% Cat. } \\
(\mathrm{mol})\end{array}$ & $\mathrm{H}_{2} \mathrm{O}(\mathrm{mL})$ & Time (min) & $M_{\mathrm{n}}(\mathrm{GPC})$ & $Ð$ & Yield (\%) \\
\hline $\mathrm{Ni}\left(\mathrm{PPh}_{3}\right) \mathrm{IPrCl}_{2}$ & 2 & 0 & 210 & 27700 & 1.63 & 67 \\
$\mathrm{Ni}\left(\mathrm{PPh}_{3}\right) \mathrm{IPrCl}_{2}$ & 2 & 0.10 & 60 & 22600 & 6.08 & 52 \\
$\mathrm{Ni}(\mathrm{dppp}) \mathrm{Cl}_{2}$ & 2 & 0.10 & 60 & 36500 & 1.13 & 59 \\
$\mathrm{Ni}(\mathrm{dppp}) \mathrm{Cl}_{2}$ & 1 & 0.10 & 120 & 49000 & 1.48 & 52 \\
\hline
\end{tabular}




\section{Synthesis of Block Copolymers}

\section{Using $\mathrm{Ni}\left(\mathrm{PPh}_{3}\right) \mathrm{IPrCl}_{2}$ as the catalyst and synthesizing P3HT first.}

In a $\mathrm{N}_{2}$ filled glovebox, a $20 \mathrm{~mL}$ scintillation vial equipped with a Teflon screw cap was charged with $\mathrm{Ni}\left(\mathrm{PPh}_{3}\right) \mathrm{IPrCl}_{2}(9.5 \mathrm{mg}, 4 \mathrm{~mol} \%), \mathrm{K}_{3} \mathrm{PO}_{4} \cdot \mathrm{H}_{2} \mathrm{O}(0.080 \mathrm{~g}, 0.35 \mathrm{mmol})$, nonadecane $(0.080 \mathrm{~g}$, $0.30 \mathrm{mmol})$ as the internal standard, monomer $2(0.114 \mathrm{~g}, 0.31 \mathrm{mmol})$ and $7 \mathrm{~mL}$ of THF. The vial was sealed, removed from the glovebox and stirred at room temperature under $\mathrm{N}_{2}$. Degassed water $(0.1 \mathrm{~mL})$ was then injected and the mixture was stirred at room temperature. After $10 \mathrm{~s}$ of stirring, an aliquot $(0.2 \mathrm{~mL})$ was withdrawn from the solution and subjected to GC-MS analysis. The reaction mixture was stirred at room temperature for $30 \mathrm{~min}$ before another aliquot $(0.4 \mathrm{~mL})$ was withdrawn to determine the monomer conversion and molecular weight of resultant polymer $\left(M_{\mathrm{n}}=21100, \nexists=1.14\right)$. Monomer $1(0.13 \mathrm{~g}, 0.31 \mathrm{mmol})$ in $2 \mathrm{~mL}$ of THF was then injected into the solution and the mixture was stirred at $40{ }^{\circ} \mathrm{C}$ for another $30 \mathrm{~min}$. A final aliquot was withdrawn to determine the monomer conversion and molecular weight of the block copolymer $\left(M_{\mathrm{n}}=29500, \oslash=1.28\right)$. The polymerization was quenched using $6 \mathrm{M}$ methanolic $\mathrm{HCl}$ solution. The precipitate was collected using vacuum filtration, then washed with methanol and acetone to remove any unreacted monomer and oligomers. The final polymer was collected as a purple solid and dried in vacuo $(54.3 \mathrm{mg}, 46 \%)$. 


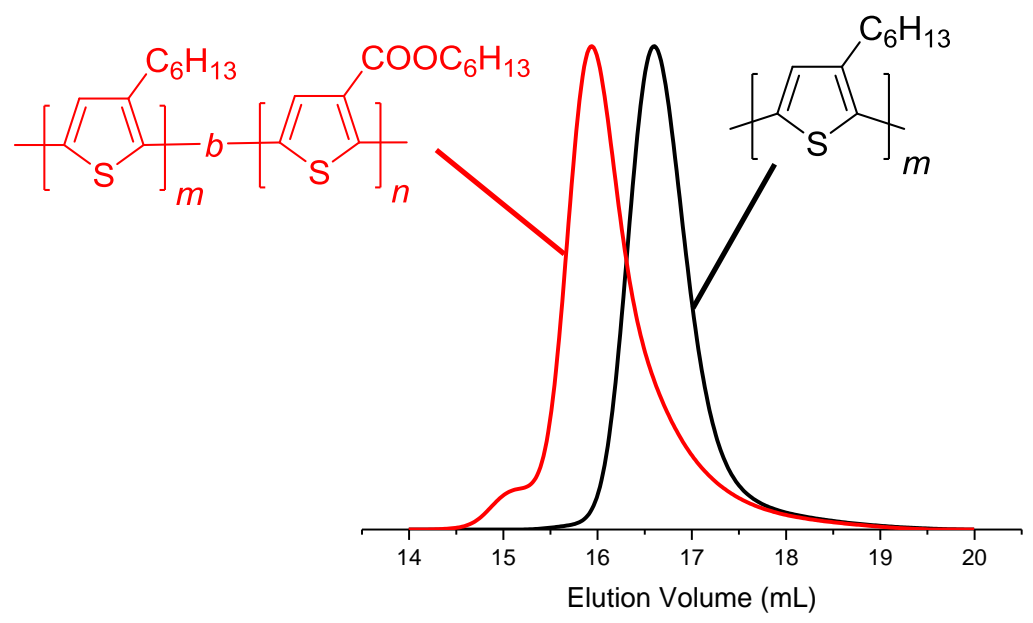

Figure S7. GPC chromatograms for the block copolymer prepared using $\mathrm{Ni}\left(\mathrm{PPh}_{3}\right) \mathrm{IPrCl}_{2}$ as the catalyst and synthesizing P3HT first.

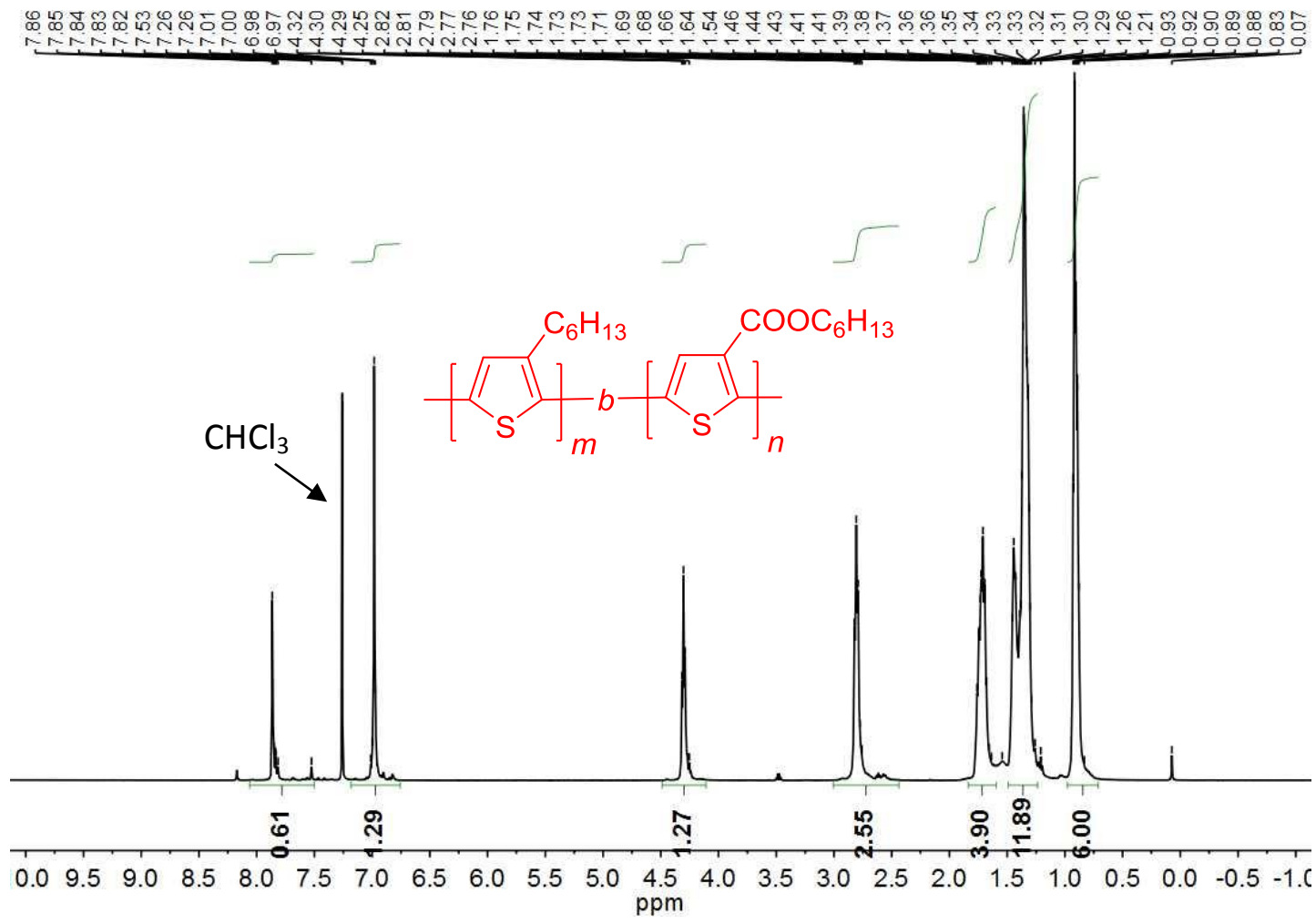

Figure S8. ${ }^{1} \mathrm{H}$ NMR Spectrum - $500 \mathrm{MHz}, \mathrm{CDCl}_{3}$. Synthesis of P3HT- $b$-P3HET using $\mathrm{Ni}\left(\mathrm{PPh}_{3}\right) \mathrm{IPrCl}_{2}$ as the catalyst and synthesizing P3HT first. 


\section{Using $\mathrm{Ni}\left(\mathrm{PPh}_{3}\right) \mathrm{IPrCl}_{2}$ as the catalyst and synthesizing P3HET first.}

In a $\mathrm{N}_{2}$ filled glovebox, a $20 \mathrm{~mL}$ scintillation vial equipped with a Teflon screw cap was charged with $\mathrm{Ni}\left(\mathrm{PPh}_{3}\right) \mathrm{IPrCl}_{2}(9.5 \mathrm{mg}, 4 \mathrm{~mol} \%), \mathrm{K}_{3} \mathrm{PO}_{4} \cdot \mathrm{H}_{2} \mathrm{O}(0.080 \mathrm{~g}, 0.35 \mathrm{mmol})$, nonadecane $(0.080 \mathrm{~g}$, $0.30 \mathrm{mmol}$ ) as the internal standard, and $5 \mathrm{~mL}$ of THF. The vial was sealed, removed from the glovebox and stirred at room temperature under $\mathrm{N}_{2}$. Monomer $1(0.13 \mathrm{~g}, 0.31 \mathrm{mmol})$ in $2 \mathrm{~mL}$ of THF was injected into the solution. After $10 \mathrm{~s}$ of stirring at room temperature, an aliquot $(0.2$ $\mathrm{mL}$ ) was withdrawn from the solution and subjected to GC-MS analysis. The reaction mixture was stirred at room temperature for $30 \mathrm{~min}$ before being placed in an oil bath at $50{ }^{\circ} \mathrm{C}$. After 80 min, another aliquot $(0.4 \mathrm{~mL})$ was withdrawn to determine the monomer conversion and molecular weight of the resultant polymer $\left(M_{\mathrm{n}}=4500, \nexists=1.19\right)$. The solution was then transferred via syringe to another vial containing monomer $2(0.114 \mathrm{~g}, 0.31 \mathrm{mmol})$ and $\mathrm{K}_{3} \mathrm{PO}_{4} \mathrm{H}_{2} \mathrm{O}(0.080 \mathrm{~g}, 0.35 \mathrm{mmol})$. Degassed water $(0.1 \mathrm{~mL})$ was added to the mixture and, after stirring for $1 \mathrm{~h}$ at $50^{\circ} \mathrm{C}$, a final aliquot was withdrawn to determine the monomer conversion and molecular weight of the block copolymer $\left(M_{\mathrm{n}}=12400, \nexists=1.21\right)$. The polymerization was quenched using $6 \mathrm{M}$ methanolic $\mathrm{HCl}$ solution. The precipitate was collected using vacuum filtration, then washed with methanol and acetone to remove any unreacted monomer and oligomers. The final polymer was collected as a purple solid and dried in vacuo $(76.3 \mathrm{mg}, 65 \%)$. 


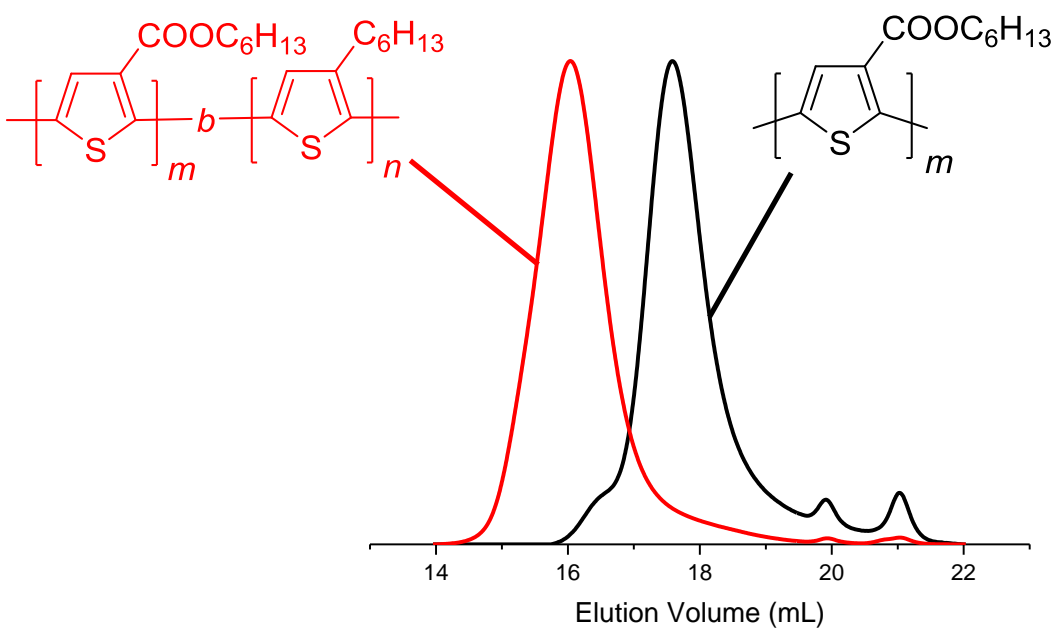

Figure S9. GPC chromatograms for the block copolymer prepared using $\mathrm{Ni}\left(\mathrm{PPh}_{3}\right) \mathrm{IPrCl}_{2}$ as the catalyst and synthesizing P3HET first.

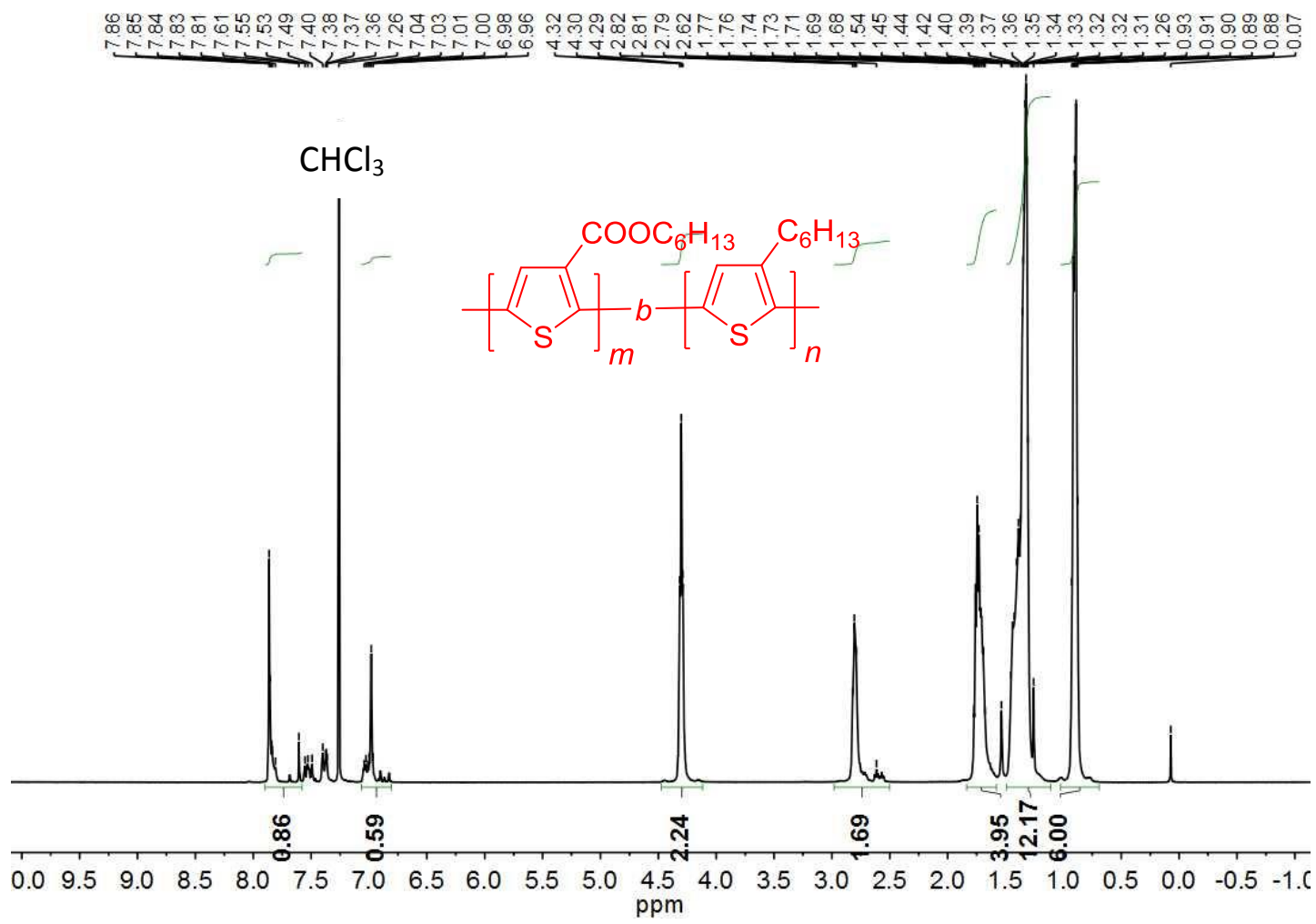

Figure S10. ${ }^{1} \mathrm{H}$ NMR Spectrum $-500 \mathrm{MHz}, \mathrm{CDCl}_{3}$. Synthesis of P3HET- $b$-P3HT using $\mathrm{Ni}\left(\mathrm{PPh}_{3}\right) \mathrm{IPrCl}_{2}$ as the catalyst and synthesizing P3HET first. 


\section{Using $\mathrm{Ni}(\mathrm{dppp}) \mathrm{Cl}_{2}$ as the catalyst and growing P3HT first.}

In a $\mathrm{N}_{2}$ filled glovebox, a $20 \mathrm{~mL}$ scintillation vial equipped with a Teflon screw cap was charged with $\mathrm{Ni}(\mathrm{dppp}) \mathrm{Cl}_{2}(6.6 \mathrm{mg}, 4 \mathrm{~mol} \%), \mathrm{K}_{3} \mathrm{PO}_{4} \cdot \mathrm{H}_{2} \mathrm{O}(0.080 \mathrm{~g}, 0.35 \mathrm{mmol})$, nonadecane $(0.080 \mathrm{~g}$, $0.30 \mathrm{mmol}$ ) as the internal standard, and $5 \mathrm{~mL}$ of THF. The vial was sealed, removed from the glovebox and stirred at room temperature under $\mathrm{N}_{2}$. Monomer $2(0.114 \mathrm{~g}, 0.31 \mathrm{mmol})$ in $2 \mathrm{~mL}$ of THF was injected into the solution followed by degassed water $(0.1 \mathrm{~mL})$. After $10 \mathrm{~s}$, an aliquot $(0.2 \mathrm{~mL})$ was withdrawn from the solution and subjected to GC-MS analysis. The vial was then placed in an oil bath at $40{ }^{\circ} \mathrm{C}$ and the reaction mixture was stirred for $1 \mathrm{~h}$ before another aliquot $(0.4 \mathrm{~mL})$ was withdrawn to determine the monomer conversion and molecular weight of resultant polymer $\left(M_{\mathrm{n}}=11800, \emptyset=1.09\right)$. The solution was then transferred via syringe to another vial containing monomer $1(0.13 \mathrm{~g}, 0.31 \mathrm{mmol})$ and $\mathrm{K}_{3} \mathrm{PO}_{4} \cdot \mathrm{H}_{2} \mathrm{O}(0.08 \mathrm{~g}, 0.35 \mathrm{mmol})$. The reaction mixture was stirred at $40^{\circ} \mathrm{C}$ for $1 \mathrm{~h}$ and a final aliquot was withdrawn to determine the monomer conversion and molecular weight of the block copolymer $\left(M_{\mathrm{n}}=15100, Ð=1.25\right)$. The polymerization was quenched using $6 \mathrm{M}$ methanolic $\mathrm{HCl}$ solution. The precipitate was collected using vacuum filtration, then washed with methanol and acetone to remove any unreacted monomer and oligomers. The final polymer was collected as a purple solid and dried in vacuo $(41 \mathrm{mg}, 35 \%)$. 


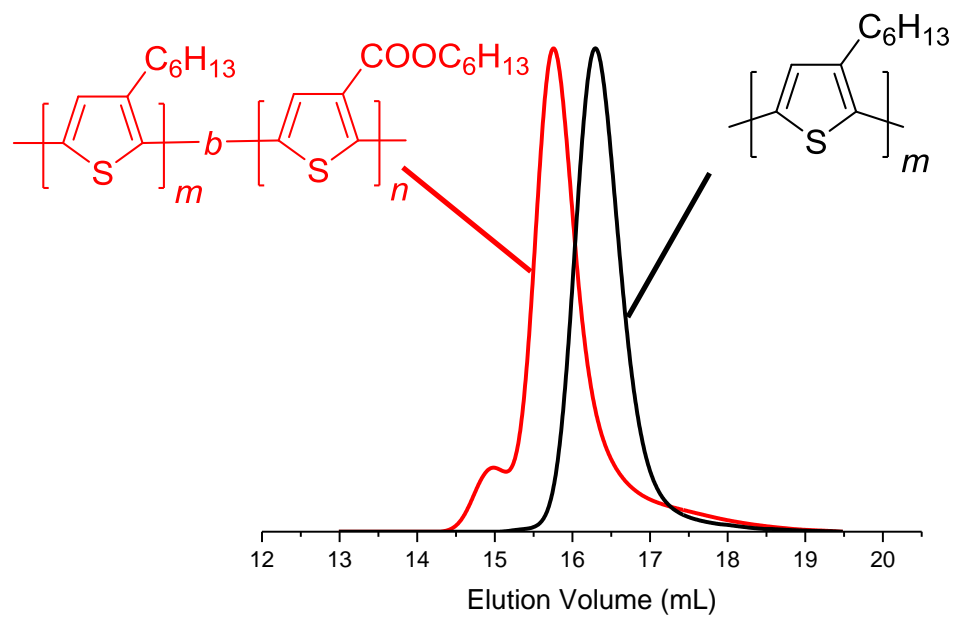

Figure S11. GPC chromatograms for the block copolymer prepared using $\mathrm{Ni}(\mathrm{dppp}) \mathrm{Cl}_{2}$ as the catalyst and growing P3HT first.

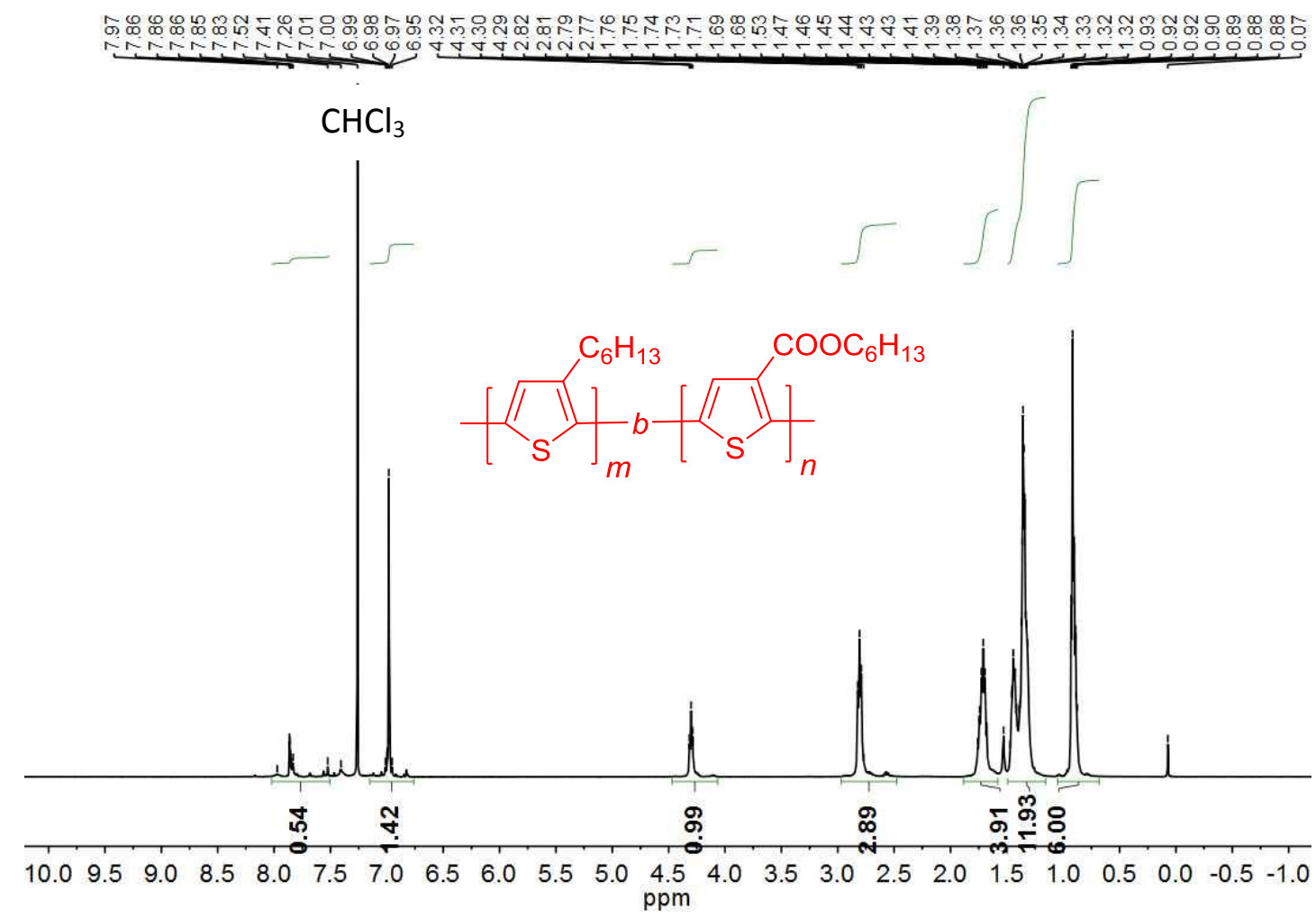

Figure S12. ${ }^{1} \mathrm{H}$ NMR Spectrum $-500 \mathrm{MHz}, \mathrm{CDCl}_{3}$. Synthesis of P3HT- $b$-P3HET using $\mathrm{Ni}(\mathrm{dppp}) \mathrm{Cl}_{2}$ as the catalyst and growing P3HT first. 


\section{Using $\mathrm{Ni}(\mathrm{dppp}) \mathrm{Cl}_{\mathbf{2}}$ as the catalyst and growing P3HET first.}

In a $\mathrm{N}_{2}$ filled glovebox, a $20 \mathrm{~mL}$ scintillation vial equipped with a Teflon screw cap was charged with $\mathrm{Ni}(\mathrm{dppp}) \mathrm{Cl}_{2}(6.6 \mathrm{mg}, 4 \mathrm{~mol} \%), \mathrm{K}_{3} \mathrm{PO}_{4} \cdot \mathrm{H}_{2} \mathrm{O}(0.08 \mathrm{~g}, 0.35 \mathrm{mmol})$, nonadecane (0.08 g, 0.30 mmol) as the internal standard, and $5 \mathrm{~mL}$ of THF. The vial was sealed, removed from the glovebox and stirred at room temperature under $\mathrm{N}_{2}$. Monomer $1(0.13 \mathrm{~g}, 0.31 \mathrm{mmol})$ in $2 \mathrm{~mL}$ of THF was injected into the solution, followed by degassed water $(0.1 \mathrm{~mL})$. After $10 \mathrm{~s}$ of stirring at room temperature, an aliquot $(0.2 \mathrm{~mL})$ was withdrawn from the solution and subjected to GCMS analysis. The vial was then placed in an oil bath at $40{ }^{\circ} \mathrm{C}$ and the reaction mixture was stirred for $1 \mathrm{~h}$ before another aliquot $(0.4 \mathrm{~mL})$ was withdrawn to determine the monomer conversion and molecular weight of resultant polymer $\left(M_{\mathrm{n}}=3600, D=1.10\right)$. The solution was then transferred via syringe to another vial containing monomer $2(0.114 \mathrm{~g}, 0.31 \mathrm{mmol})$ and $\mathrm{K}_{3} \mathrm{PO}_{4} \mathrm{H}_{2} \mathrm{O}(0.08 \mathrm{~g}, 0.35 \mathrm{mmol})$. Water $(0.1 \mathrm{~mL})$ was added and the mixture was stirred at $40{ }^{\circ} \mathrm{C}$ for $1 \mathrm{~h}$ when a final aliquot was withdrawn to determine the monomer conversion and molecular weight of the block copolymer $\left(M_{\mathrm{n}}=10500, \nexists=1.28\right)$. The polymerization was quenched using $6 \mathrm{M}$ methanolic $\mathrm{HCl}$ solution. The precipitate was collected using vacuum filtration, then washed with methanol and acetone to remove any unreacted monomer and oligomers. The final polymer was collected as a purple solid and dried in vacuo (40 $\mathrm{mg}, 34 \%)$. 


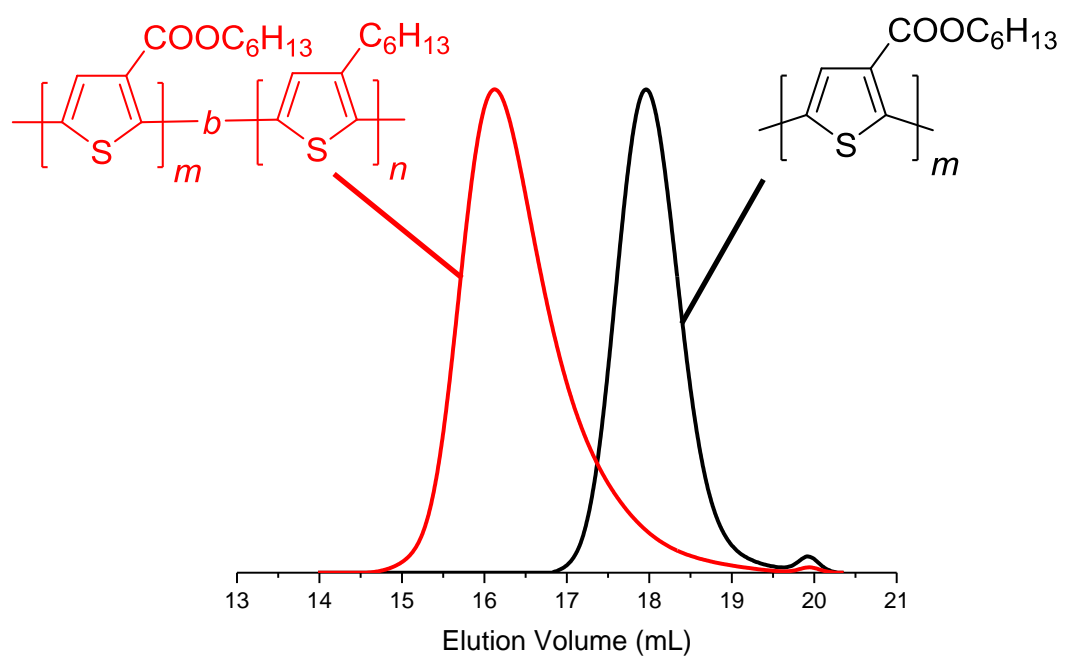

Figure S13. GPC chromatograms for the block copolymer prepared using $\mathrm{Ni}(\mathrm{dppp}) \mathrm{Cl}_{2}$ as the catalyst and growing P3HET first.

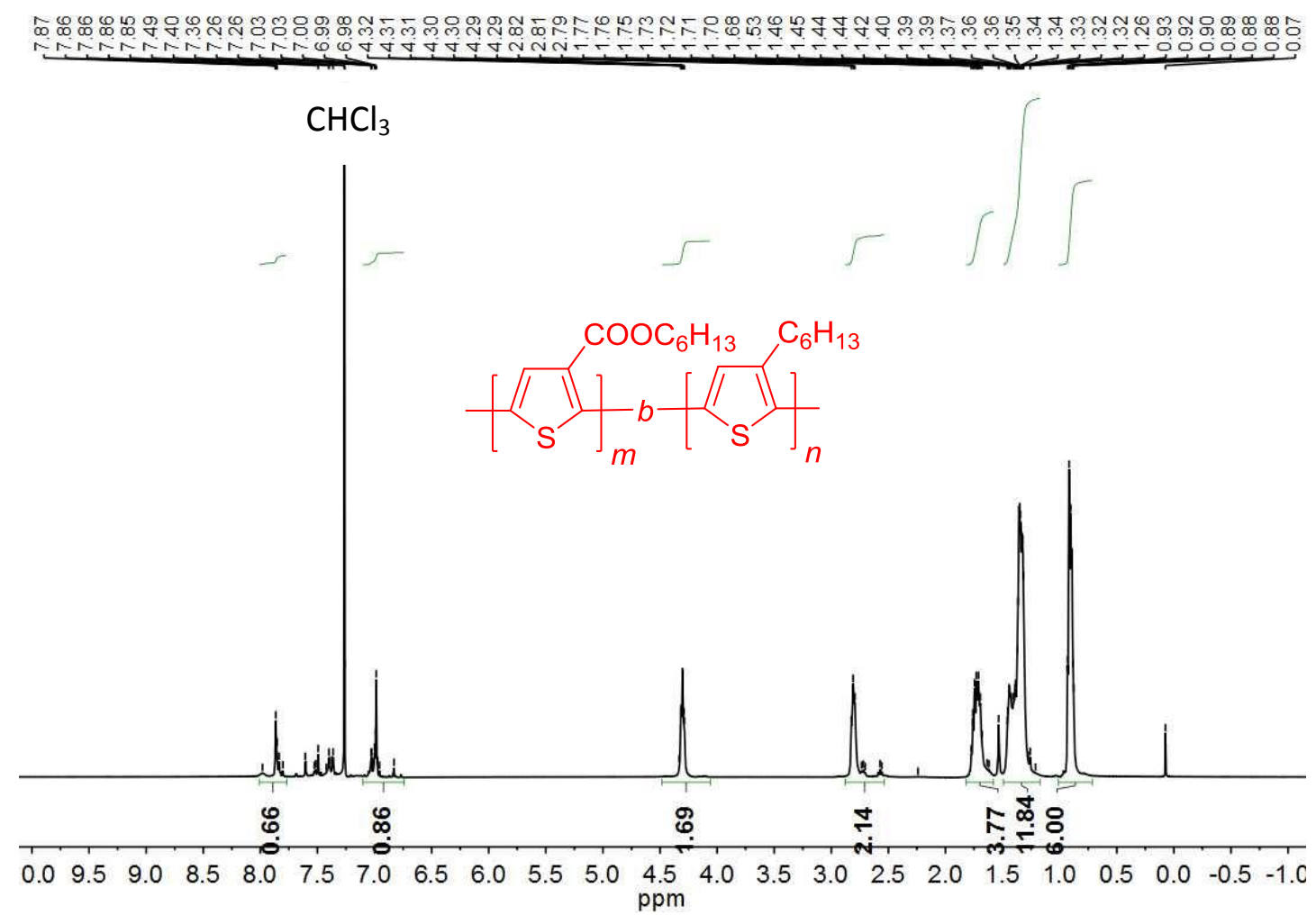

Figure S14. ${ }^{1} \mathrm{H}$ NMR Spectrum $-500 \mathrm{MHz}, \mathrm{CDCl}_{3}$. Synthesis of P3HET- $b$-P3HT using $\mathrm{Ni}(\mathrm{dppp}) \mathrm{Cl}_{2}$ as the catalyst and growing P3HET first. 
NMR Spectra Collected for All Monomers and Monomer Precursors

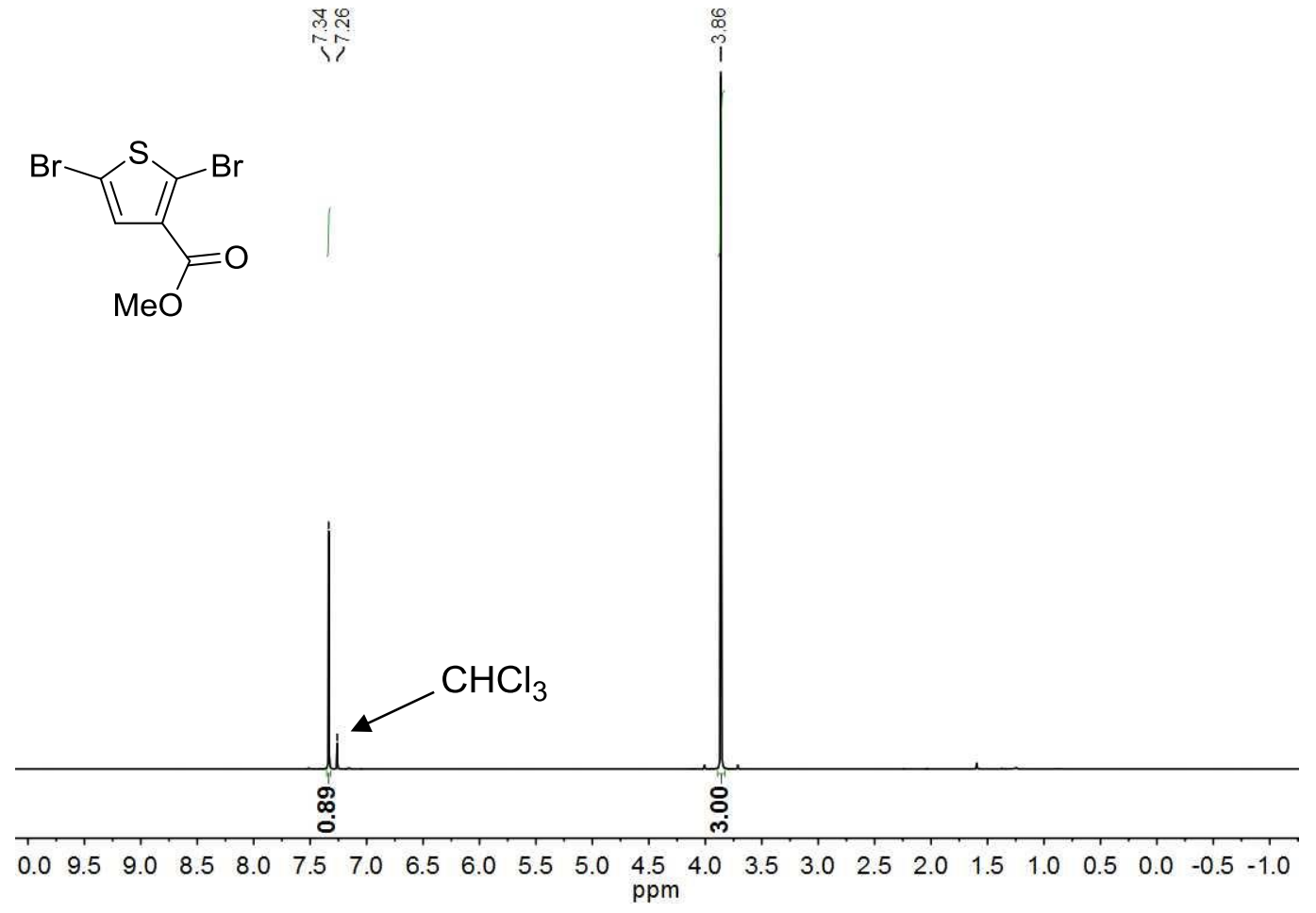

Figure S15. Methyl-2,5-dibromothiophene-3-carboxylate ${ }^{1} \mathrm{H}$ NMR Spectrum - $500 \mathrm{MHz}, \mathrm{CDCl}_{3}$.

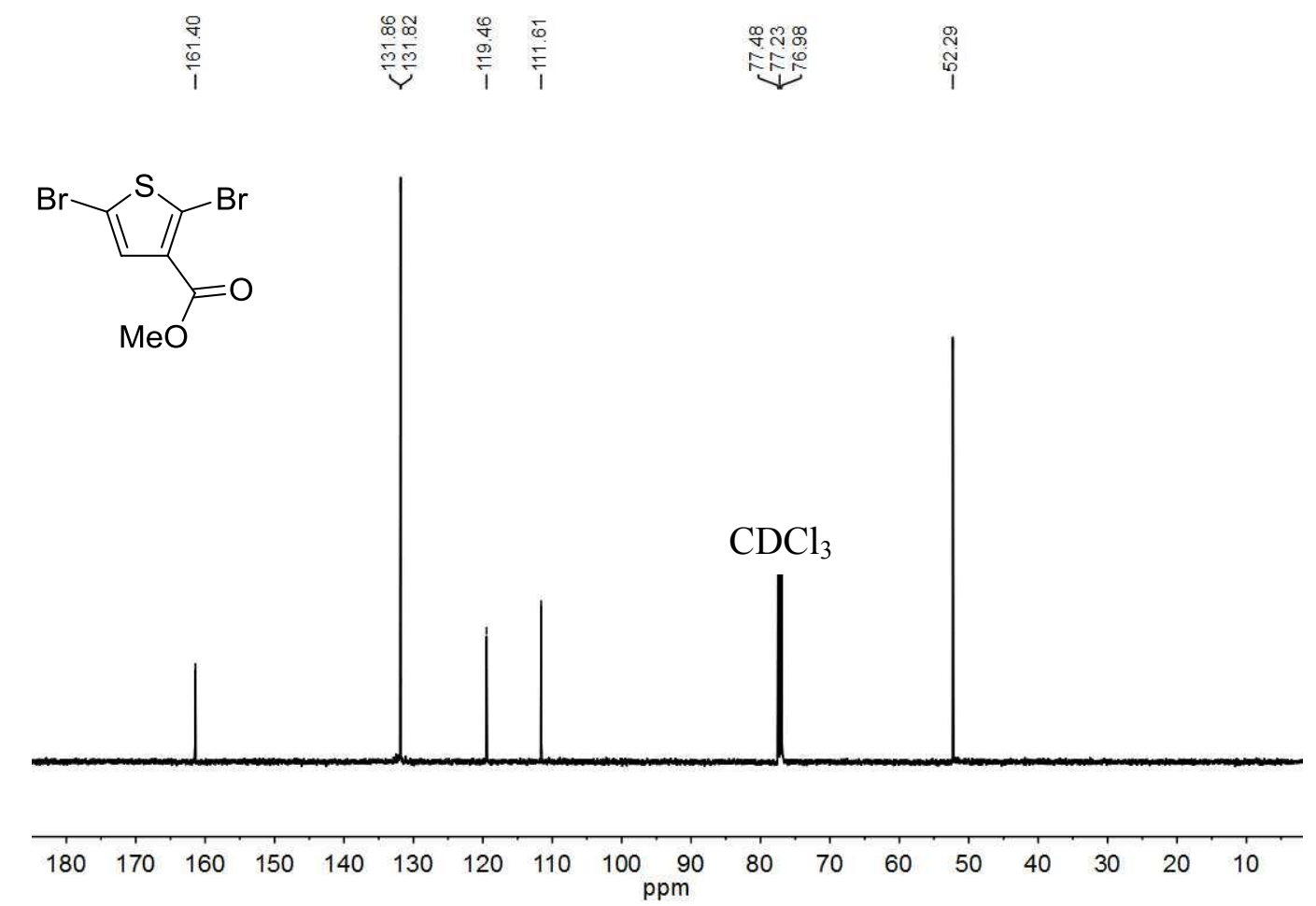

Figure S16. Methyl-2,5-dibromothiophene-3-carboxylate ${ }^{13} \mathrm{C}$ NMR Spectrum - $126 \mathrm{MHz}$, $\mathrm{CDCl}_{3}$. 


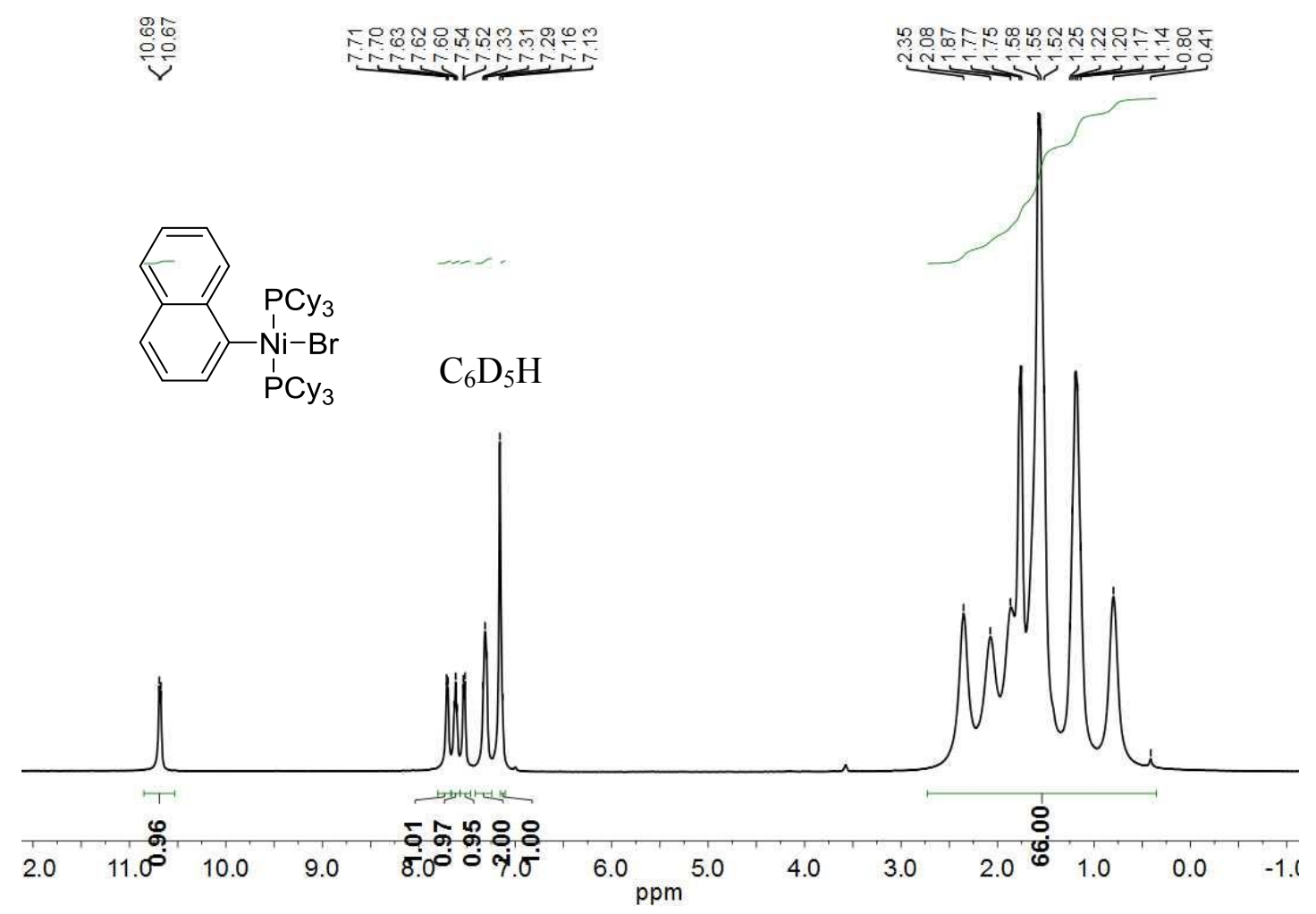

Figure S17. $\mathrm{Ni}(1-\mathrm{Naph})\left(\mathrm{PCy}_{3}\right)_{2} \mathrm{Br}^{1} \mathrm{H}$ NMR Spectrum - $500 \mathrm{MHz}, \mathrm{C}_{6} \mathrm{D}_{6}$.

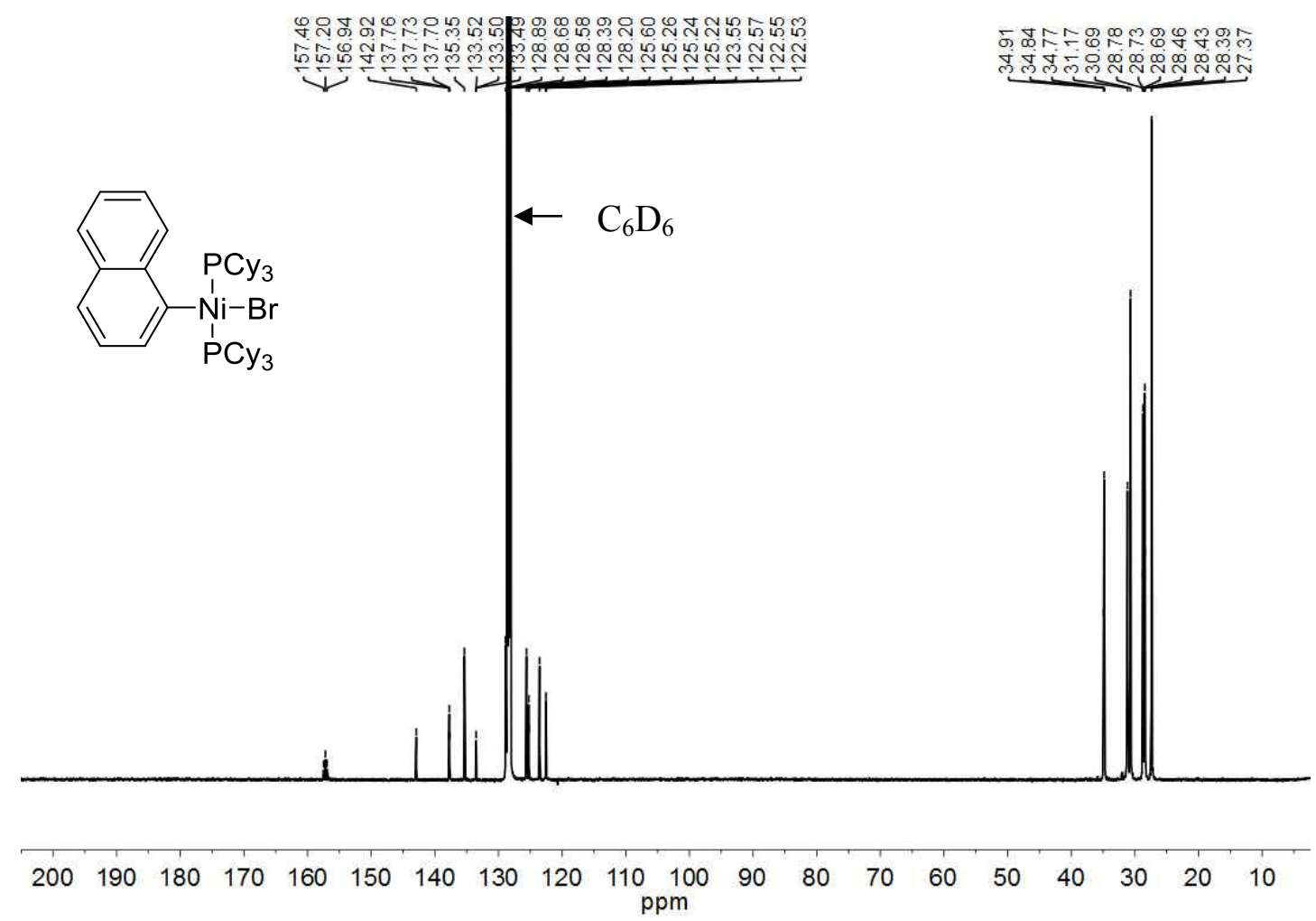

Figure S18. Ni(1-Naph) $\left(\mathrm{PCy}_{3}\right)_{2} \mathrm{Br}{ }^{13} \mathrm{C}$ NMR Spectrum - $126 \mathrm{MHz}, \mathrm{C}_{6} \mathrm{D}_{6}$. 


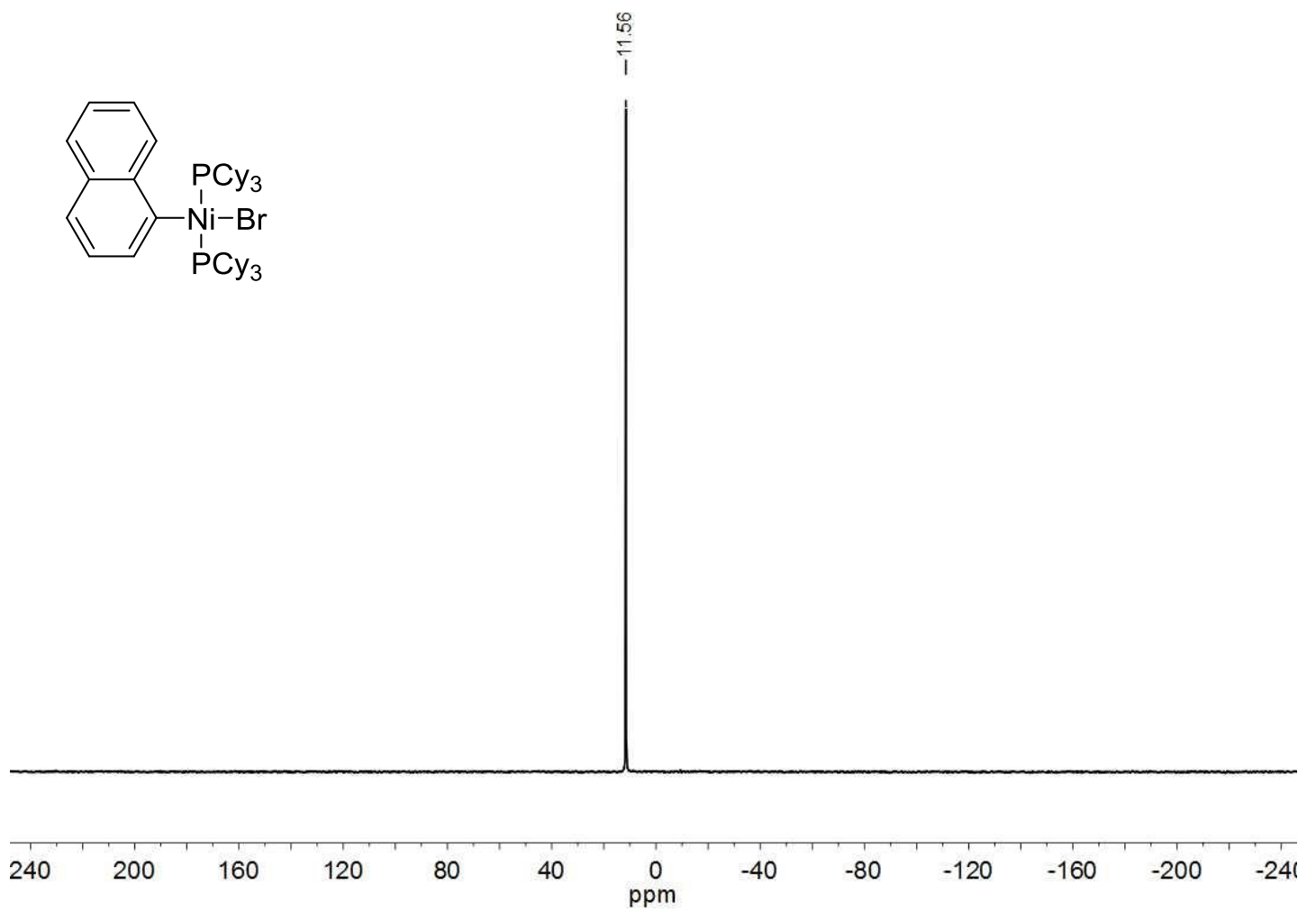

Figure S19. $\mathrm{Ni}(1-\mathrm{Naph})\left(\mathrm{PCy}_{3}\right)_{2} \mathrm{Br}^{31} \mathrm{P}$ NMR Spectrum - $202 \mathrm{MHz}, \mathrm{C}_{6} \mathrm{D}_{6}$.

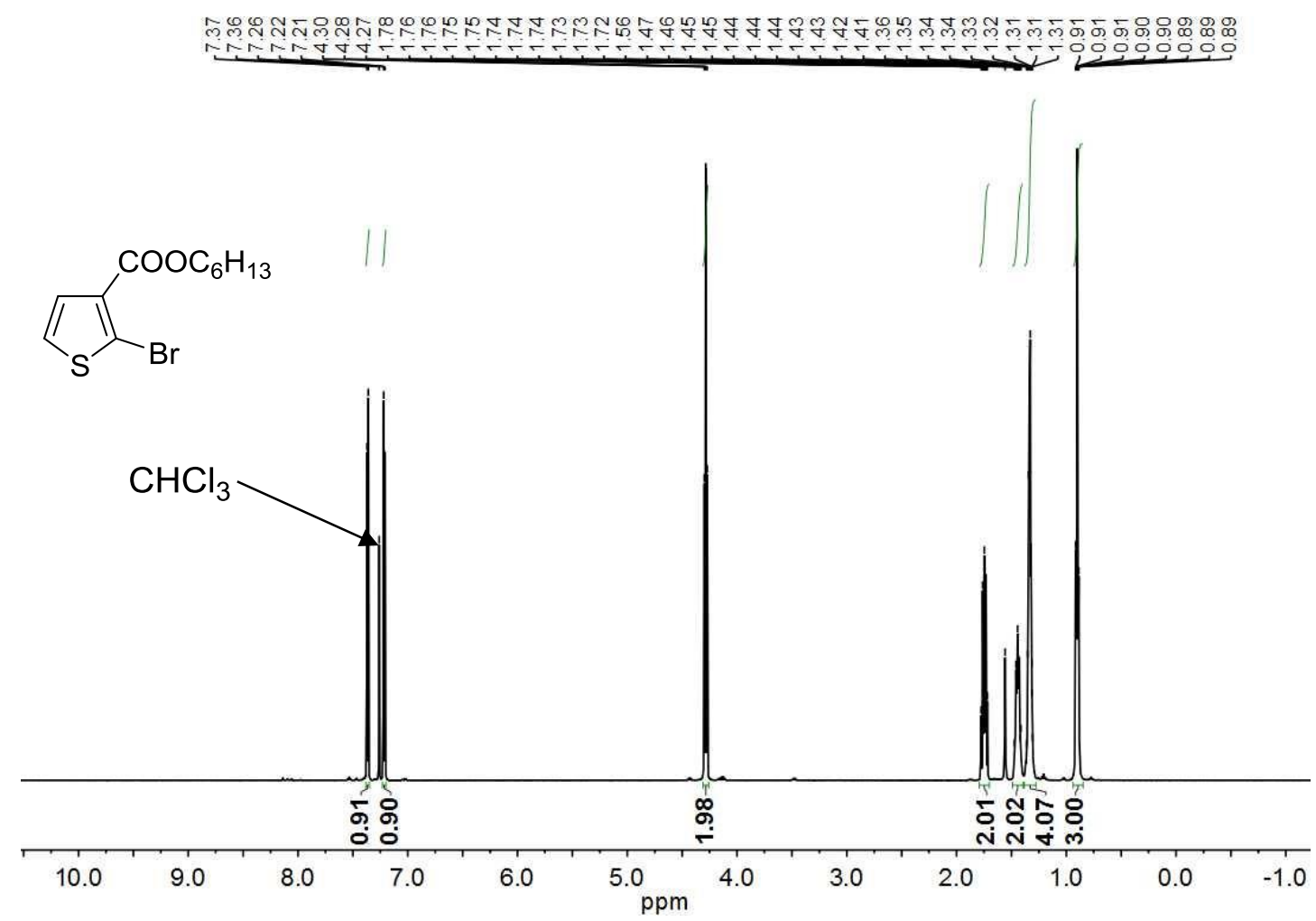

Figure S20. Compound $\mathbf{B}{ }^{1} \mathrm{H}$ NMR Spectrum - $500 \mathrm{MHz}, \mathrm{CDCl}_{3}$. 


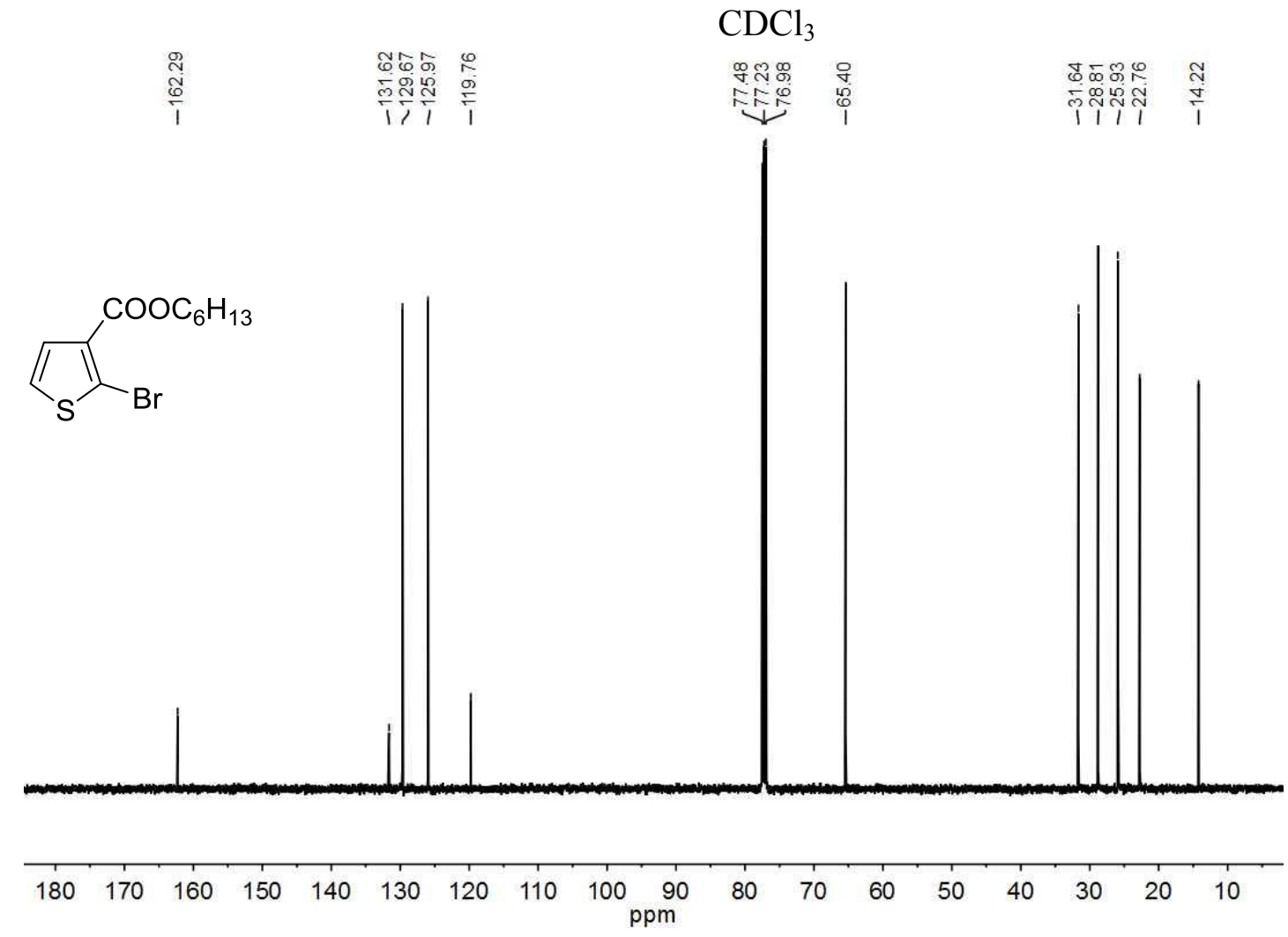

Figure S21. Compound $\mathbf{B}^{13} \mathrm{C}$ NMR Spectrum - $126 \mathrm{MHz}, \mathrm{CDCl}_{3}$.

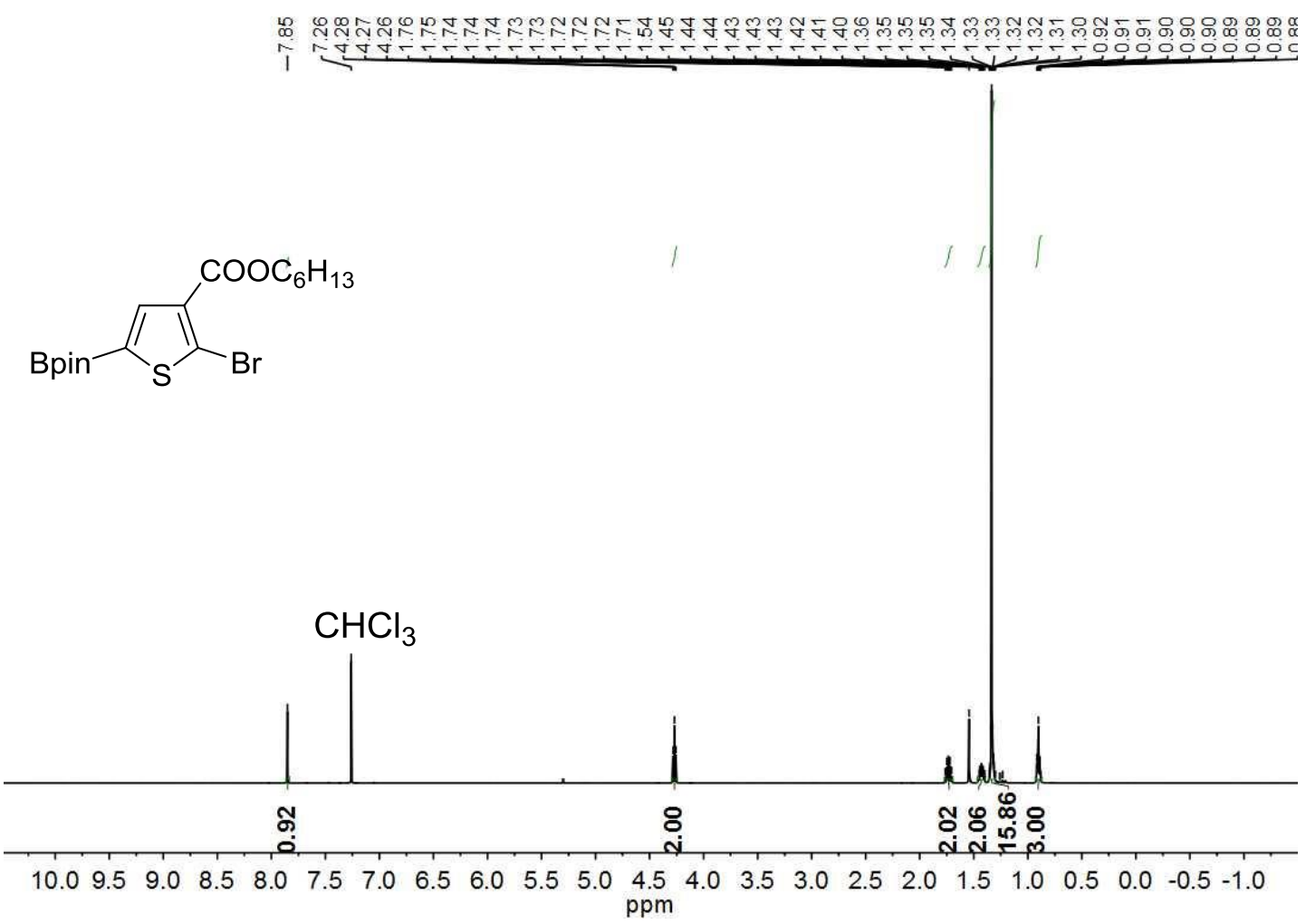

Figure S22. Monomer $1{ }^{1} \mathrm{H}$ NMR Spectrum - $500 \mathrm{MHz}, \mathrm{CDCl}_{3}$. 


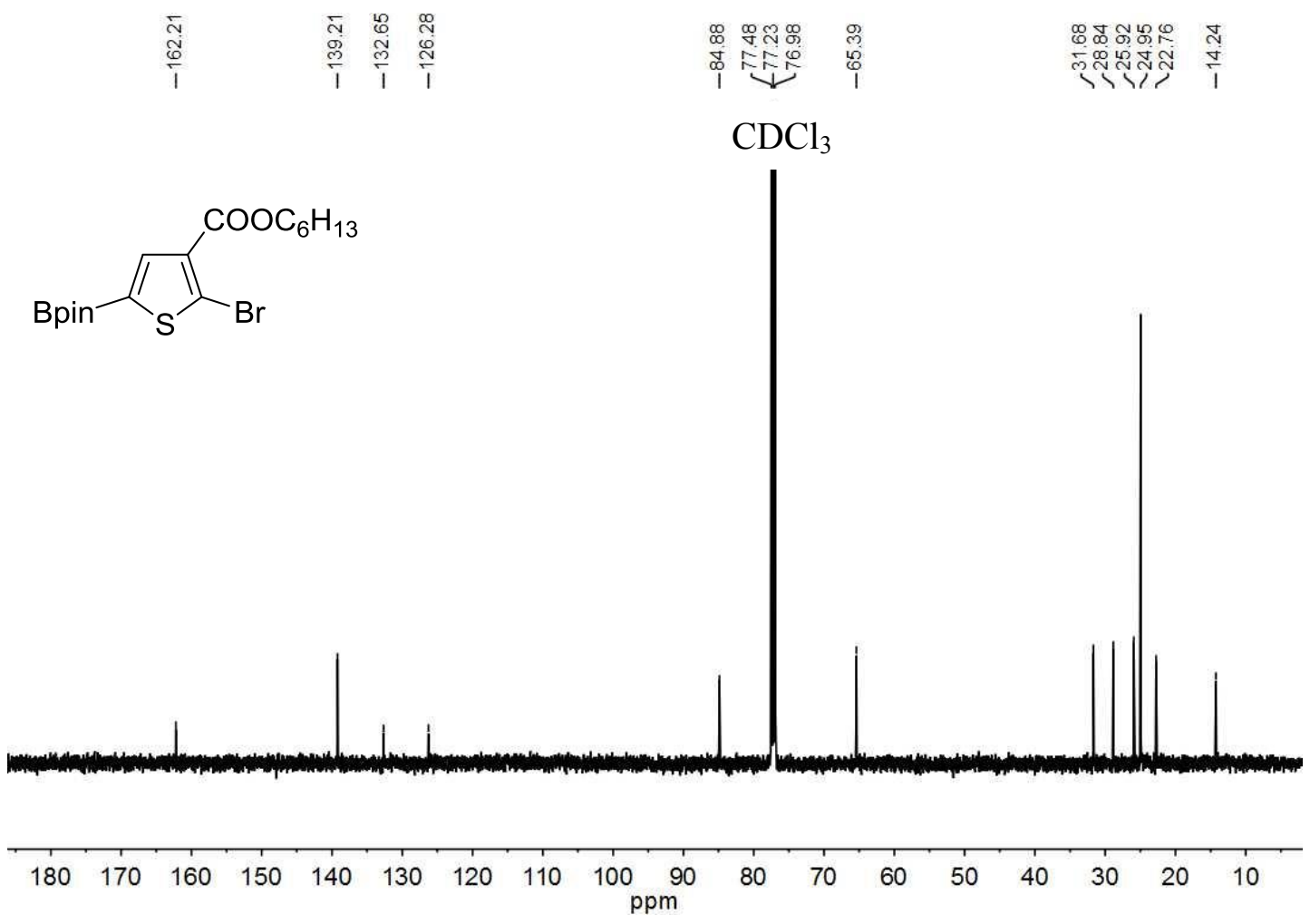

Figure S23. Monomer $1{ }^{13} \mathrm{C}$ NMR Spectrum - $126 \mathrm{MHz}, \mathrm{CDCl}_{3}$.

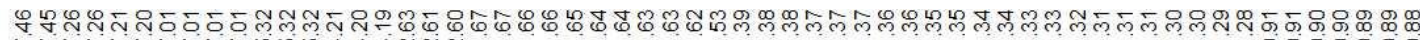

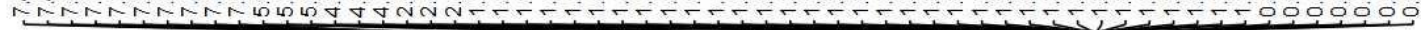

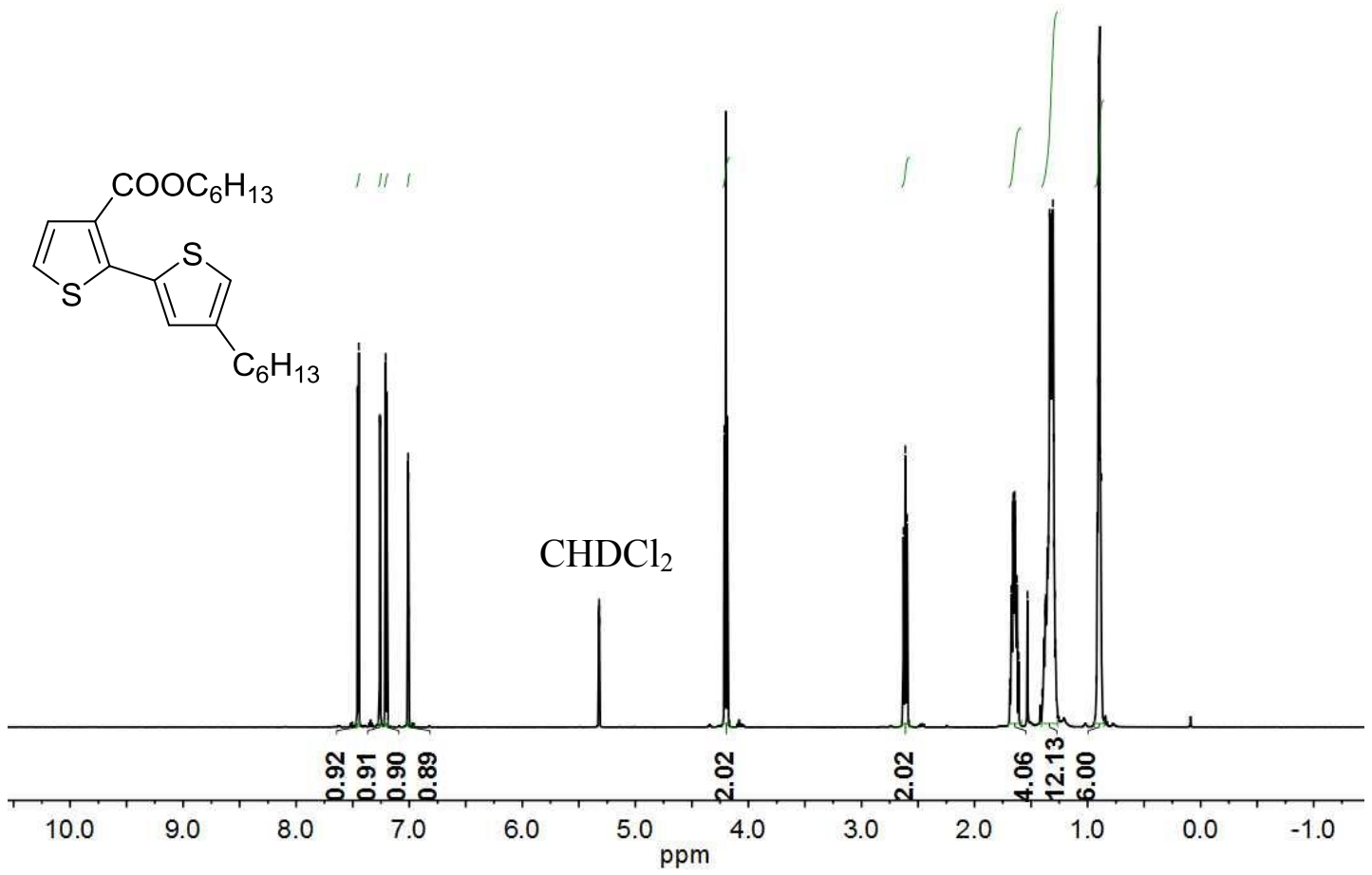

Figure S24. Compound $\mathbf{C}{ }^{1} \mathrm{H}$ NMR Spectrum - $500 \mathrm{MHz}, \mathrm{CD}_{2} \mathrm{Cl}_{2}$. 

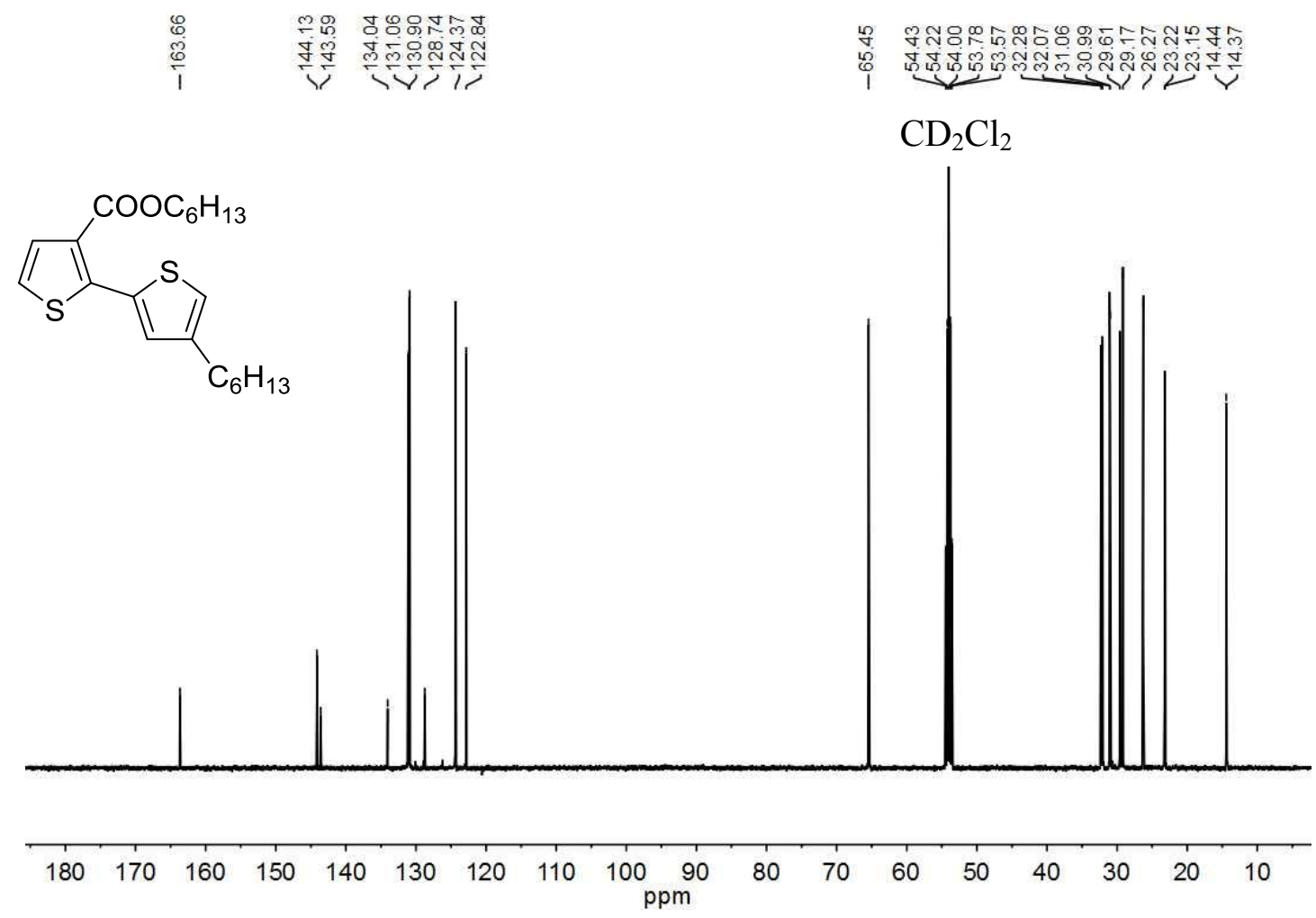

Figure S25. Compound $\mathbf{C}{ }^{13} \mathrm{C}$ NMR Spectrum - $126 \mathrm{MHz}, \mathrm{CD}_{2} \mathrm{Cl}_{2}$.

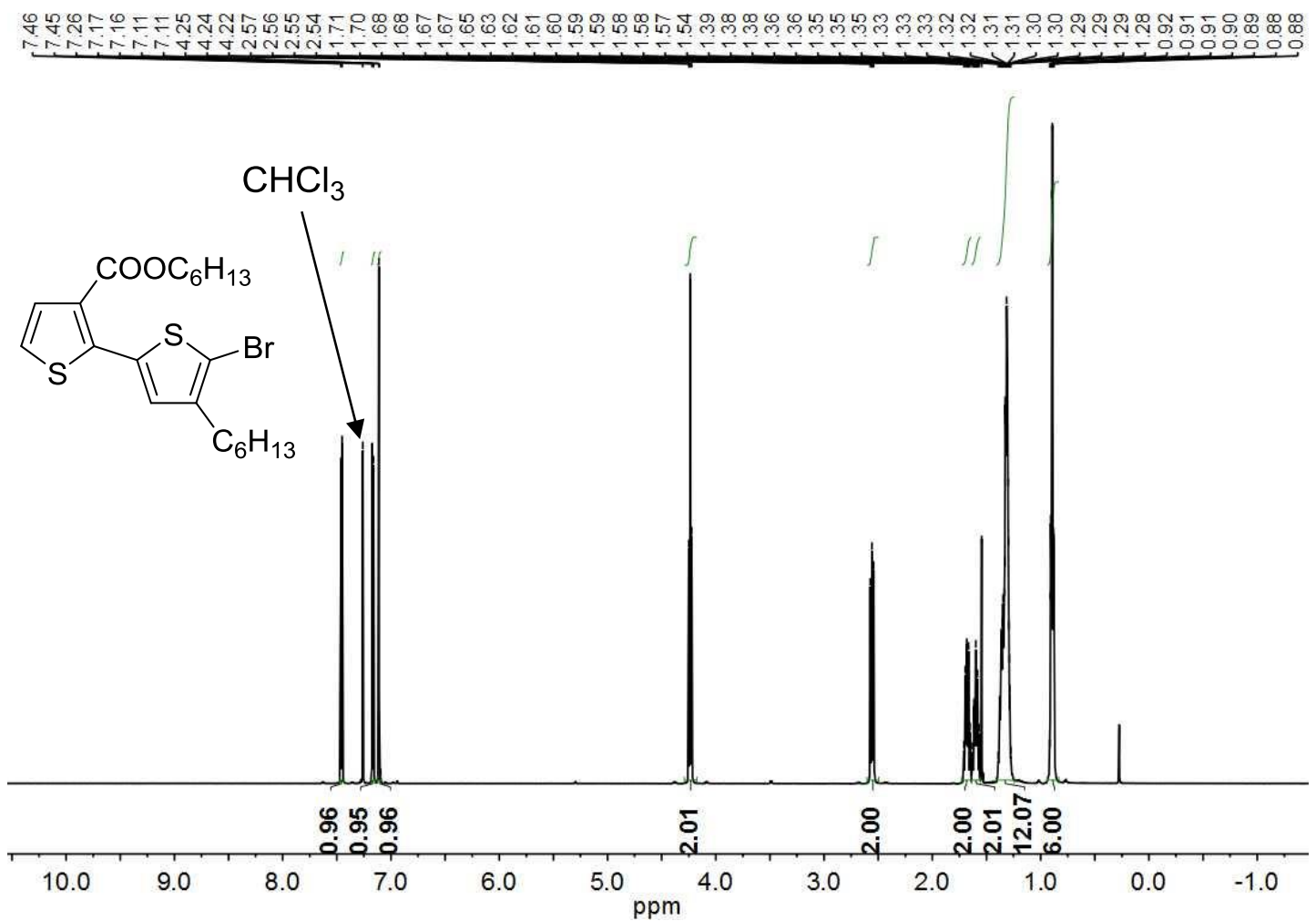

Figure S26. Compound $\mathbf{D}^{1} \mathrm{H}$ NMR Spectrum - $500 \mathrm{MHz}, \mathrm{CDCl}_{3}$. 


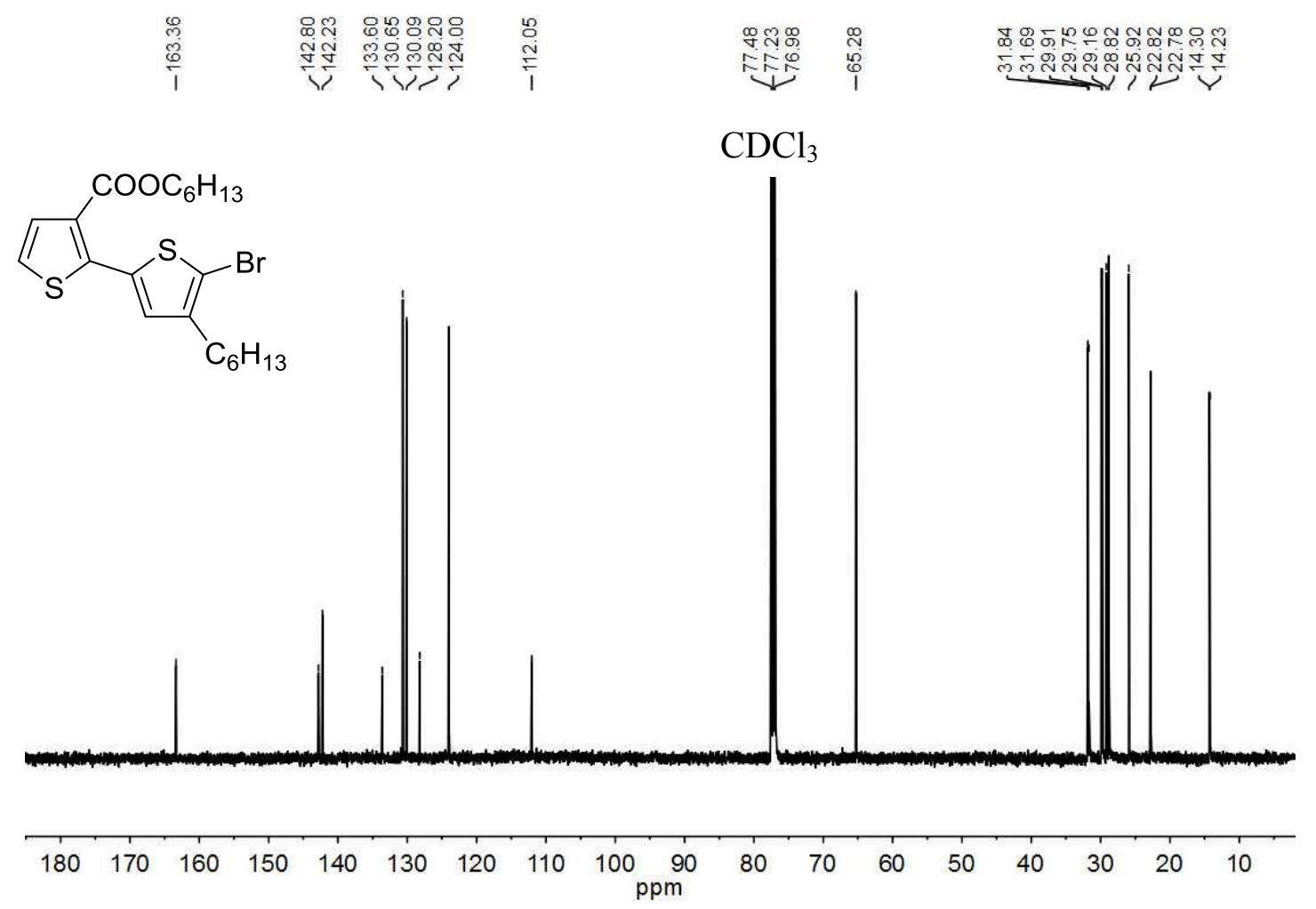

Figure S27. Compound $\mathbf{D}^{13} \mathrm{C}$ NMR Spectrum - $126 \mathrm{MHz}, \mathrm{CDCl}_{3}$.

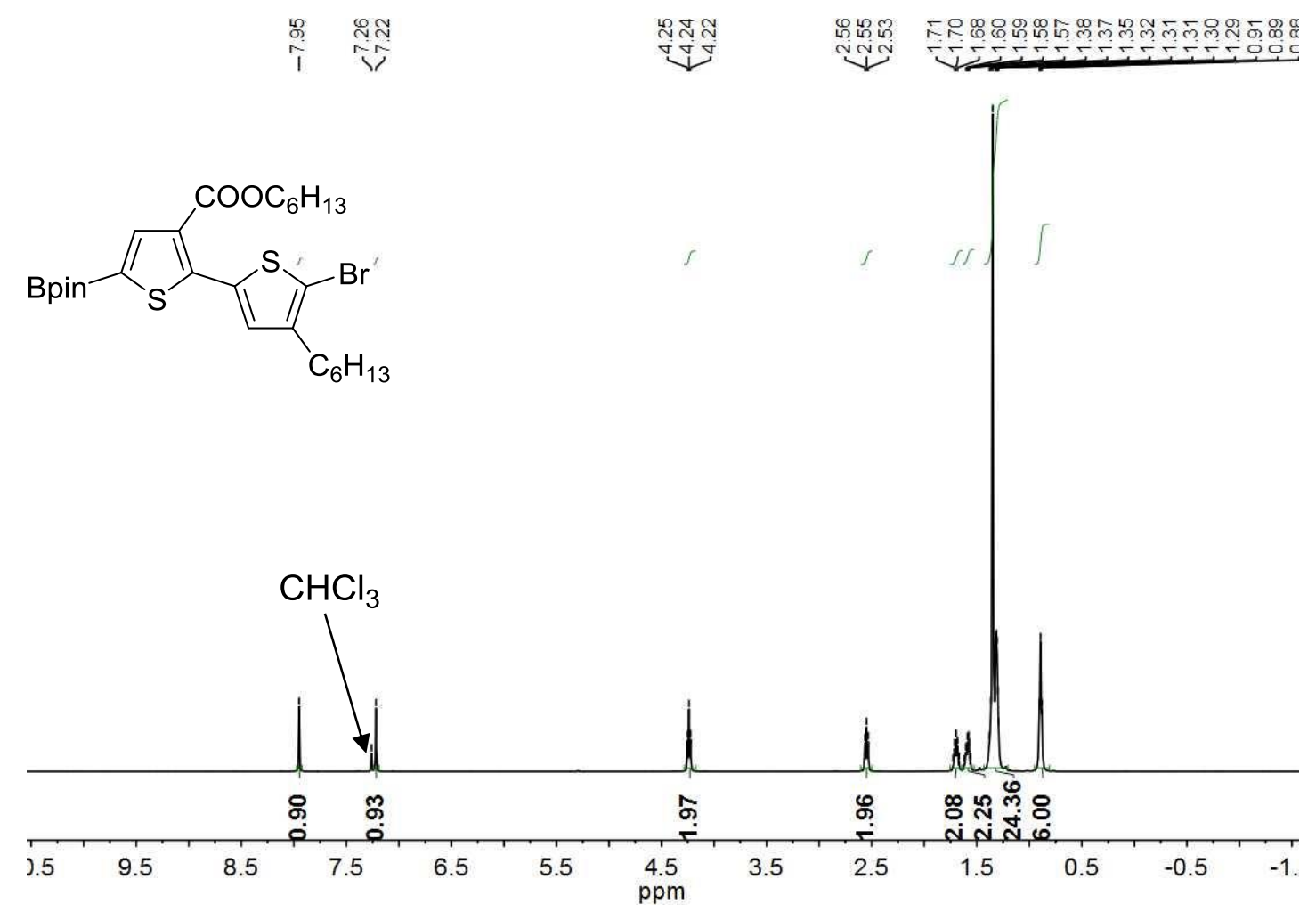

Figure S28. Monomer $3{ }^{1} \mathrm{H}$ NMR Spectrum - $500 \mathrm{MHz}, \mathrm{CDCl}_{3}$. 


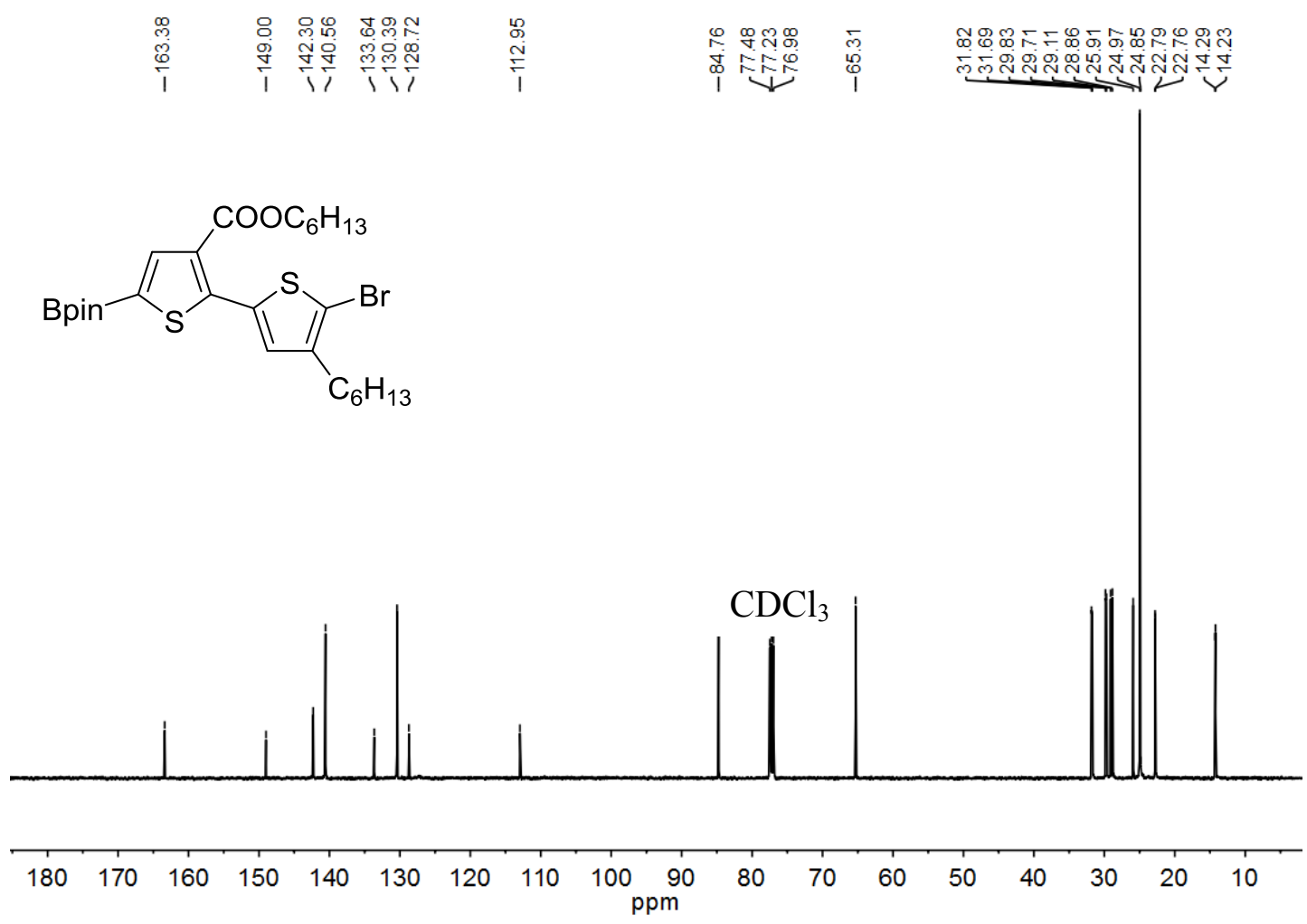

Figure S29. Monomer $3{ }^{13} \mathrm{C}$ NMR Spectrum - $126 \mathrm{MHz}, \mathrm{CDCl}_{3}$. 
NMR Spectra Collected for Polymers

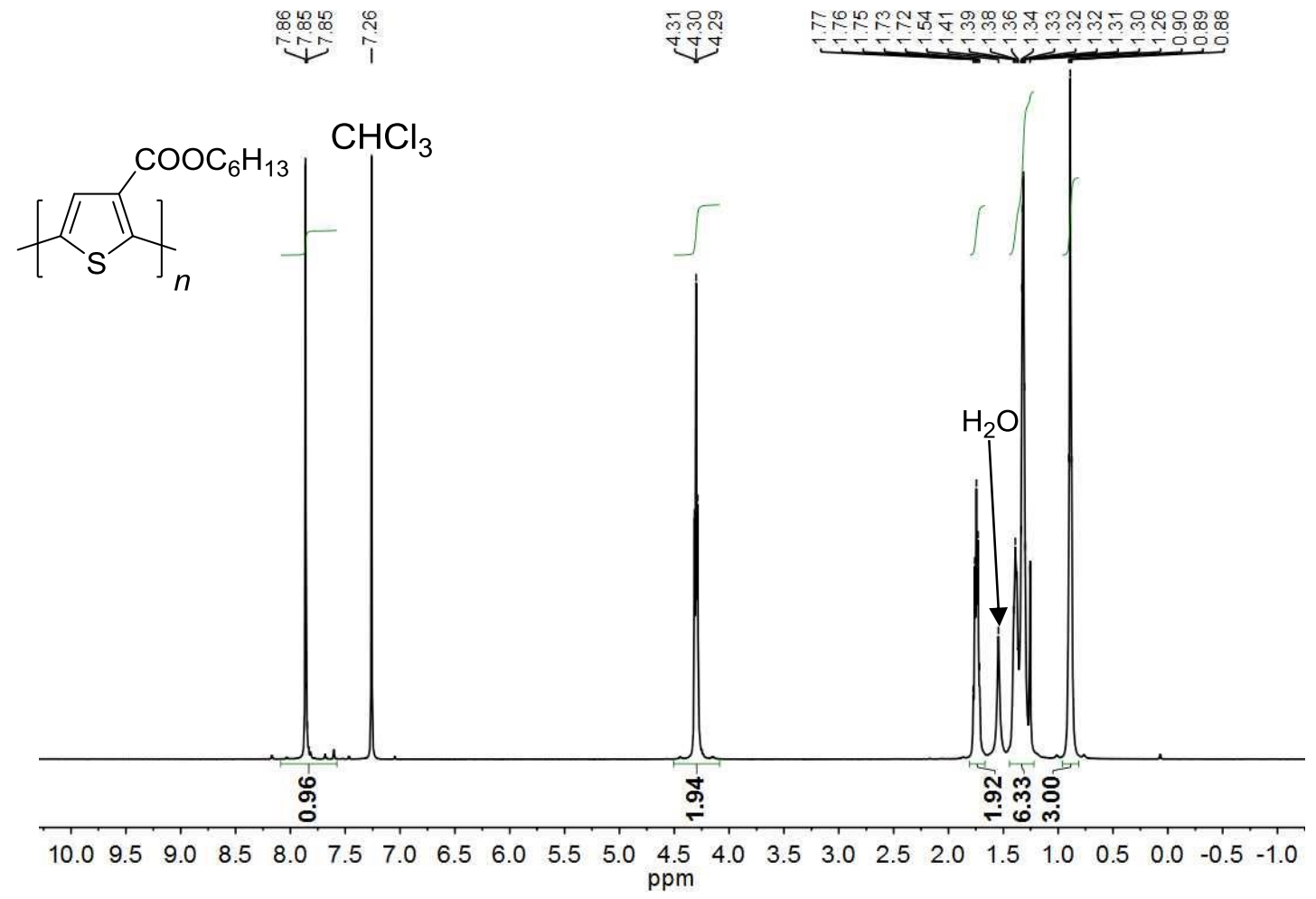

Figure S30. P3HET ${ }^{1} \mathrm{H}$ NMR Spectrum $-500 \mathrm{MHz}, \mathrm{CDCl}_{3}$.
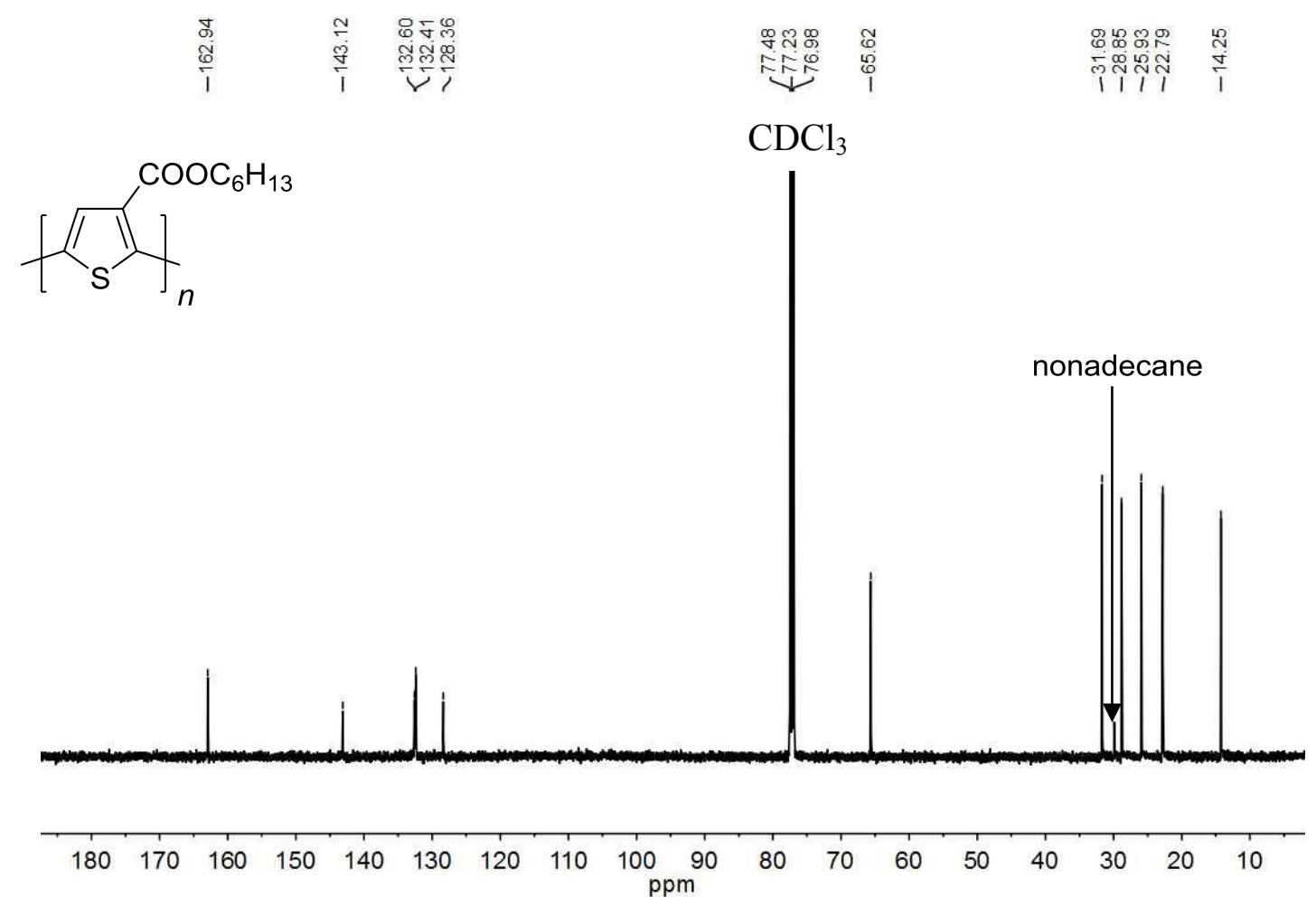

Figure S31. P3HET ${ }^{13} \mathrm{C}$ NMR Spectrum $-126 \mathrm{MHz}, \mathrm{CDCl}_{3}$. 


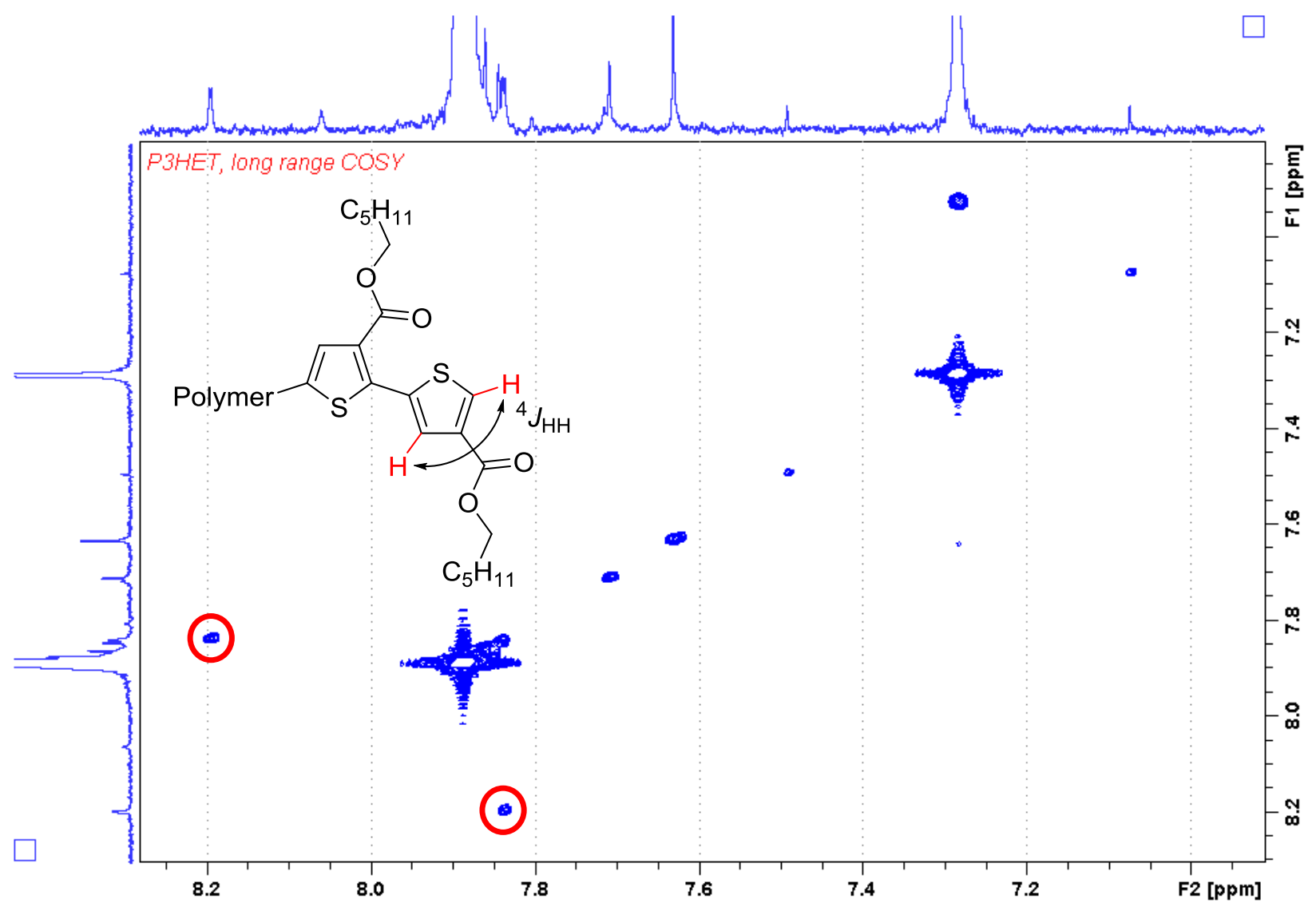

Figure S32. Long-range COSY illustrating the coupling for the H-terminated end-group of P3HET prepared using $1 \mathrm{~mol} \% \mathrm{Ni}\left(\mathrm{PPh}_{3}\right) \mathrm{IPrCl}_{2}$. 


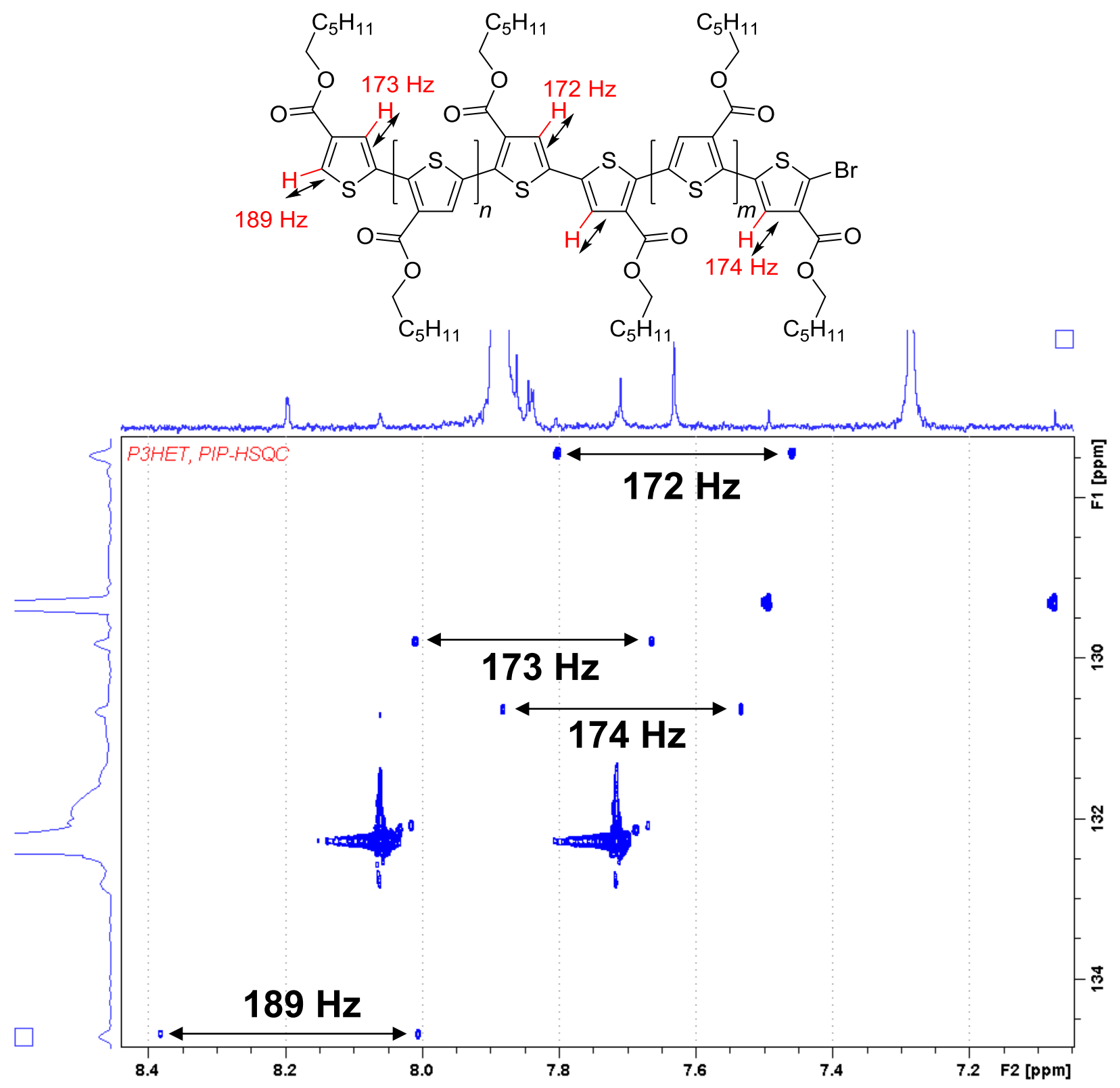

Figure S33. High resolution coupled HSQC illustrating the regioregular polymer backbone of P3HET prepared using $1 \mathrm{~mol} \% \mathrm{Ni}\left(\mathrm{PPh}_{3}\right) \mathrm{IPrCl}_{2}$. 


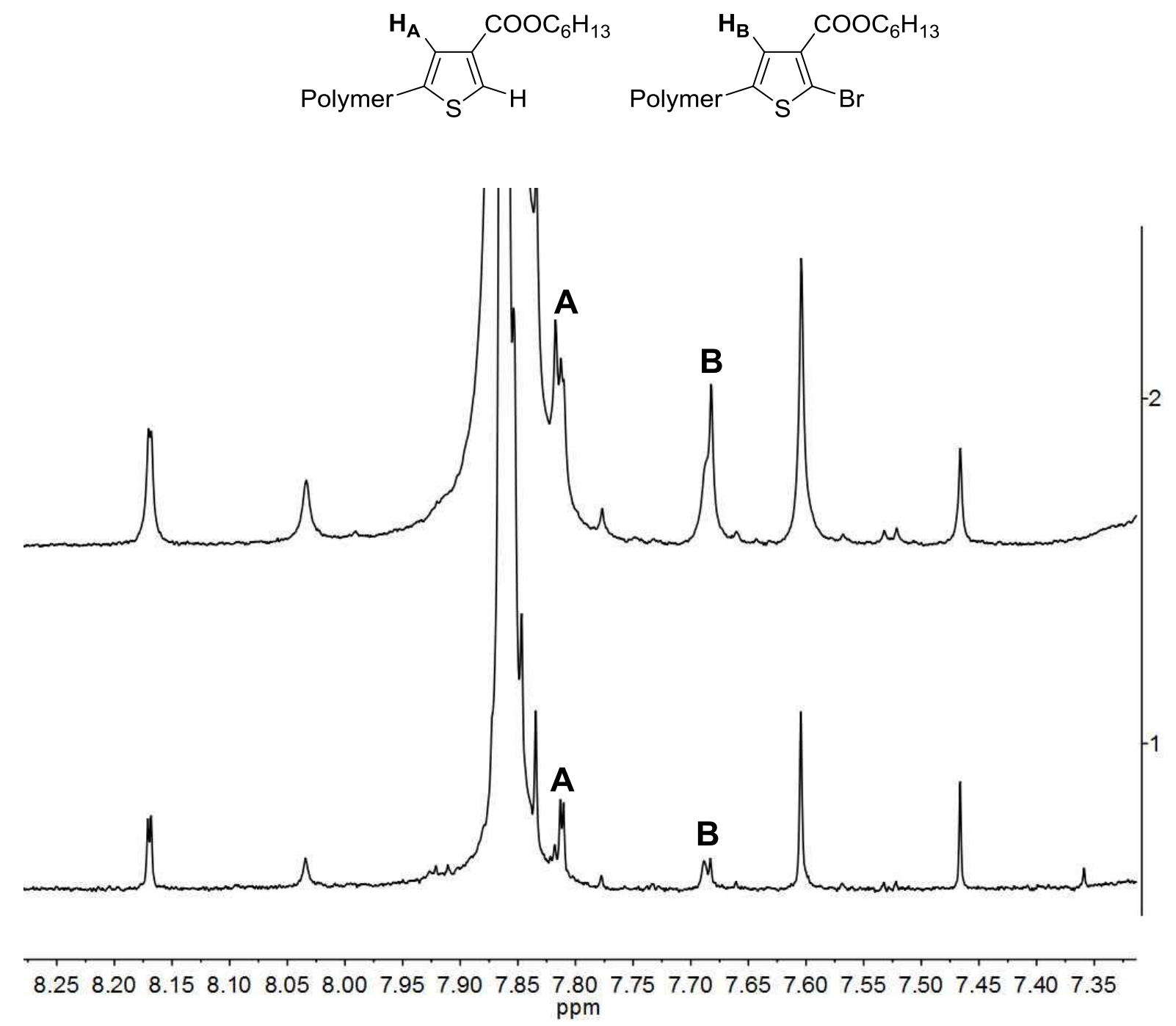

Figure S34. Top $-{ }^{1} \mathrm{H}$ NMR Spectrum of P3HET. Bottom $-\mathrm{P} 3$ HET treated with Ni(COD $)_{2}$ and $\mathrm{HCl}$ illustrating the loss of the Br-terminated end group. 


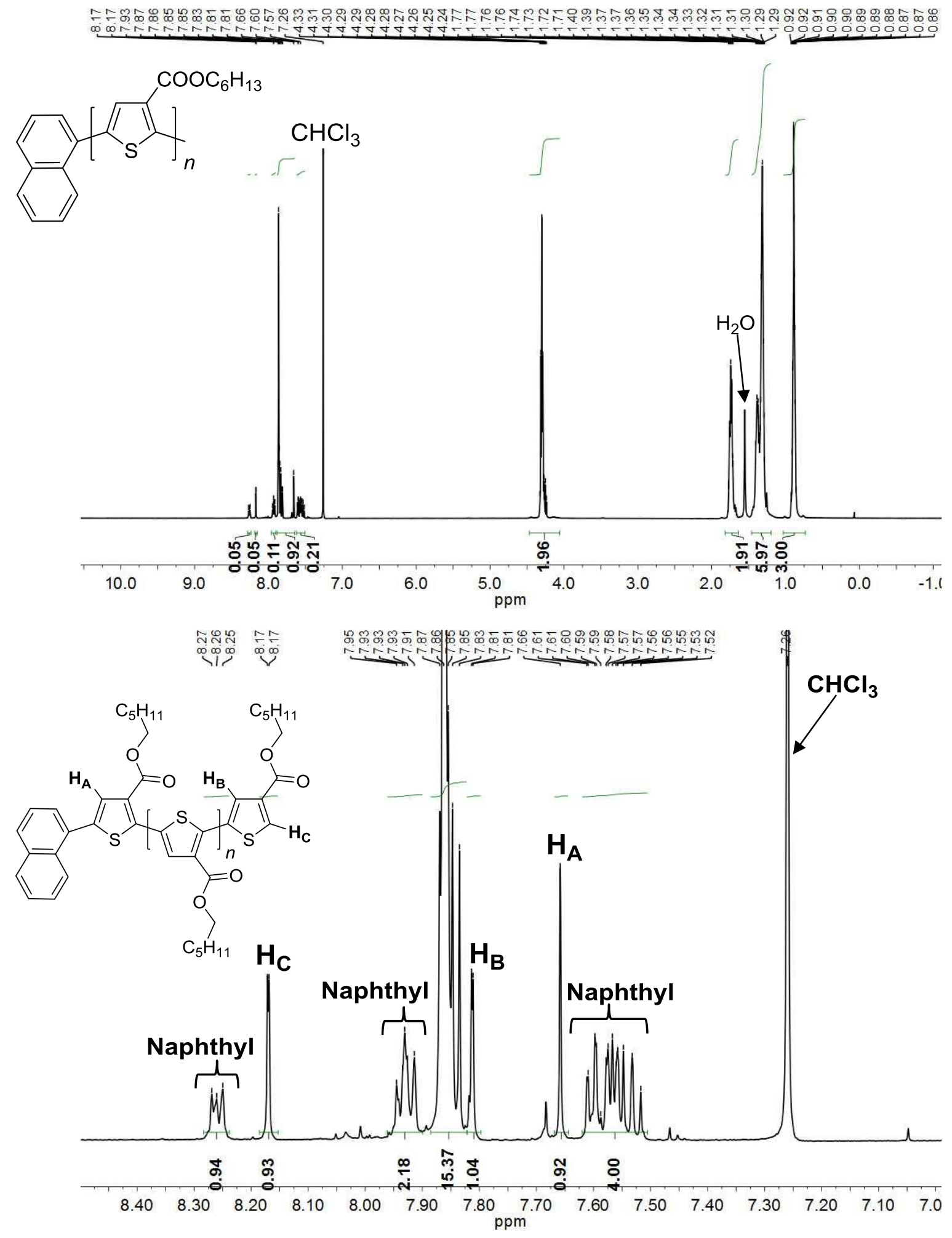

Figure S35. P3HET prepared using $5 \mathrm{~mol} \% \mathrm{Ni}(1-\mathrm{Naph})(\mathrm{PCy})_{2} \mathrm{Br}$. Top $-{ }^{1} \mathrm{H}$ NMR Spectrum, $500 \mathrm{MHz}, \mathrm{CDCl}_{3}$. Bottom - enlarged aromatic region with tentative assignments provided. 


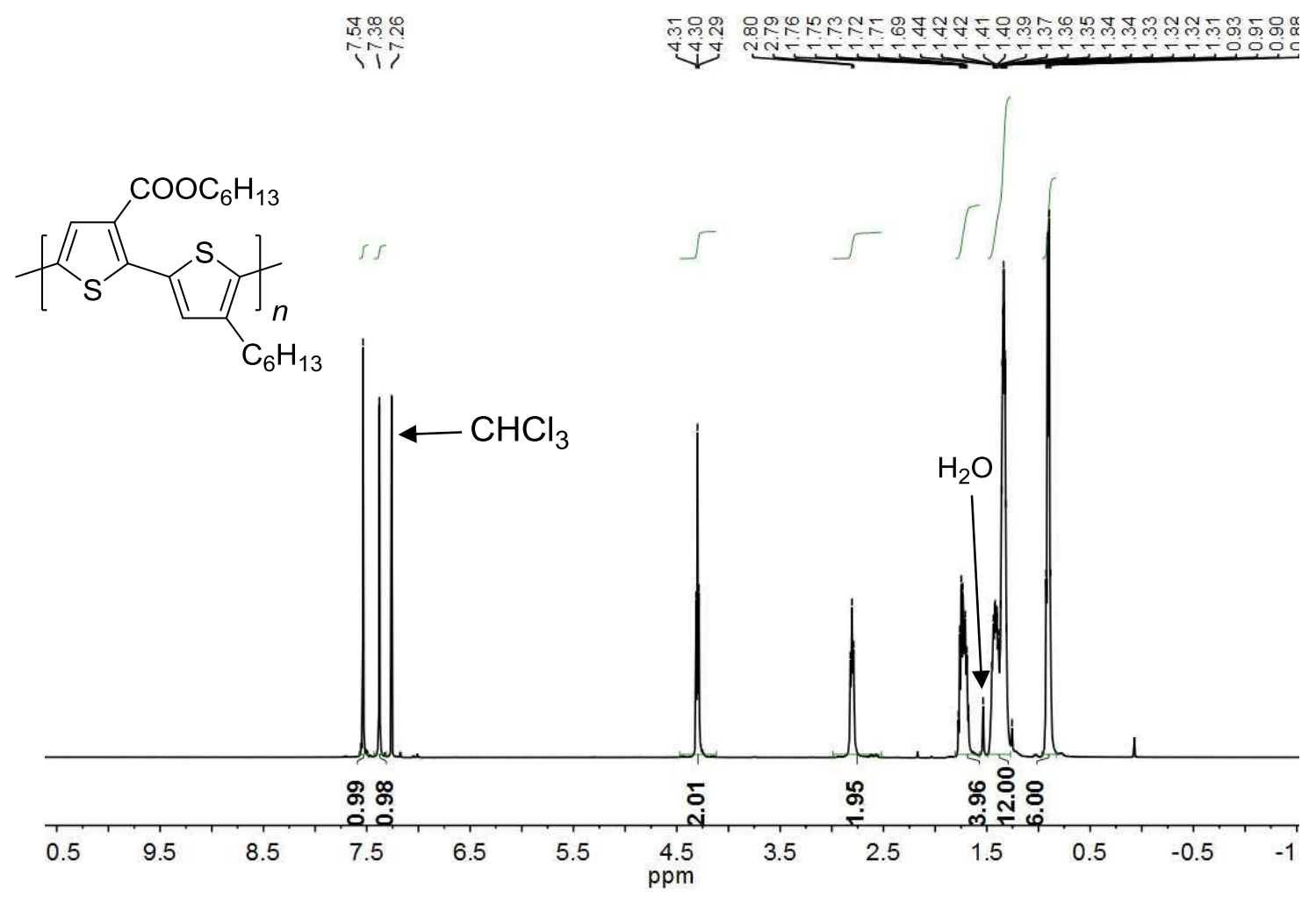

Figure S36. P3HET- $a$-P3HT ${ }^{1} \mathrm{H}$ NMR Spectrum - $500 \mathrm{MHz}, \mathrm{CDCl}_{3}$.
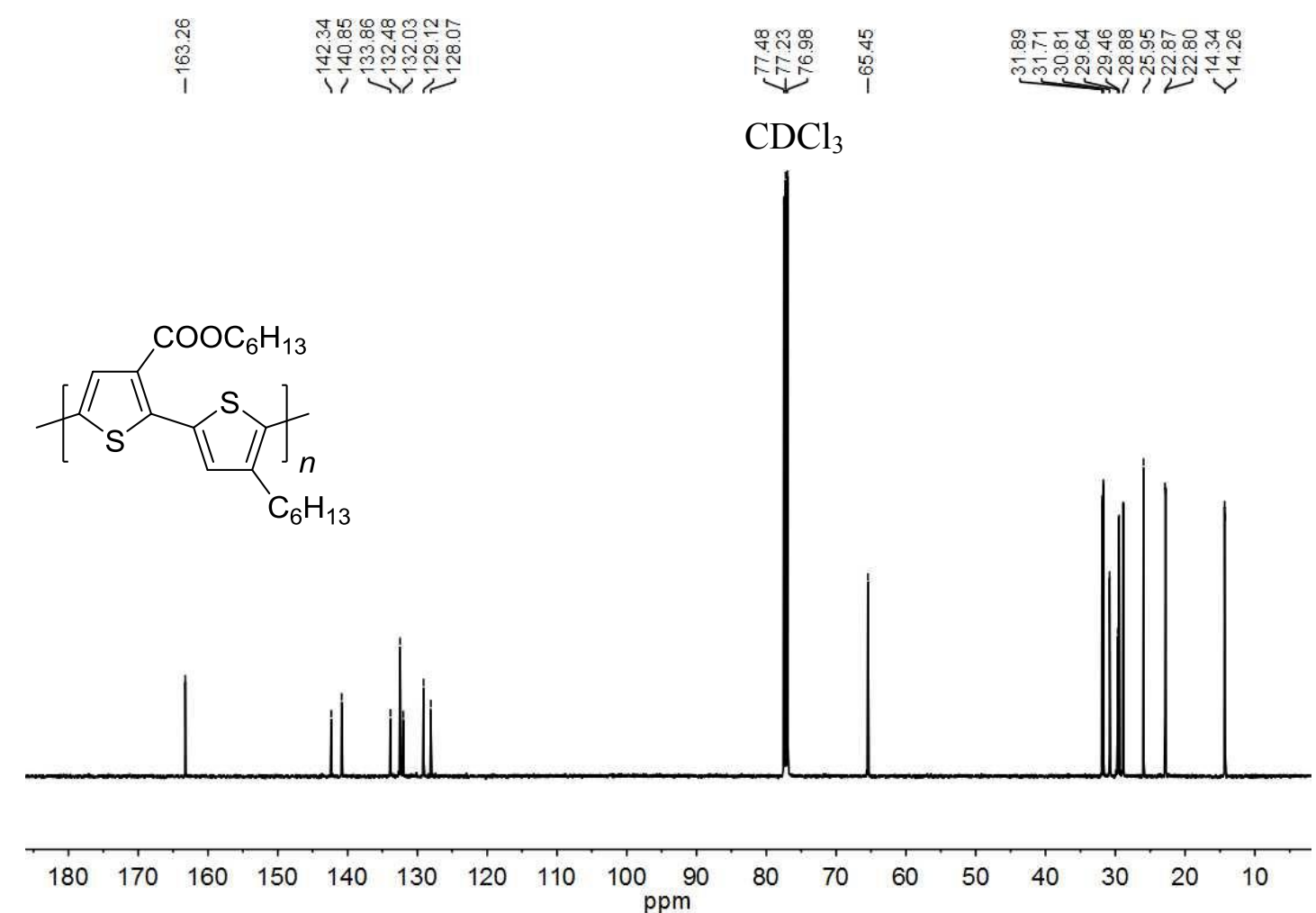

Figure S37. P3HET- $a$-P3HT ${ }^{13} \mathrm{C}$ NMR Spectrum - $126 \mathrm{MHz}, \mathrm{CDCl}_{3}$. 


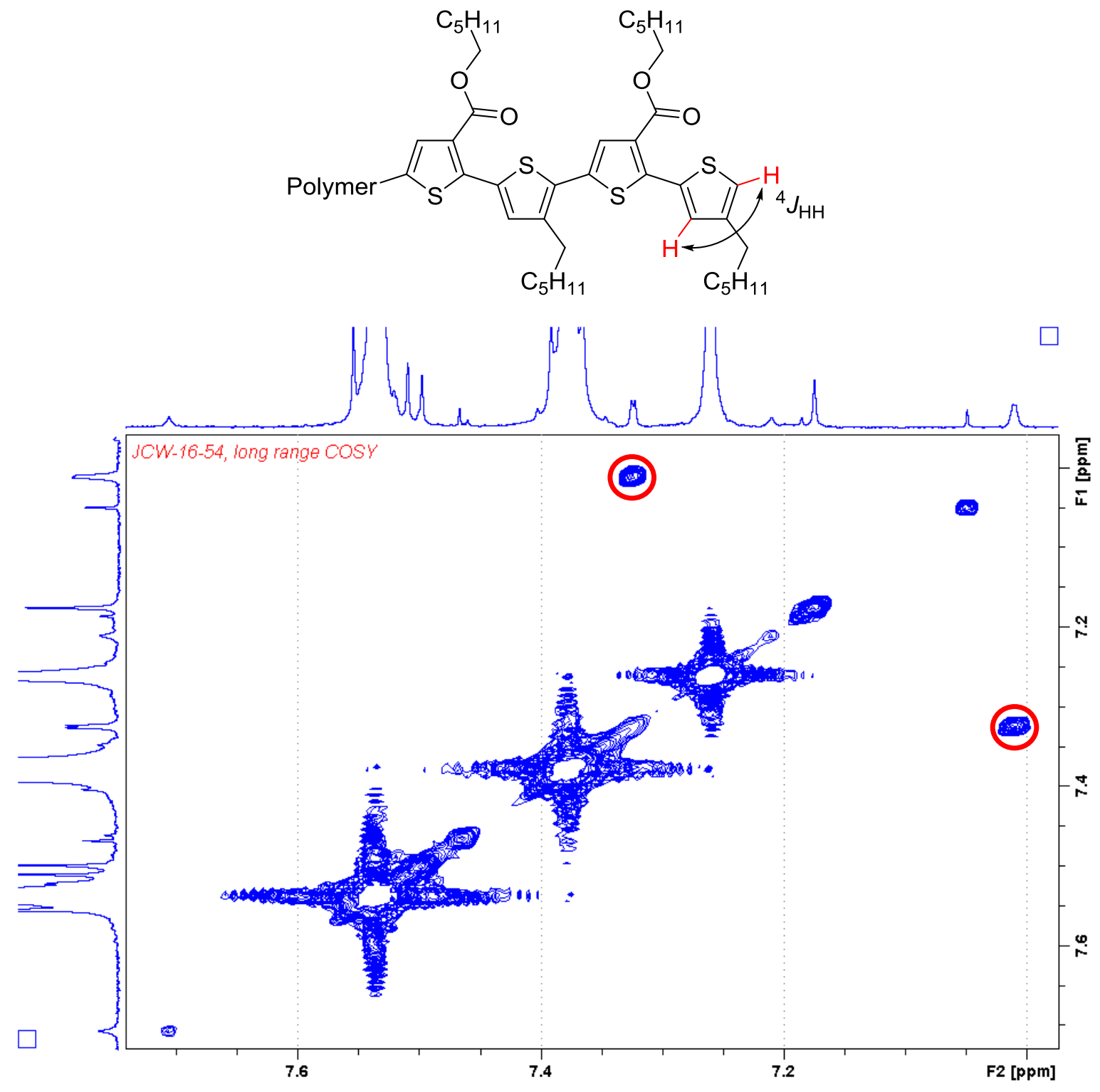

Figure S38. Long-range COSY illustrating the coupling of the aromatic protons of the end-group in P3HET- $a$-P3HT. 

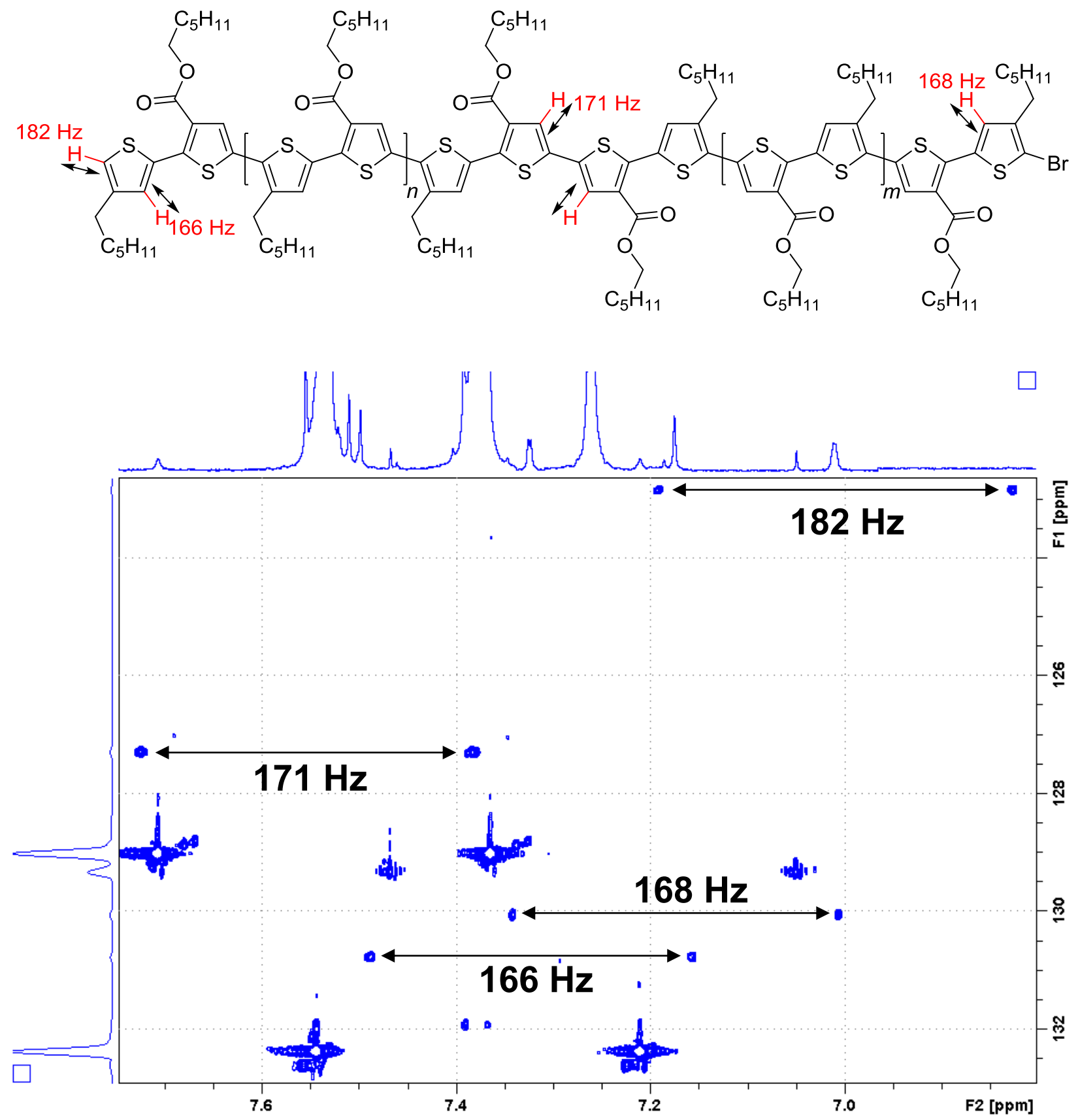

Figure S39. High resolution HSQC illustrating the regioregular polymer backbone of P3HET- $a$ P3HT. 


\section{GPC Traces}
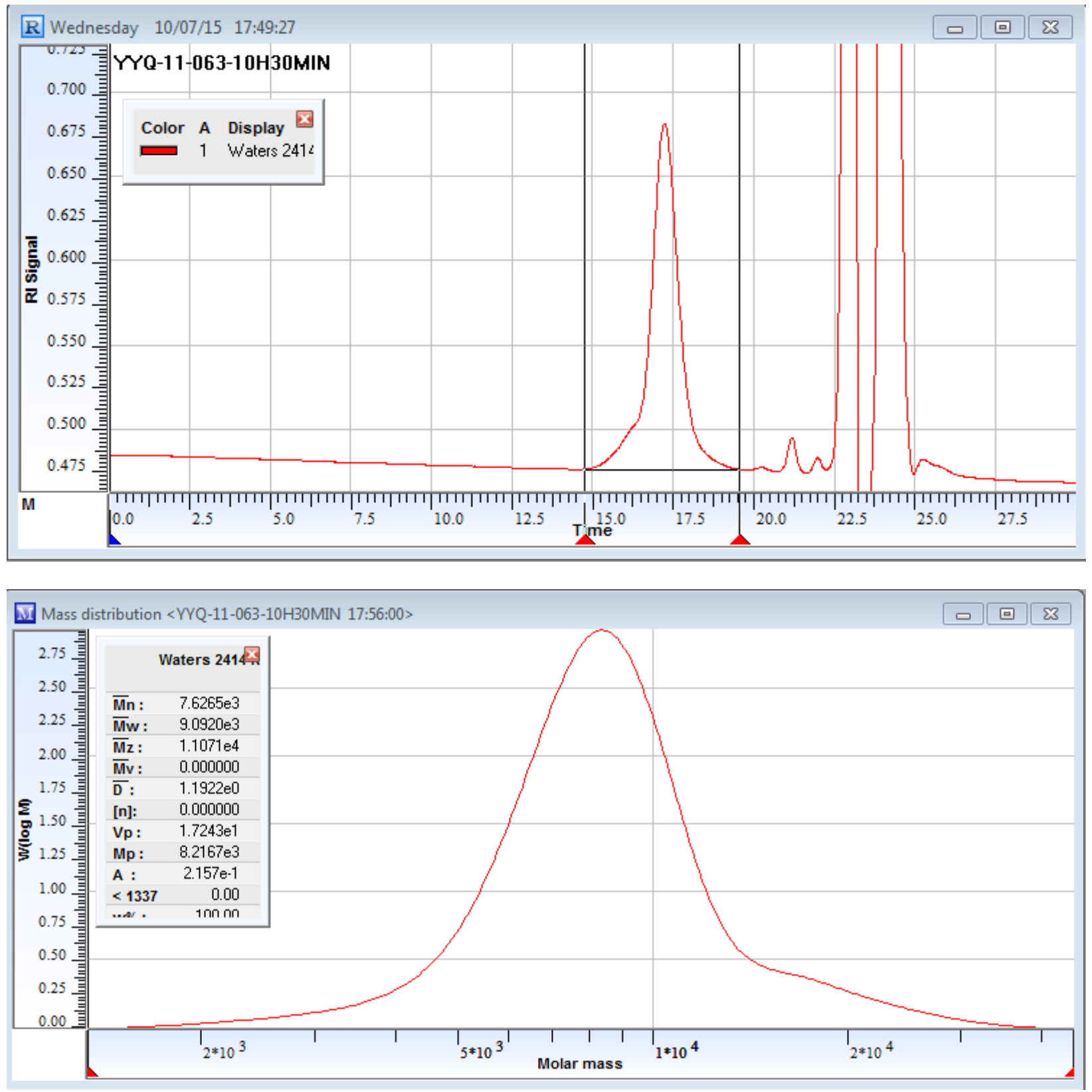

Figure S40. GPC Chromatogram and analysis of P3HET sample. Entry 1 Table 2 in the Paper. 

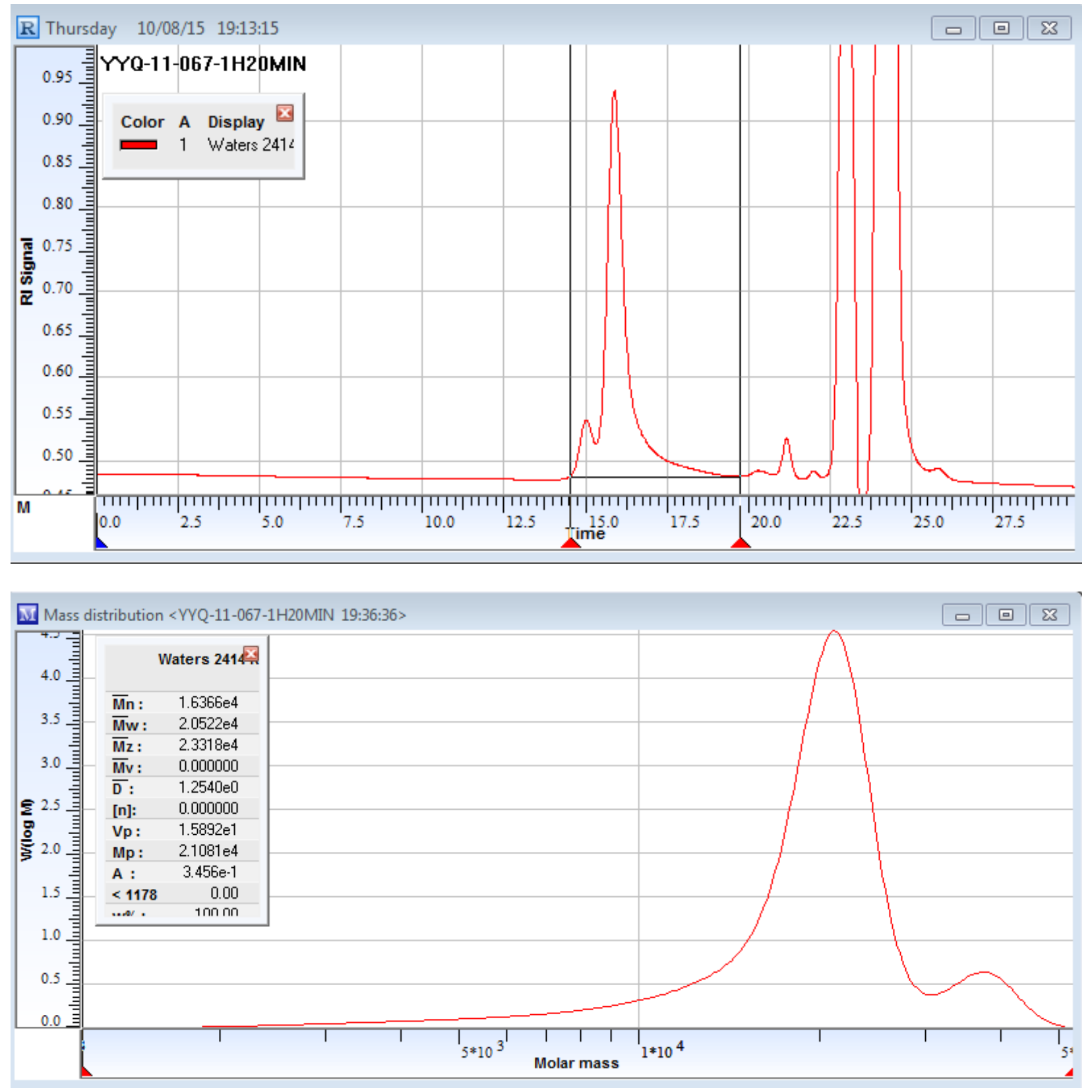

Figure S41. GPC Chromatogram and analysis of P3HET sample. Entry 2 Table 2 in the Paper. 

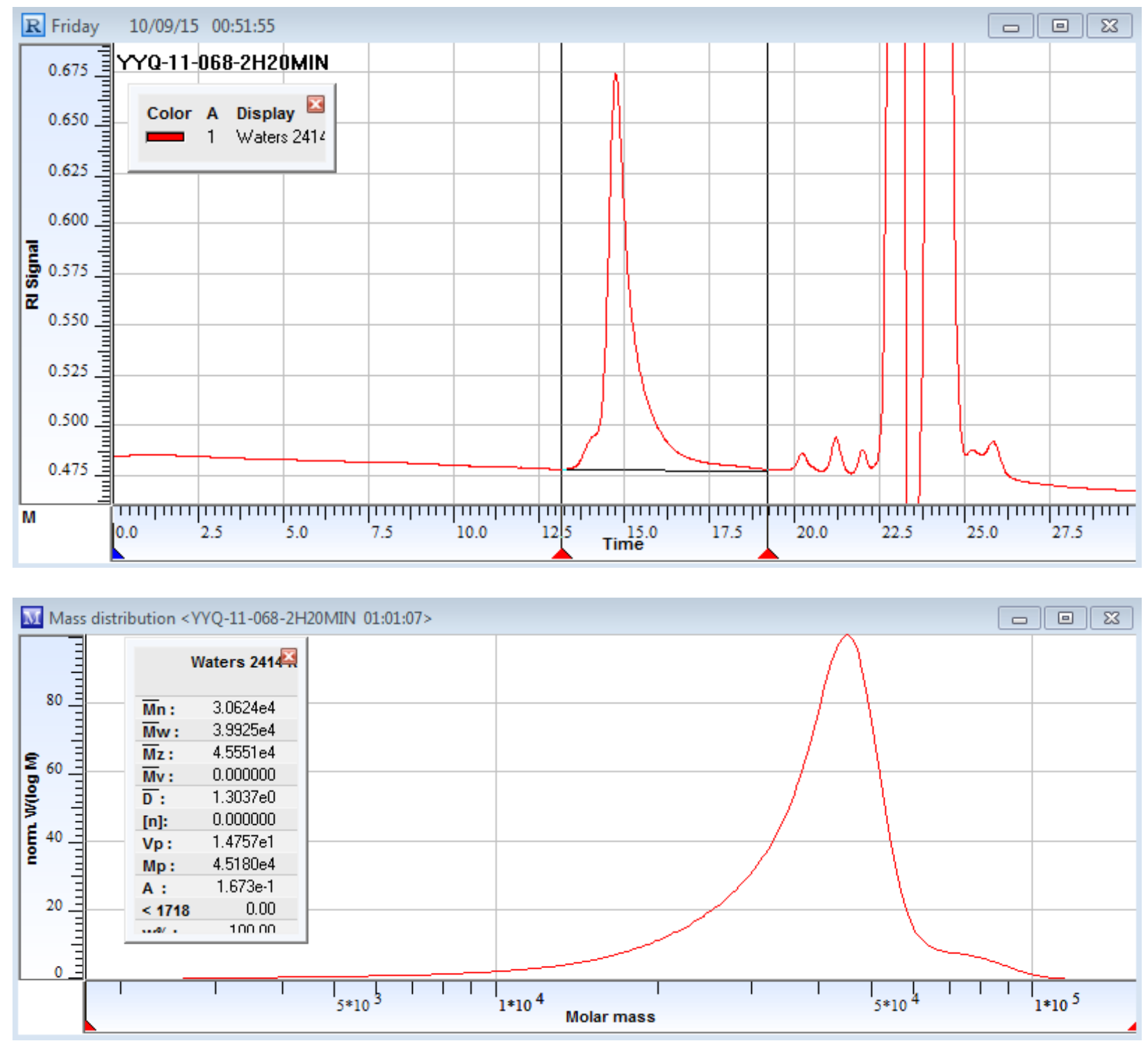

Figure S42. GPC Chromatogram and analysis of P3HET sample. Entry 3 Table 2 in the Paper. 

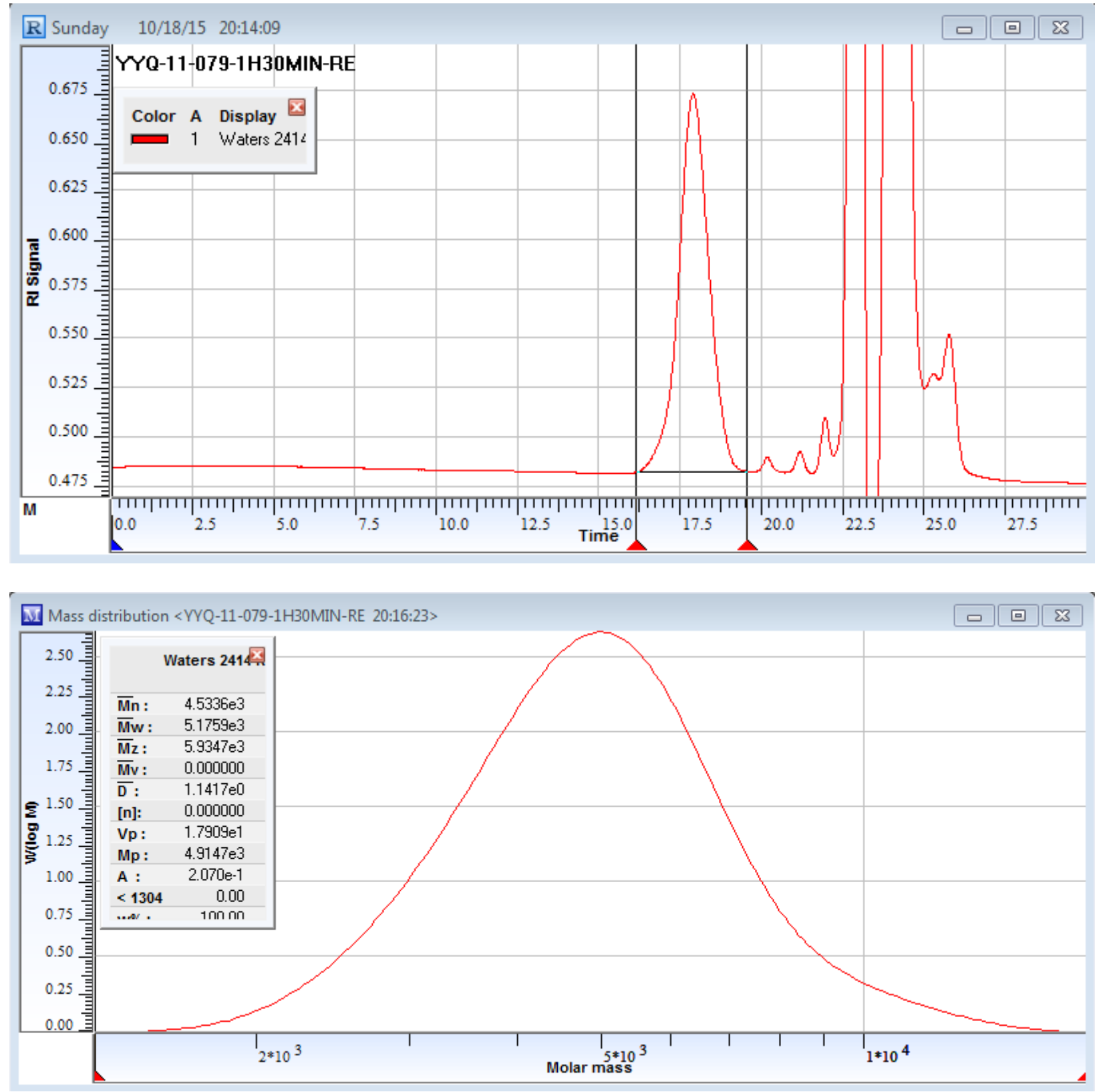

Figure S43. GPC Chromatogram and analysis of P3HET sample. Entry 4 Table 2 in the Paper. 

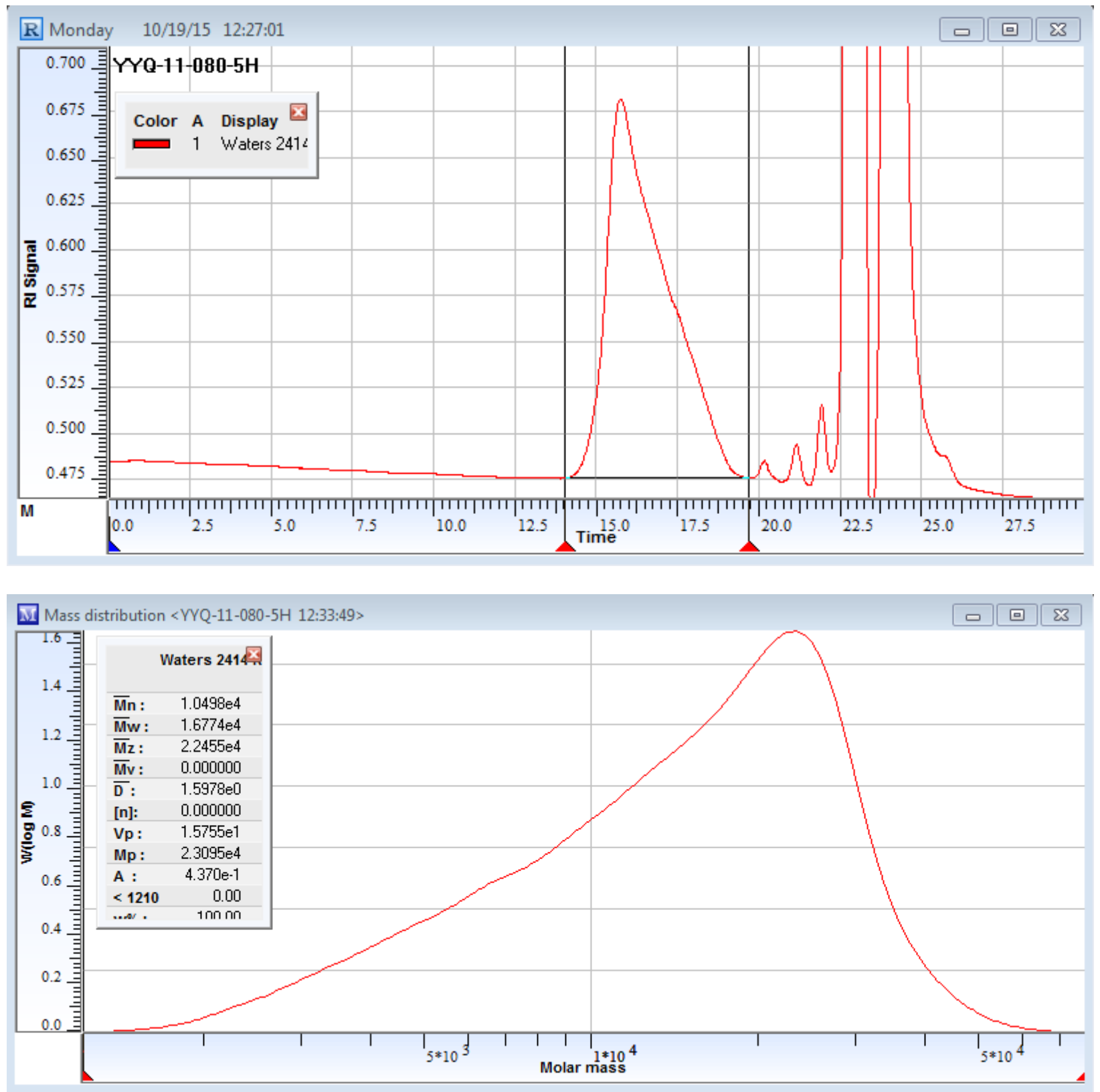

Figure S44. GPC Chromatogram and analysis of P3HET sample. Entry 5 Table 2 in the Paper. 


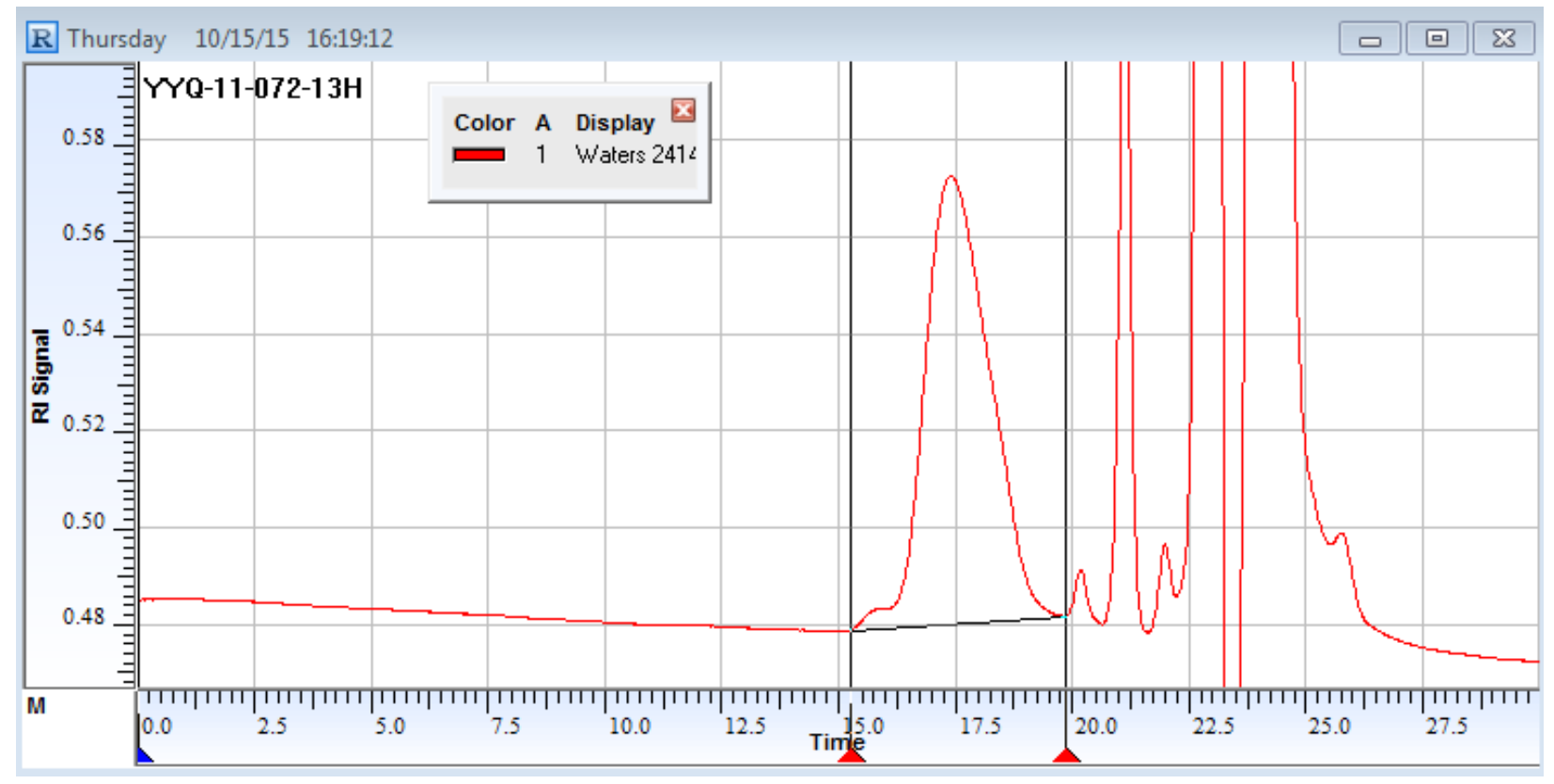

M Mass distribution <YYQ-11-072-13H 16:21:12>

0 回 83

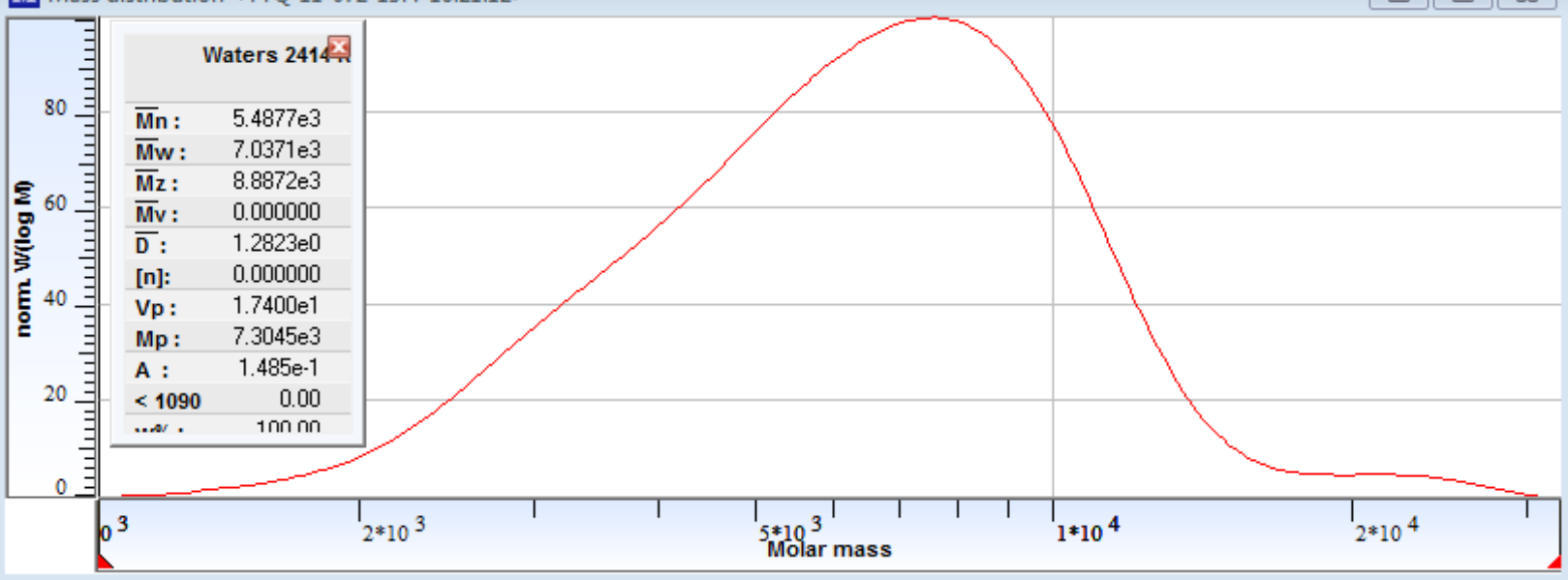

Figure S45. GPC Chromatogram and analysis of P3HET sample. Entry 6 Table 2 in the Paper. 

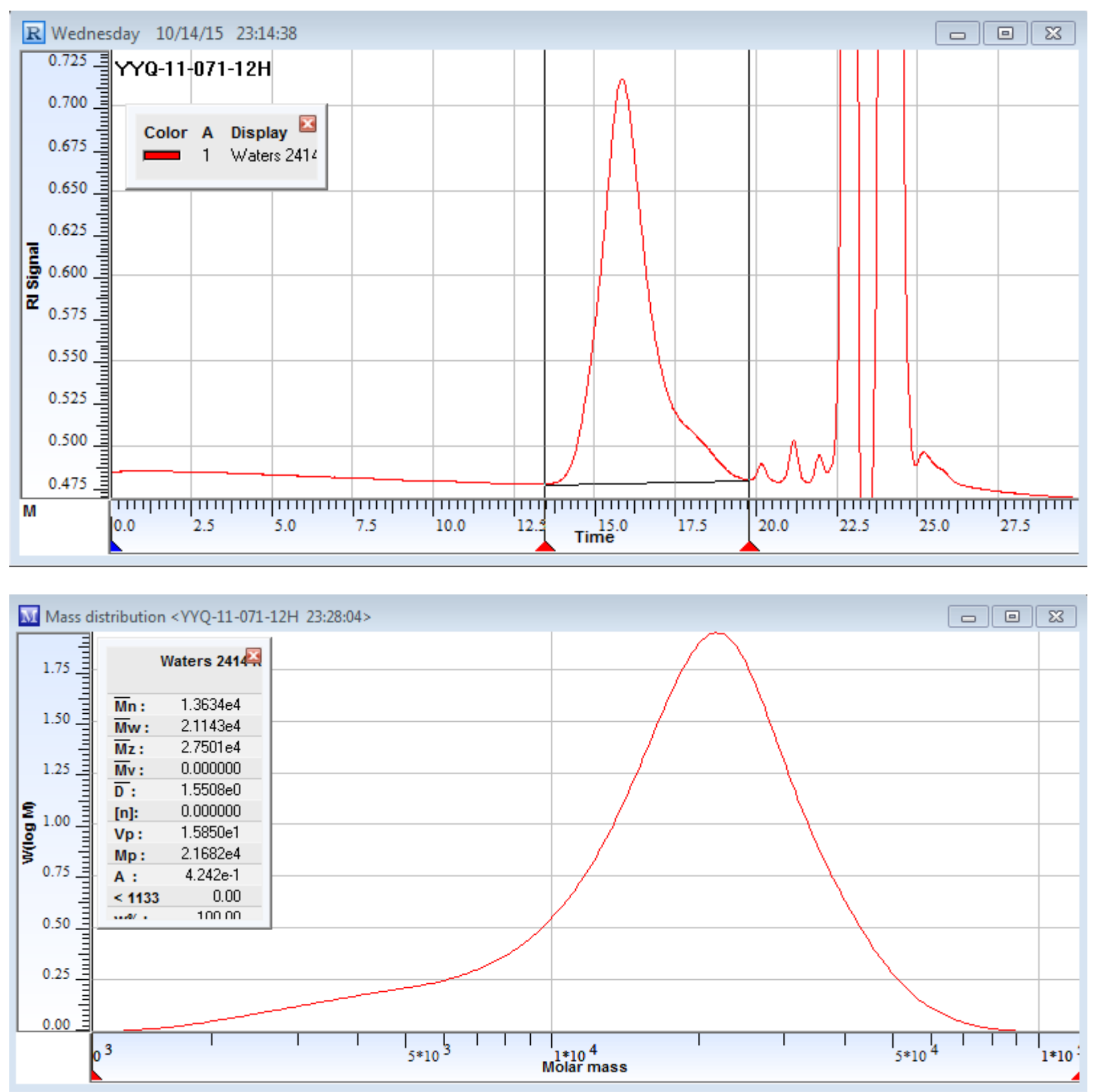

Figure S46. GPC Chromatogram and analysis of P3HET sample. Entry 7 Table 2 in the Paper. 

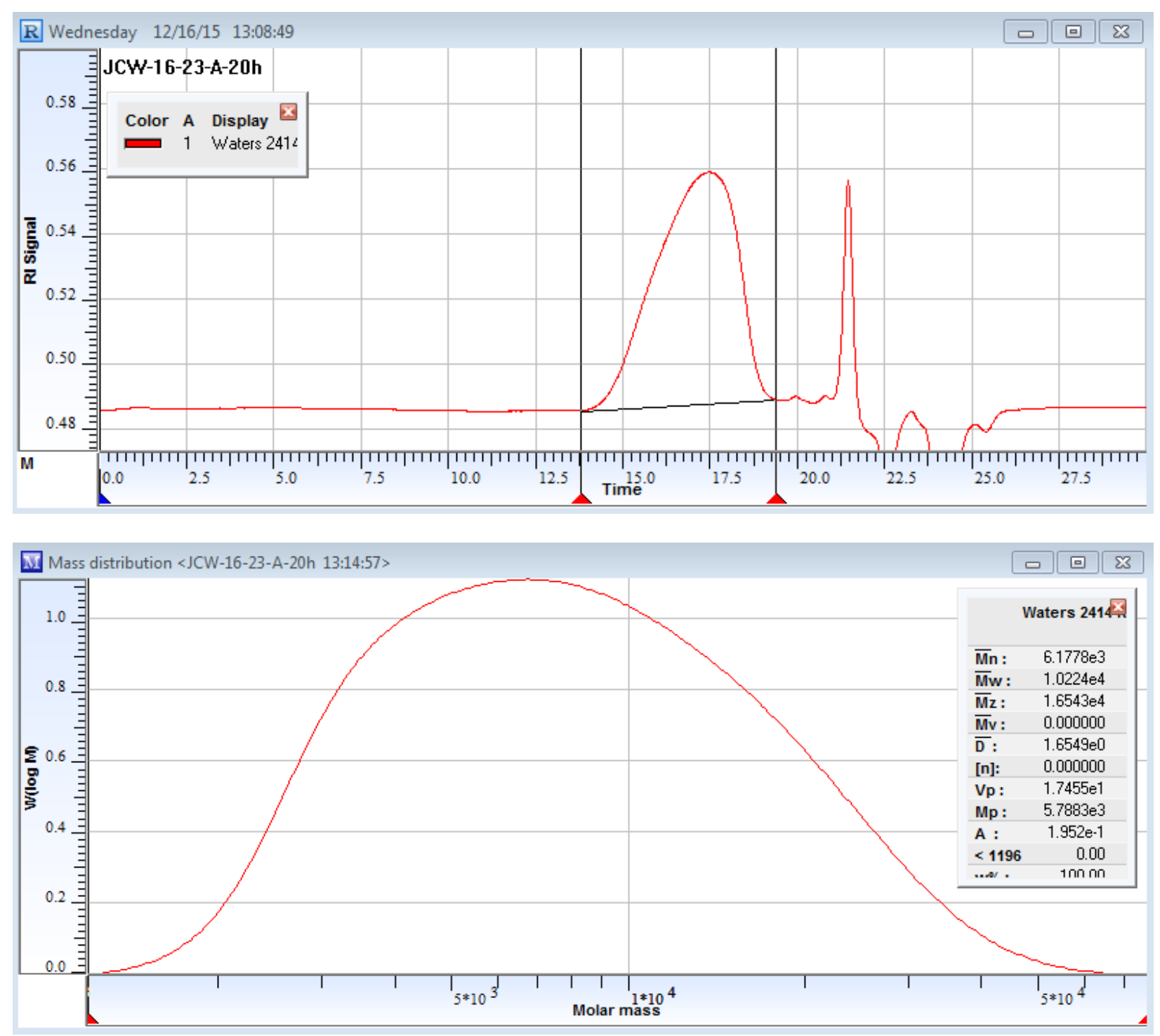

Figure S47. GPC Chromatogram and analysis of P3HT sample using $\mathrm{Ni}\left(\mathrm{PPh}_{3}\right) \mathrm{IPrCl}_{2}$ as the catalyst without water (Table S3, entry 1). 

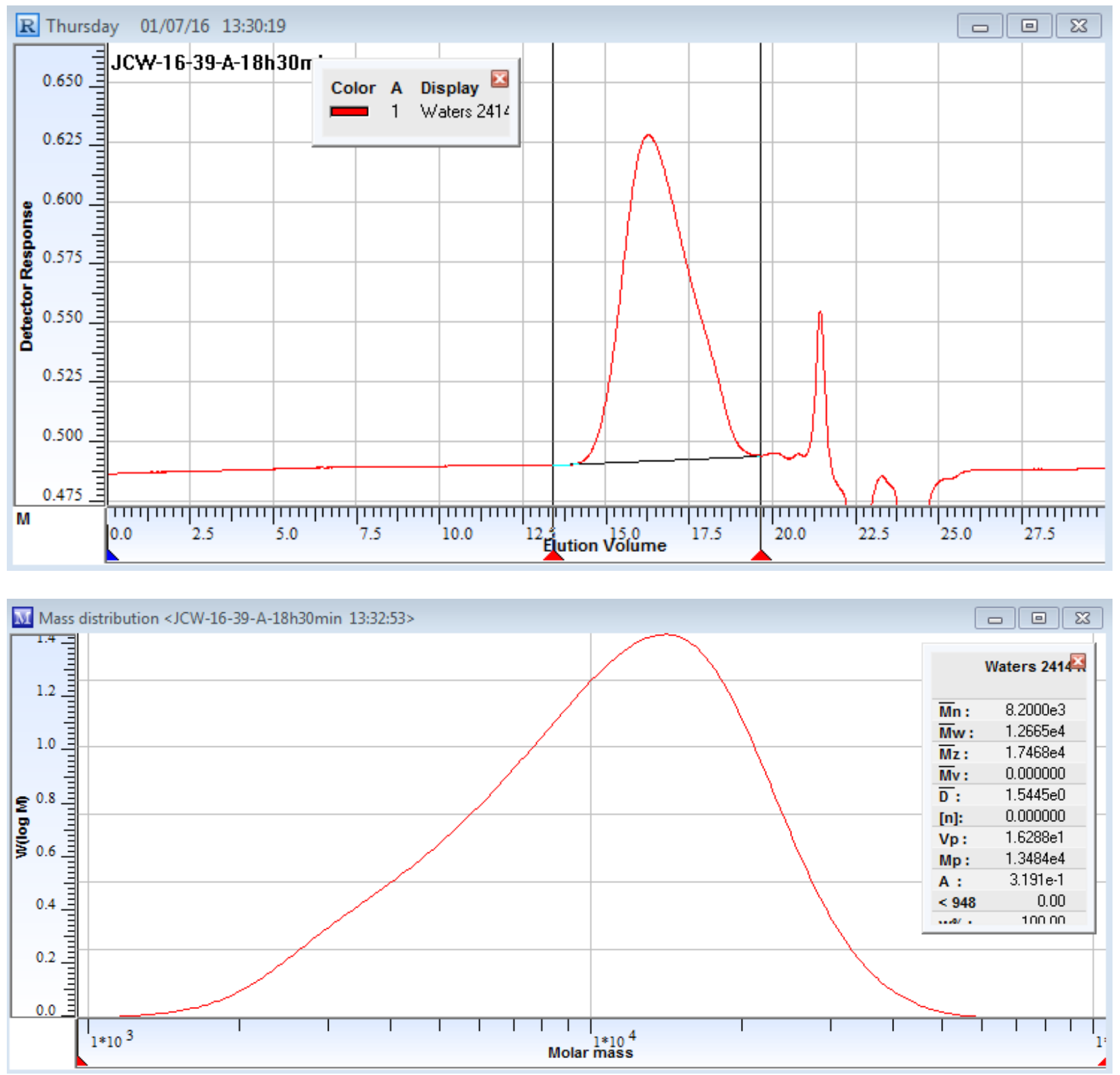

Figure S48. GPC Chromatogram and analysis of P3HT sample using $\mathrm{Ni}(\mathrm{dppp}) \mathrm{Cl}_{2}$ as the catalyst without water (Table S3, entry 7). 

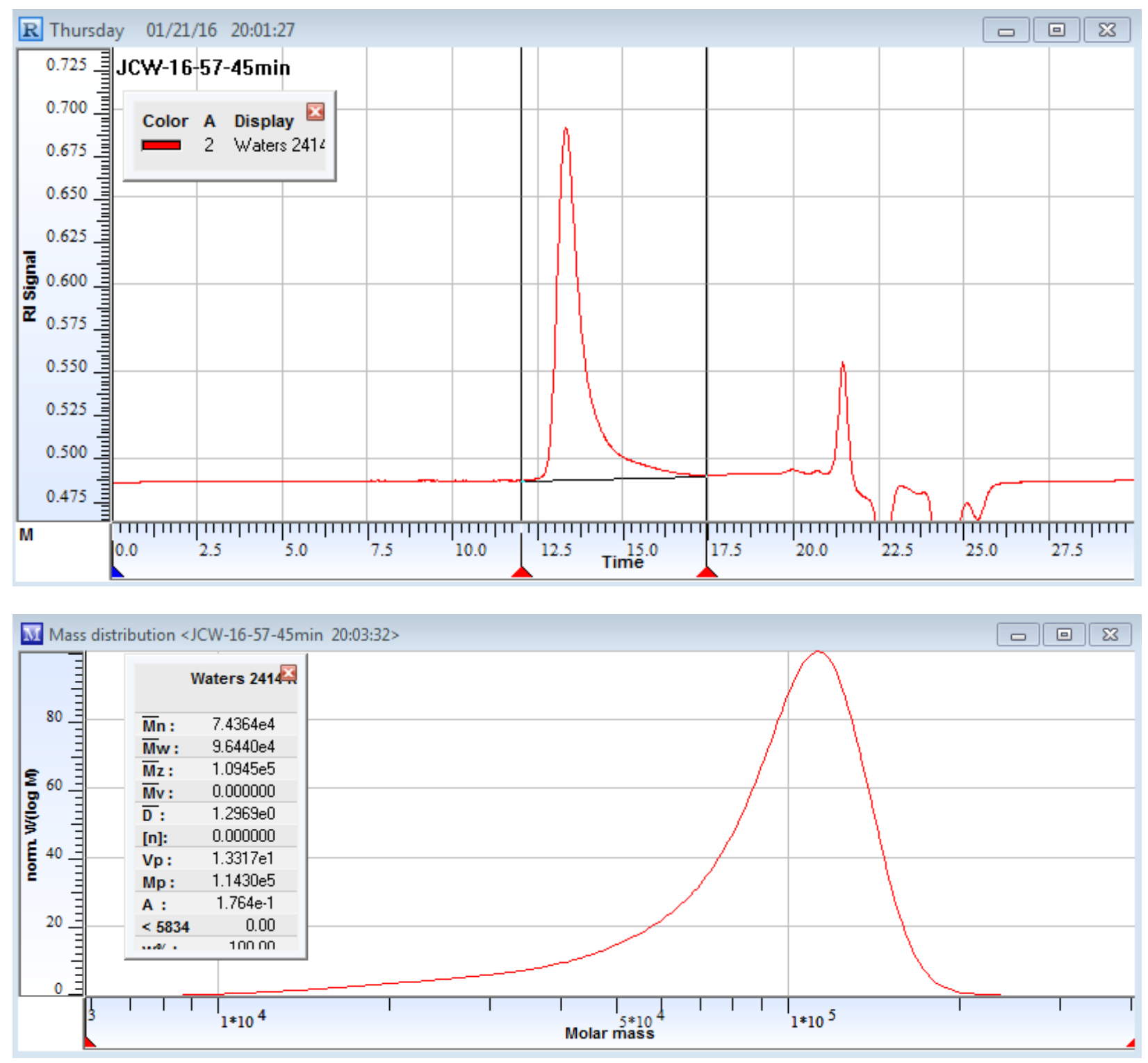

Figure S49. GPC Chromatogram and analysis of P3HT sample. Entry 8 Table 2 in the Paper. 

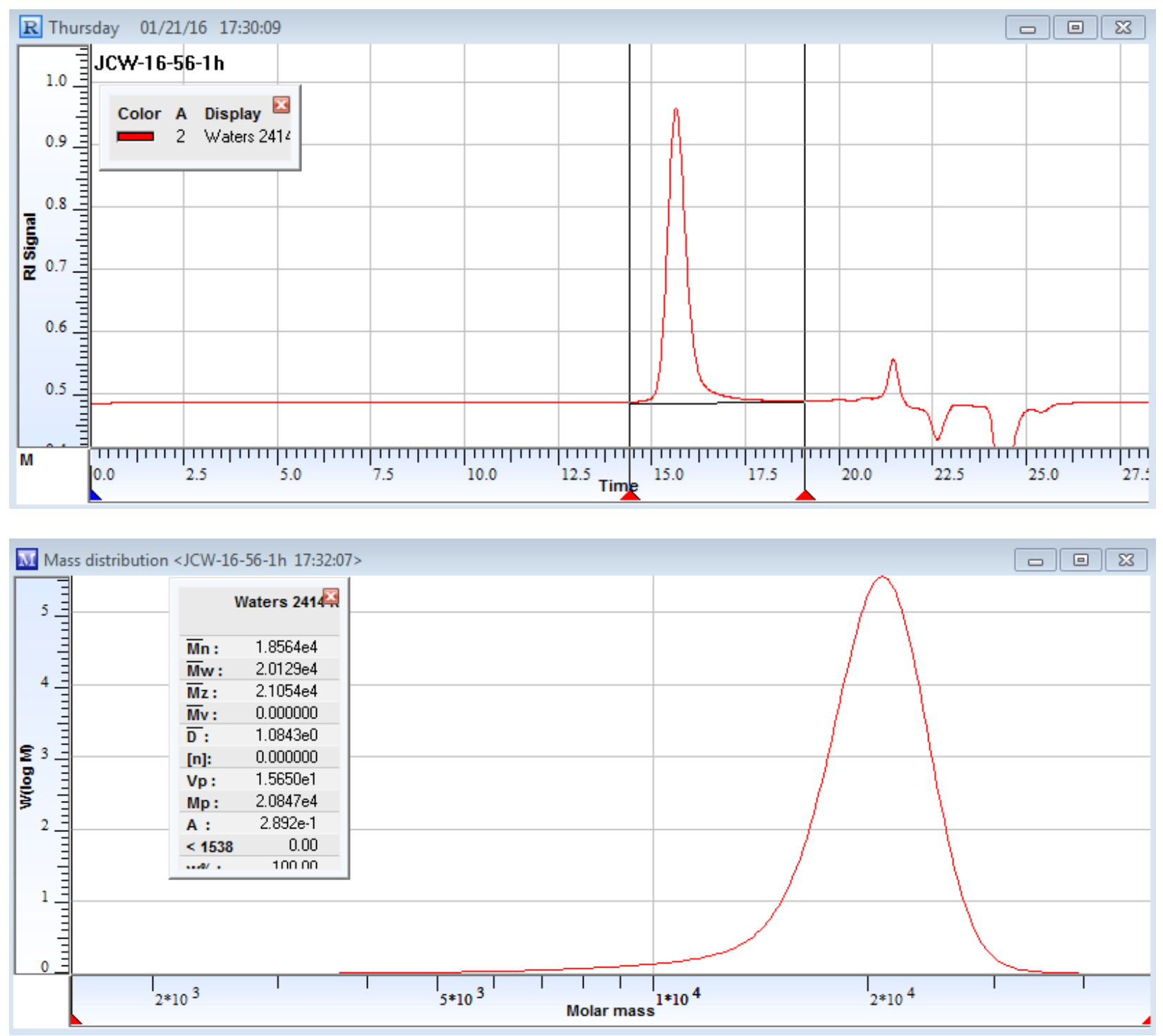

Figure S50. GPC Chromatogram and analysis of P3HT sample. Entry 9 Table 2 in the Paper. 

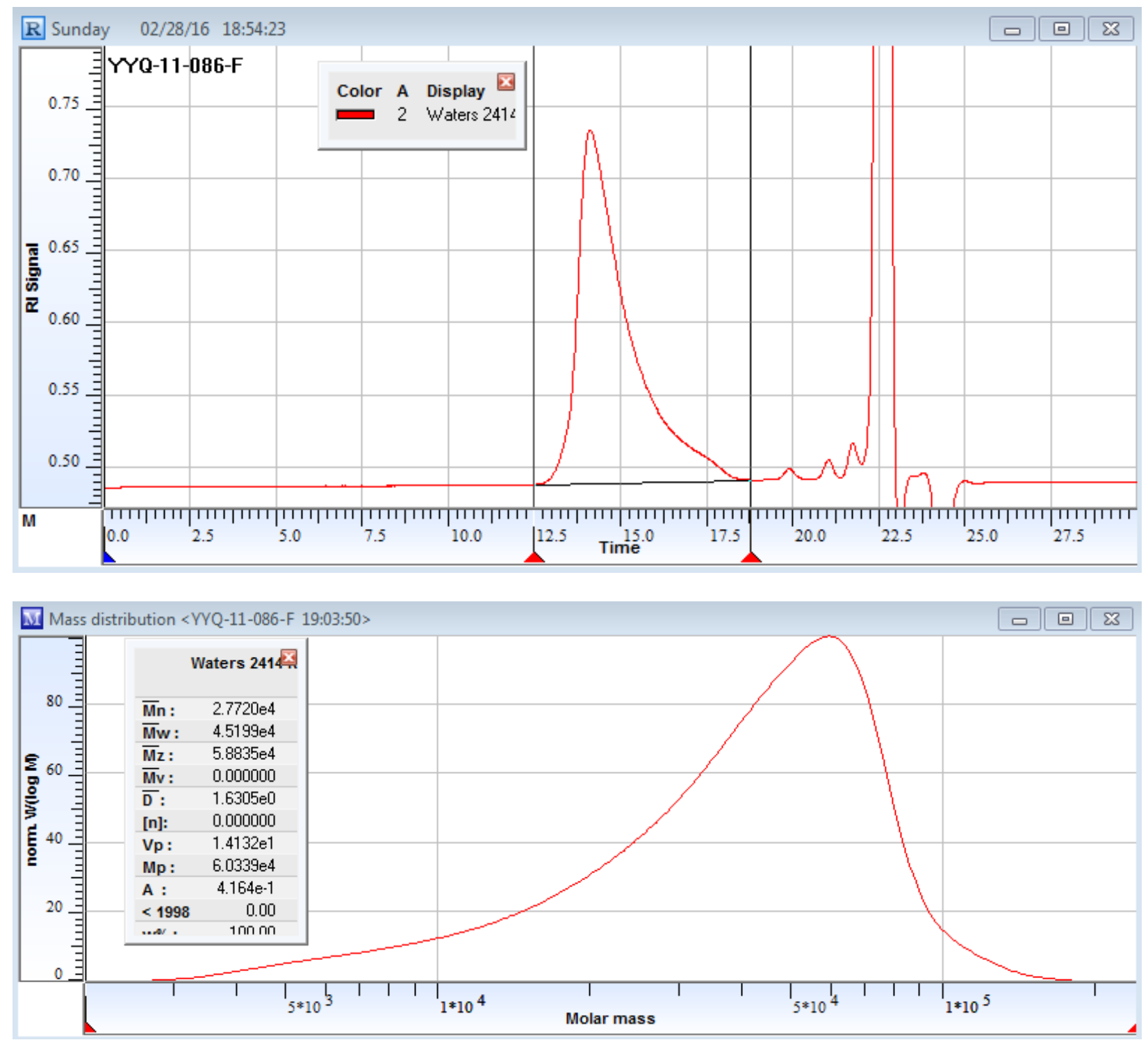

Figure S51. GPC Chromatogram and analysis of P3HET- $a$-P3HT sample. Entry 10 Table 2 in the Paper. 

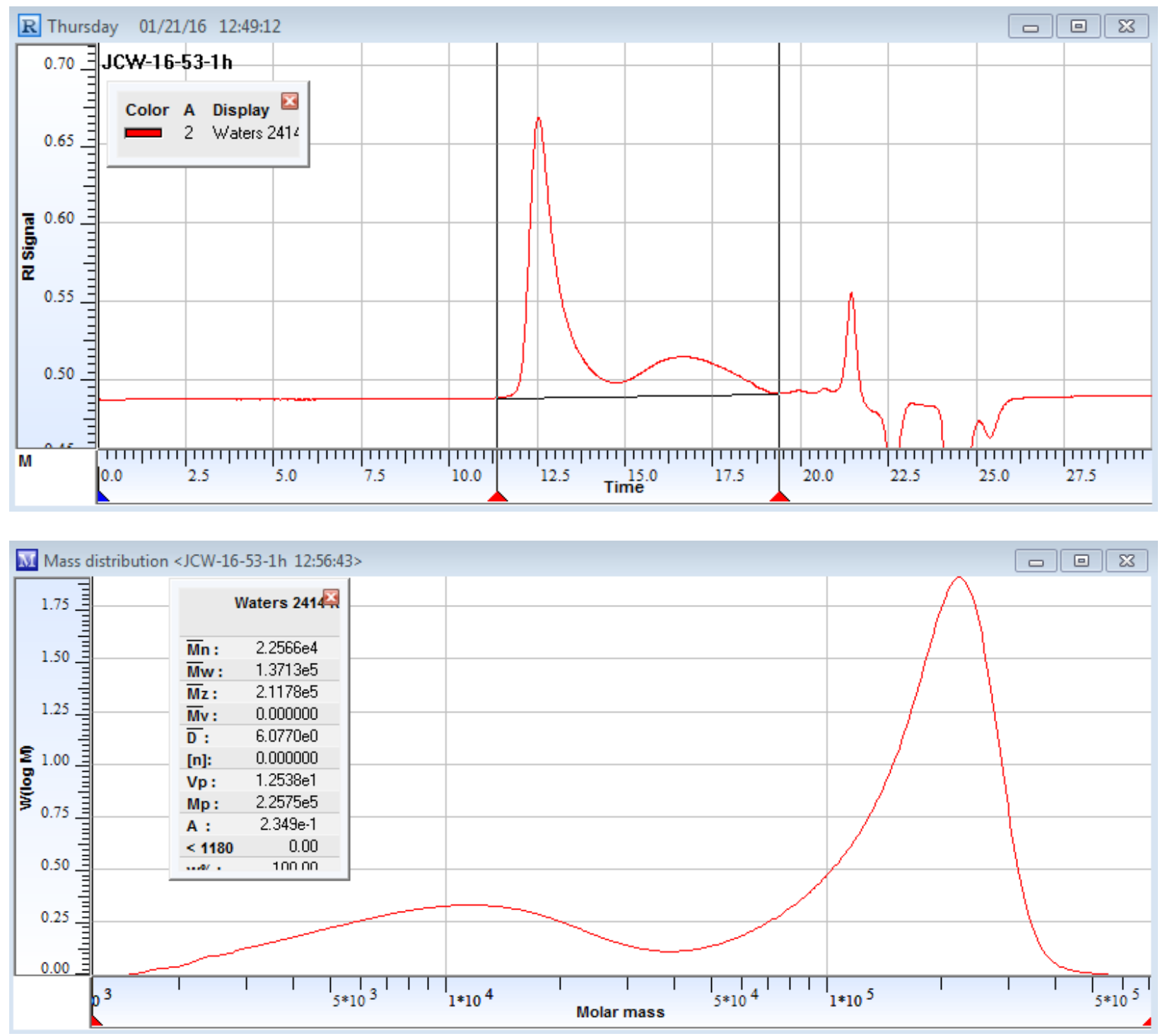

Figure S52. GPC Chromatogram and analysis of P3HET- $a$-P3HT sample using $\mathrm{Ni}\left(\mathrm{PPh}_{3}\right) \mathrm{IPrCl}_{2}$ as the catalyst with water (Table S4, entry 2). 

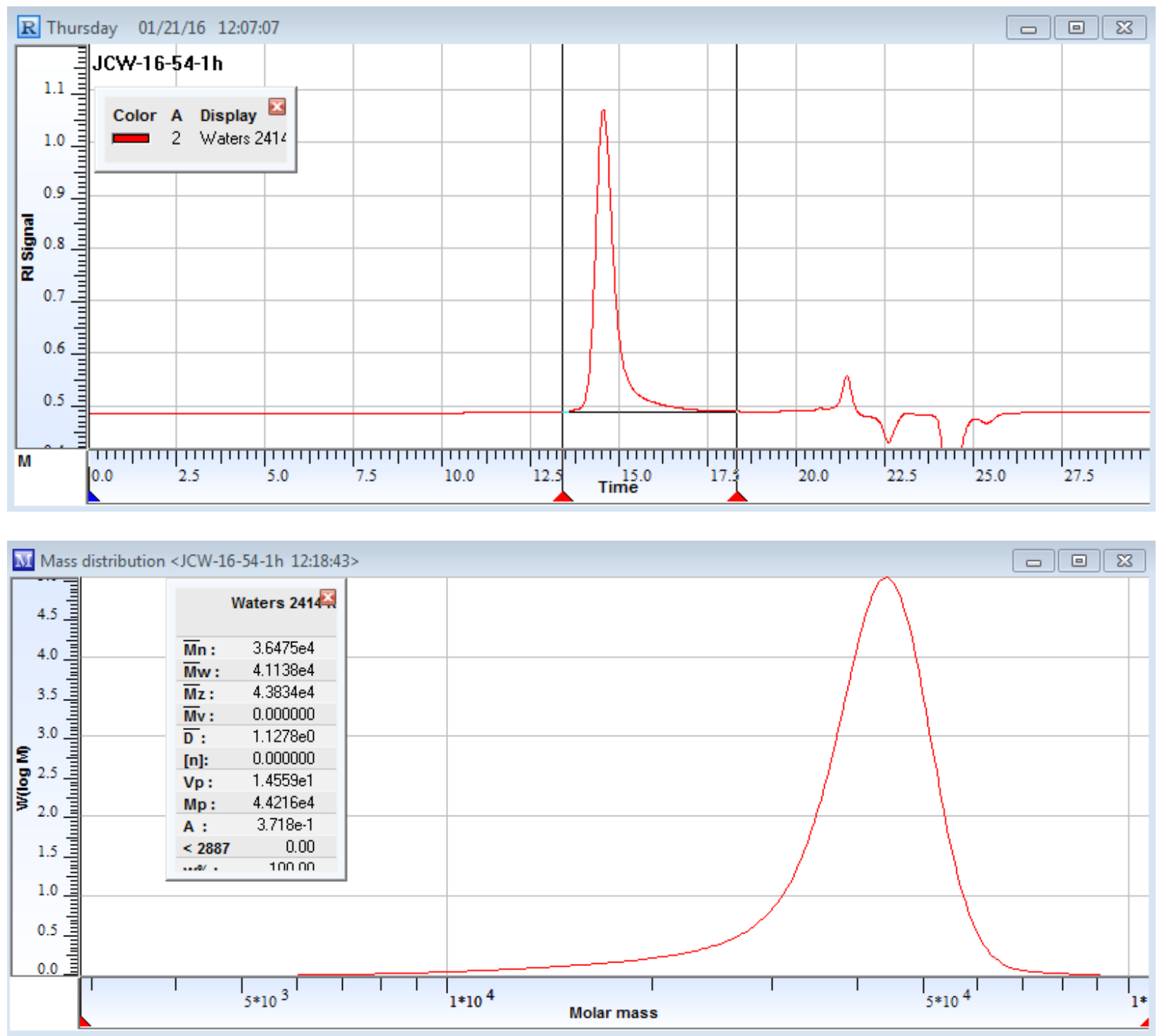

Figure S53. GPC Chromatogram and analysis of P3HET- $a$-P3HT sample. Entry 11 Table 2 in the Paper. 

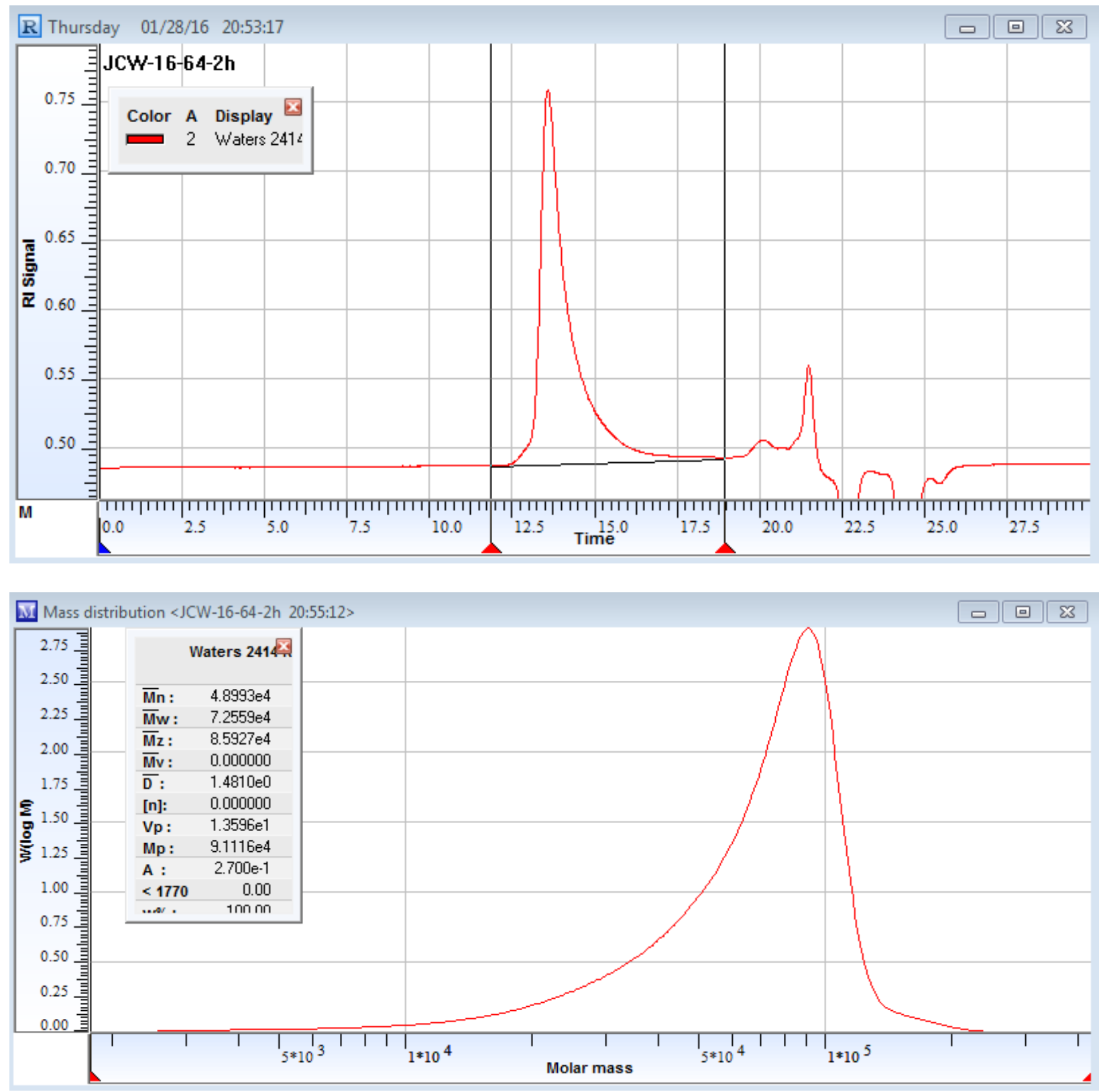

Figure S54. GPC Chromatogram and analysis of P3HET- $a$-P3HT sample. Entry 12 Table 2 in the Paper. 
Table S5. Summary of optical properties of P3HET, P3HT- $b$-P3HET, P3HET- $a$-P3HT \& P3HT.

\begin{tabular}{cccc}
\hline Polymer & $\lambda_{\max } \mathrm{CHCl}_{3}$ & $\lambda_{\max }$ film & $\mathrm{E}_{\mathrm{g}}{ }^{\text {pt }}(\mathrm{eV})^{a}$ \\
\hline P3HET & 435 & 505 & 2.17 \\
P3HT- $b$-P3HET & 445 & 550 & 1.92 \\
P3HET- $a$-P3HT & 452 & 627 & 1.85 \\
P3HT & 453 & 560 & 1.89
\end{tabular}

${ }^{a}$ Determined by onset of absorption (UV-Vis).
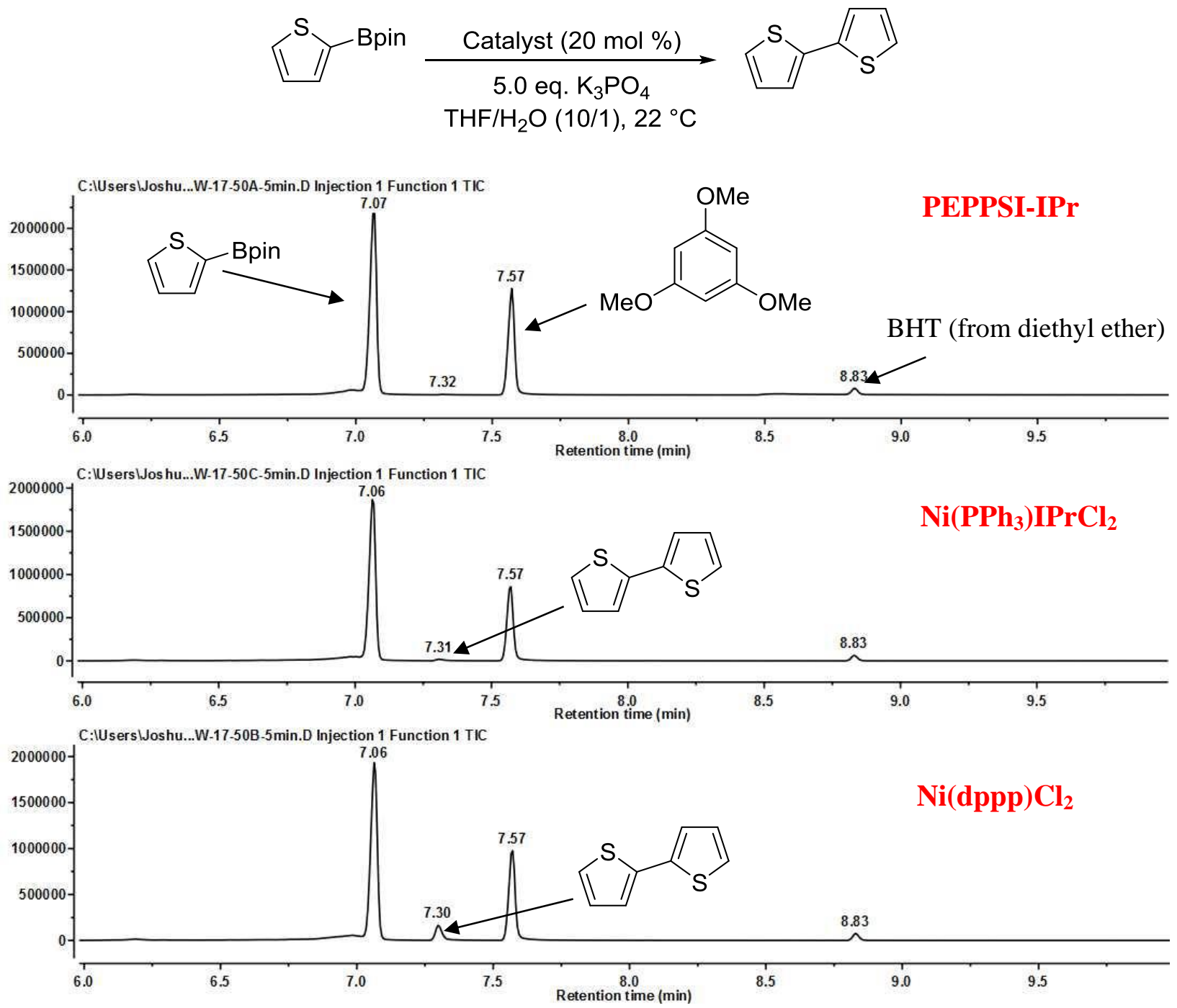

Figure S55. GC-MS chromatograms for catalyst initiation at $22{ }^{\circ} \mathrm{C}$ using $\mathrm{ThBpin}$ and catalyst $(20 \mathrm{~mol} \%)$ sampled after 5 minutes. Top - PEPPSI-IPr. Middle - Ni(PPh $) \mathrm{IPrCl}_{2}$. Bottom $\mathrm{Ni}(\mathrm{dppp}) \mathrm{Cl}_{2}$. Signal at $7.3 \mathrm{~min}$ is bithiophene formed during precatalyst initiation. 

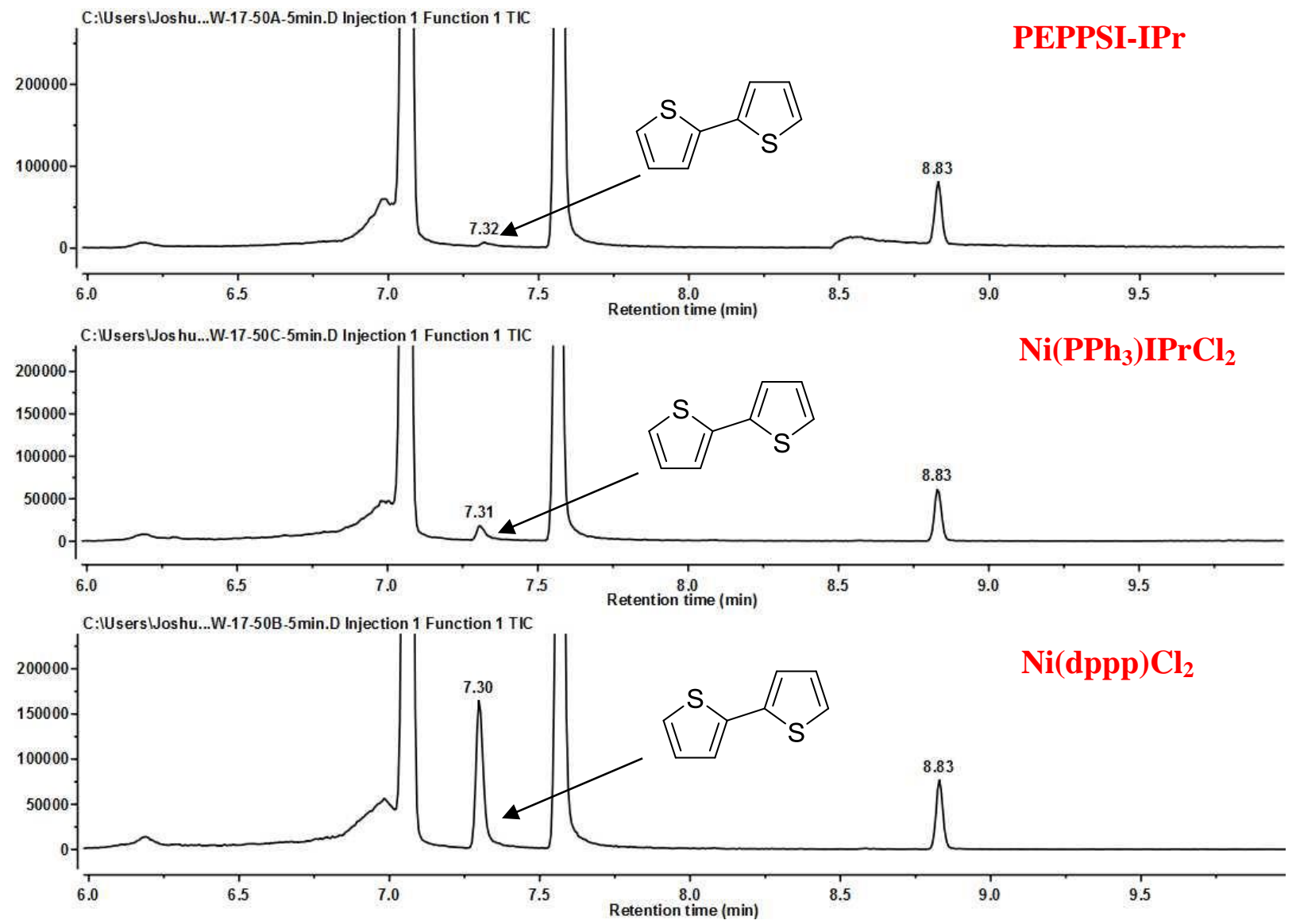

Figure S56. Enlarged GC-MS chromatograms to illustrate bithiophene formation during catalyst initiation at $22{ }^{\circ} \mathrm{C}$ using ThBpin and catalyst $(20 \mathrm{~mol} \%)$ sampled after 5 minutes. Top PEPPSI-IPr. Middle $-\mathrm{Ni}\left(\mathrm{PPh}_{3}\right) \mathrm{IPrCl}_{2}$. Bottom $-\mathrm{Ni}(\mathrm{dppp}) \mathrm{Cl}_{2}$. Signal at $7.3 \mathrm{~min}$ is bithiophene formed during precatalyst initiation. 


\section{References}

(1) Huo, L.; Chen, T. L.; Zhou, Y.; Hou, J.; Chen, H.-Y.; Yang, Y.; Li, Y. Improvement of Photoluminescent and Photovoltaic Properties of Poly(thienylene vinylene) by Carboxylate Substitution. Macromolecules 2009, 42, 4377-4380.

(2) Li, J.-C.; Lee, S.-H.; Hahn, Y.-B.; Kim, K.-J.; Zong, K.; Lee, Y.-S. Synthesis and Characterization of Triphenylamine-3-hexylthiophene Oligomer Hybrids: A Triphenylamine Core Carrying Three Terthiophene Branches and Triphenylamine End-capped Quaterthiophene. Synth. Met. 2008, 158, 150-156.

(3) (a) Yokozawa, T.; Suzuki, R.; Nojima, M.; Ohta, Y.; Yokoyama, A. Precision Synthesis of Poly(3-hexylthiophene) from Catalyst-Transfer Suzuki-Miyaura Coupling Polymerization. Macromol. Rapid Commun. 2011, 32, 801-806. (b) Liversedge, I. A.; Higgins, S. J.; Giles, M.; Heeney, M.; McCulloch, I. Suzuki Route to Regioregular Polyalkylthiophenes Using Ir-catalysed Borylation to make the Monomer, and Pd Complexes of Bulky Phosphanes as Coupling Catalysts for Polymerisation. Tetrahedron Lett. 2006, 47, 5143-5146.

(4) Castañar, L.; Sistaré, E.; Virgili, A.; Williamson, R. T.; Parella, T. Suppression of Phase and Amplitude $\mathrm{J}(\mathrm{HH})$ Modulations in HSQC Experiments. Magn. Reson. Chem. 2015, 53, 115-119. (5) Jezorek, R. L.; Zhang, N.; Leowanawat, P.; Bunner, M. H.; Gutsche, N.; Pesti, A. K. R.; Olsen, J. T.; Percec, V. Air-Stable Nickel Precatalysts for Fast and Quantitative Cross-Coupling of Aryl Sulfamates with Aryl Neopentylglycolboronates at Room Temperature. Org. Lett. 2014, 16, 6326-6329.

(6) Pomerantz, M.; Amarasekara, A. S.; Rasika Dias, H. V. Synthesis and Solid-State Structures of Dimethyl 2,2'-Bithiophenedicarboxylates. J. Org. Chem. 2002, 67, 6931-6937. 